\title{
Chromosomal abnormalities in human gametes
}

Citation for published version (APA):

Martini, E. (1998). Chromosomal abnormalities in human gametes. [Doctoral Thesis, Maastricht University]. Datawyse / Universitaire Pers Maastricht. https://doi.org/10.26481/dis.19981125em

Document status and date:

Published: 01/01/1998

DOI:

10.26481/dis.19981125em

Document Version:

Publisher's PDF, also known as Version of record

\section{Please check the document version of this publication:}

- A submitted manuscript is the version of the article upon submission and before peer-review. There can be important differences between the submitted version and the official published version of record.

People interested in the research are advised to contact the author for the final version of the publication, or visit the DOI to the publisher's website.

- The final author version and the galley proof are versions of the publication after peer review.

- The final published version features the final layout of the paper including the volume, issue and page numbers.

Link to publication

\footnotetext{
General rights rights.

- You may freely distribute the URL identifying the publication in the public portal. please follow below link for the End User Agreement:

www.umlib.nl/taverne-license

Take down policy

If you believe that this document breaches copyright please contact us at:

repository@maastrichtuniversity.nl

providing details and we will investigate your claim.
}

Copyright and moral rights for the publications made accessible in the public portal are retained by the authors and/or other copyright owners and it is a condition of accessing publications that users recognise and abide by the legal requirements associated with these

- Users may download and print one copy of any publication from the public portal for the purpose of private study or research.

- You may not further distribute the material or use it for any profit-making activity or commercial gain

If the publication is distributed under the terms of Article $25 \mathrm{fa}$ of the Dutch Copyright Act, indicated by the "Taverne" license above, 
Chromosomal abnormalities in human gametes 


\section{Promotores:}

Prof. dr. FCS Ramaekers

Prof. cr. JPM Geraedts

\section{Co-promotor:}

Dr. AHN Hopman

\section{Beoordelingscommissle:}

Prof. dr. JLH Evers (voorzitter)

Prof. dr. R Angell (University of Edinburgh, United Kingdom)

Prof. dr. TWA de Bruin

Prof. dr. PhEV van Kerrebroek

Prof. dr. CD Matthews (University of Adelaide, Australia)

The project was financially supported by "Praeventiefonds" (2825820), and by a Training and Mobility of Researchers (TMR) grant from the European Community (ERB4001GT955293).

Publication of this thesis was partially financed by:

Organon B.V. 
@Elena Martini, Maastricht, 1998

Maastricht: Universitaire Pers Maastricht.

ISBN 90-5278-242-3

Cover illustration: $\mathrm{MJ}$

Back cover: Aldous Huxley, from "Leda" (part of the Fifth Philosopher's song) 


\title{
Chromosomal abnormalities in human gametes
}

\author{
Proefschrift
}

ter verkrijging van de graad van doctor

aan de Universiteit Maastricht,

op gezag van de Rector Magnificus,

Prof. Dr. A Nieuwenhuijzen Kruseman

volgens het besluit van het College van Decanen,

in het openbaar te verdedigen

op woensdag 25 november 1998 om 16.00 uur

door

Elena Martini

geboren op 29 februari 1968 te Livorno, Itallië

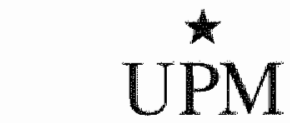

UNIVERSITAIRE PERS MAASTRICHT 
in memoria di GianLuigi Capitanio 



\section{Contents}

Grazie!

Chapter 1 Generalintroduction

1.1 Definition of chromosomal abnormalities

1.2 Gametes and meiosis

1.3 Medically assisted reproduction (MAR)

1.4 Methodological aspiects

1.5 Aims of this thesis

1.6 References

Chapter 2 Application of different in situ hybridization detection methods for human sperm analysis.

Chapter 3 Constitution of semen samples from $X Y Y$ and $X X Y$ males as analysed by in situ hybridization.

Chapter 4 Comparison of gonosomal aneuploidy in spermatozoa of normal fertile men and those with severe male factor detected by in-situ hybridization.

Chapter 5 Detection of structural abnormalities in spermatozoa of a translocation carrier $t(3 ; 11)(\mathrm{q} 27.3 ; \mathrm{q} 24.3)$ by triple FISH.

Chapter 6 Analysis of unfertillized oocytes subjected to intracytoplasmic sperm injection using two rounds of fluorescence in situ hybridization and probes to five chromosomes.

Chapter $7 \quad$ FISH analysis in unfertilized oocytes after polar body removal.

Chapter 8 General discussion

Summary

Samenvatting

Curriculum vitae

Publications and Abstracts 



\section{Grazie!}

Firstly, and rather unusually, the acknowledgments.

There is, however, a very good reason to stant this Ph.D. thesis with the part that nomally is the last one. Some years ago, when I never would have believed to complete the experments and wite a thesis, thought" "Well the only thing / can do right now is to write the acknowledgments".

Unfortunately a part had to be changed. Professor Capitanio, the person who made it possible for me to stay in Maastricht, begin this work and meet my husband (with all the consequences), died unexpectedly this summer. He was a special person to me and there are not enough words to thank him appropriately. Caro Prof, quanto awrei voluto che lei fosse presente in questo giomo! Lei rimarrà per me un esempio di professionalita unita ad una grande umanità. Le saro" sempre grata ed eterna debitrice.

Vorrei ringraziare anche Franca Dagna e Mauro Costa per la fiducia che hanno riposto in me.

Joep Geraedts was the first person I met in Maastricht and the first to believe in me and give me the opportunity to prolong my initial stage of six months to a five years stay. Beste Joep, jij hebt altijd naar min problemen geluisterd, en meestal een oplossing daarvoor gewonden. Dankzij jouw scherpzinnigheid, humor "en pretoogjes" ben jij altijd een stimulans geweest voor mij. Alhoewel het altijd goed was, er was toch een maar...... er moesten nog duizenden spermaatjes extra geteld worden, andere grafiekjes, andere (betere, ..... maar jij had op het einde toch wel gelijk. Verder zorgde jij voor de financièle ondersteuning (Praeventiefonds) en de kritische aanpak van mijn onderzoek.

Frans Ramaekers allowed me to stay in his department and had some collisions with my ltalian temper, but his concrete suggestions and ideas were always helpful. Beste Frans, jouw deur stond altijd open als er problemen waren, zowel op de werkplek maar ook thuis (de planken die jij aan de mur hebt bevestigd in mijn kamer boven de slager heb ik niet kunnen verwijderen, zo goed zitten zij vastl). Jouw nuchtere blik op het celbiologische universum heeft mijn manuscripten verhelderd.

Ton Hopman, the one and only expent in FISHI Zonder jouw hulp, expertise en ervaring was dit proefschrift nooit tot stand gekomen. We hadden zo nu en dan wel eens meningsverschillen, maar meestal kwamen we er wel samen uit.

My "superbrain, muscle" supervisor, Sean Flaherty proved to be a neverending source of stimulating ideas, advices and attitudes. Thanks to him I now use PowerPoint, can manage with the attached files, have published more articles and have worked with oocytes! He and his wife Dianna made me feel accepled and at home in the hot Adelaide, thanks to both of you (Ta!). Colin Matthews welcomed 
me in his department at the Queen Elizabeth Hospital and was always a caring and helping person He even understood my homesickness! Further thank you"s to my colleagues, Sarah. Nicole and especially Nick, withoul whom the oocyte work would not have been accomplished.

Ook de Nederlandse medewerkers die betrokken waren bij de samenwerking tussen Genetica, het IVF lab en het FISH lab wil ik bedanken voor de prettige werksteer. Verder wil ik in het bijzonder de MCB collega's en de "Ton-club" danken. Dankzij hun gezelligheid voor, tijdens en na koffietijd, waarbij vlaai en roddels altjd aanwezig waren, woelde ik me thuis. Beste Anne, jij hebt een groot deel van de translocatie experimenten uitgevoerd. Zonder jouw bijdrage en inzet was hoofolstuk 5 nu nog niet af! Verder hebben Frank, Jannie, Victor, Manon, Joris, Monique, Annick. Wiel en Bert op verschillende manieren hun bijarage aan dit boekje geleverd, zoals met adviezen, verdunningen, (belgische) humor, bestellingen en ltaliaanse uitspraken. Francine, als ik ooit eens belangrik ben, dan uraag ik jou als secretaresse...

Guillaume, de beste stuurhi staan aan wal, maar de vissen weten wel beter. Marie-Hélène, het was leuk met jou de kamer te delen en over alles te praten. Cari Monique e Harm Jan, ifine settimana passati insieme, chiacchierando, mangiando e bevendo sono stati dei veri e propri toccasana! Un bacione a tutti e due e una carezza al pancionel Jacqui en Roger, bedankt voor de gezellige en culinaire avonden. Beste Miriam en Hugo, daank zij ouch höb jech miech hej auch en bitche thoes geveuld en höb ouch ut Mestreechs liere begriepen...

Lieve paranimfen, het is voor mij een eer dat julie mij terzijde willen staan, bedankt. Jullie zijn geweldigl!!

Giuse, grazie per essere sempre stata presente. Forse limprinting non e' solo questione di genetica, ma anche di affetto! Eric, senza di te non sarei qui, graziel Uhe;, Sabri, potevo star lontana al massimo per un anno, e invece ti ho "fradito". Scusa. Sei sempre la mia "compagna di studi" preferital Carissima Nonna, so quanto ti manco e ammiro la tua forza d'animo. Spero di essere come te alla tua etàl Cara Mammocchia, senza il tuo coraggio, caparbietà ed educazione non sarei quella che sono; grazie. Tootsie...!

Caro piccolo Martino, siamo cosi contenti che tu ci sia. Sei dolcissimo... Maurice, een betere collega en echtgenoot had ik mij niet kunen wensen, bedankt voor al de hulp, de lay-out en dat je twee uur voor mil promoveert! en... More, je weet het al: tot wij 90 zijn!!! Baci. 


\section{Chapter 1}

General Introduction 


\subsection{Definition of Chromosomal Abnormalities}

Chromosomal abnormalities are responsible for at least half of spontaneous miscarriages and are an important cause of congenital malformations (Hassold 1986; Edwards 1986; De Grouchy and Turleau 1984; Gardner and Sutherland 1989). Chromosome abnormalities may be numerical or structural.

The number of human chromosomes in a normal somatic cell is 46 (diploid or $2 n, n$ being the number of chromosomes in a normal haploid gamete) (Figure 1.1). Triploidy is an euploid situation ( $3 n$ ) and is a common chromosomal abnormality found in spontaneous abortions (van Lijnschoten et al., 1993). Aneuploidy is any number of chromosomes that is not euploid (an exact multiple of $n$ ) and refers to either an extra chromosome, i.e. trisomy (as in trisomy 21, Down's syndrome), or the absence of a chromosome, i.e. monosomy (as in monosomy 45, X0, Turner's syndrome). The consequences of such numerical aberrations vary from early embryonic or fetal wastage, perinatal and infant mortality to mental retardation and congenital anomalies, depending on the chromosome involved. Some estimates suggest that up to $50 \%$ of all human concepti carry a chromosomal abnormality (Boue' et al., 1975; Hassold et al., 1980; Eiben et al., 1990), and chromosomal aberrations which arise during gametogenesis and early embryonic development play a significant role in fetal loss (Chard 1991). In human live born infants, trisomy is commonly only seen for chromosomes 13,18,21 and the sex chromosomes (De Grouchy and Turleau 1984). Such trisomies occur in $4 \%$ of all clinically recognized pregnancies, $24 \%$ of spontaneous abortions and $0.5 \%$ of live borns (Jacobs and Hassold 1995).

There is a process of natural selection whereby most trisomies and monosomies that arise during gametogenesis, fertilization or early embryonic development are expelled during the first stages of gestation. Trisomy has been observed for every chromosome in human spontaneous abortions (Hassold et al., 1980), with the exception of chromosome 1, for which a trisomy has been seen only once in an 8-cell human pre-embryo (Watt et al., 1987), suggesting that trisomy 1 is lethal very early in development. Embryos with trisomy 16 (the most frequent trisomy at conception) are lost at about 10 weeks of gestation, while embryos carrying a trisomy 13,18 or 21 will eventually develop to term, but the majority of embryos with these abnormalities are expelled during the different stages of gestation (De Grouchy and Turleau 1984; Martin and Rademaker 1990; Warburton el al., 1987). Structural abnormalities of chromosomes usually involve one or two chromosomes, but may involve more than two. They are categorised as (i) inversions, deletions, insertions or duplications of parts of the chromosome(s) or (ii) translocations. In the case of a balanced translocation (reciprocal or Robertsonian), usually no genetic material is lost and usually no genes are damaged, which means that individuals carrying such a translocation will be genetically, and thus clinically, normal (Jacobs 1977). However, they are at increased risk of having chromosomally unbalanced offspring (De Braekeleer and Dao 1990; Martin et al., 1991; Goldman and Hulten 1993a; Goldman and Hulten 1993b; Estop et al., 1995; Martini et al., 1998a).

\subsection{Gametes and Meiosis}

Human gametes, spermatozoa and oocytes, originate from germ cells in the testis and ovary, respectively. The stem cells, spermatogonia and oogonia, are diploid and it is through the process of meiosis during spermatogenesis and oogenesis, that the resulting haploid gametes are produced (Figure 1.2). There are several causes of aneuploidy in gametes, depending on the stage at which the delicate process of meiosis is disturbed. Human meiosis, especially in females, is a process that seems to be prone to error (Warburton 1997). The major cause of aneuploidy is non-disjunction (NDJ) of the homologues during 
meiosis, in which the homologues line up at the meiotic spindle but fail to separate at anaphase I. The resultant cells either lack a chromosome (hypohaploidy) or have an extra chromosome (hyperhaploidy) (Figures 1.4-1.5). This error can occur either in meiosis 1 or meiosis II and such aneuploid gametes will produce abnormal embryos. Another meiotic error responsible for NDJ is anaphase lagging, as a result of which single chromosome is lost because it lags behind the others during anaphase and does not migrate to the opposite pole of the spindle. Anaphase lagging at syngamy can lead to mosaicism, with one euploid and one monosomic cell population.

MEIOSIS

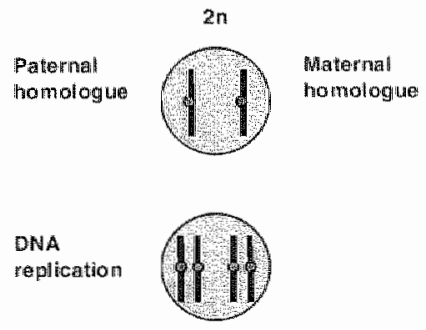

Paìring of homologues: and Metaphase 1

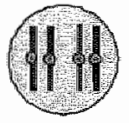

1st melotic: division
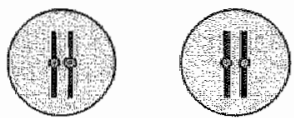

2nd melotic division

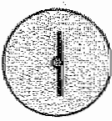

n

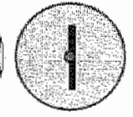

皬

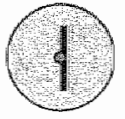

(i)

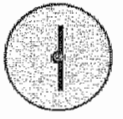

n

\section{MITOSIS}
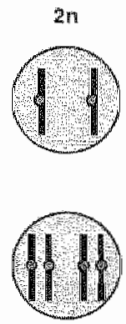

Mataphase

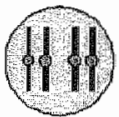

Gefli AI Witallon

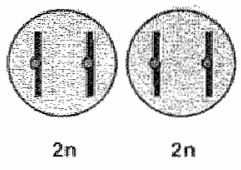

Figure 1.1. Schematical explanation of meiosis and mitosis.

The differences between male and female meiosis are illustrated in Figure 1.2. The principal difference is that male meiosis proceeds throughout adult life whereas female meiosis is arrested at prophase of the first meiotic division at the fetal stage and is only completed many years later in the adult ovary. Just before or shortly after birth, human oocyles undergo prophase of meiosis I and then arrest at the diplotene stage of prophase. At this point, the oocyte is characterized by the presence of a distinctive nucleus called a germinal vesicle (GV). This state seems the most appropriate for prolonged conservation of the 
DNA. Melosis I resumes after the pre-ovulatory surge of luteinising hormone $(\mathrm{LH})$ during a process known as oocyte maturation. The GV disappears and the chromatin condenses into bivalents. The homologues separate and the first polar body (PB), containing the first set of haploid chromosomes (each consisting of two chromatids), is extruded into the peri-vitelline space. Meiosis then arrests again at metaphase II until after fertilization, at which time it resumes. A second PB is extruded during telophase II, leaving the oocyte with a haploid number of chromosomes (Figure 1.3).

\section{MEIOSIS}

\section{FEMALE} $46 . X X$
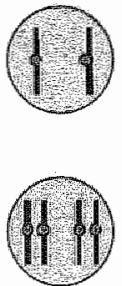

MALE

\section{$46, X Y$}
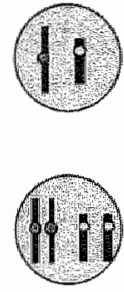

1 st meiotic

division
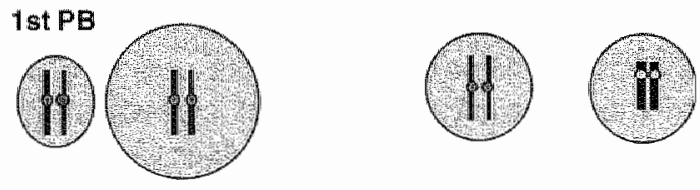

2nd melotic division
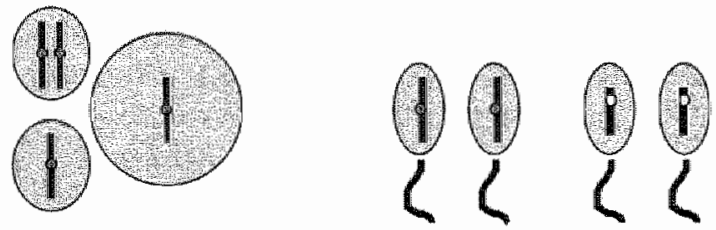

2nd PB

Figure 1.2. Female and malle meiosis are illustrated and as an example the sex chromosomes are visualised and followed through the meiotic process. (Polar body $=\mathrm{PB}$ )

While male meiosis produces four haploid gametes from one diploid germ cell, female meiosis yields only one haploid gamete. Since the length of melosis I in mammals is directly correlated with maternal age, it was both expected and verified that meiosis I errors were associated with increased maternal age. The data support the hypothesis that, in older women, bivalents lacking peri-centromeric chiasmata separate prematurely, resulting in meiotic NDJ, whereas in young women the same oocyte is likely to be processed normally (Warburton 1997; Angell 1997; Plachot 1997) (Figure 1.4). 


\section{MEIOSIS \& FERTILIZATION}

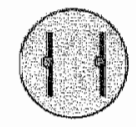

Oogonium

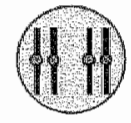

Metaphase I

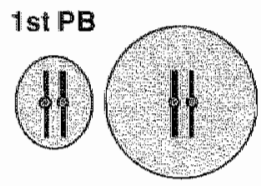

Metaphase II

On

2nd PB

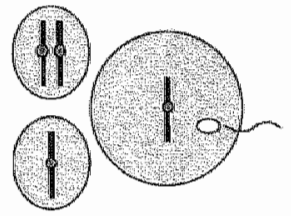

Fertilization

\section{Pronuclear} formation

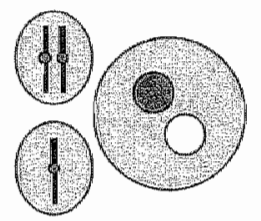

Zygote

Figure 1.3. The different sequences of female meiosis are illustrated, from oogonium to the formation of the zygote after fertilization.

Spermatogenesis is a process that serves to expand the number of germ cells and to permit their development into mature spermatozoa. This process takes place in the seminiferous tubule, a long tubular structure lined by a single layer of Sertoli cells.

During spermatogenesis, spermatogonia slowly evolve into spermatocytes, then spermatids and finally through spermiogenesis the complete maturation is achieved and sperma* tozoa are released into the lumen (Bellvé and O'Brien 1983; De Kretser and Kerr 1988; Moore 1995). Errors can occur during the first or second meiotic division and aneuploid spermatozoa are released into the lumen of the seminiferous tubule, ejaculated and may fertilize oocytes and give rise to abnormal embryos (Martin et al., 1991; Goldman and Hulten 1993b; Williams et al., 1993; Spriggs et al., 1996) (Figure 1.5).

\subsection{Medically Assisted Reproduction}

During the last two decades, techniques for medically assisted reproduction (MAA) have been developed enabling couples to overcome infertility. A study by the World Health Organization (WHO 1993) found that infertility was due to female factors in $41 \%$ of the cases, male factors in $24 \%$, a combination of female and male factors in $24 \%$, and no cause 
could be found in $11 \%$. In vitro fertilization (IVF) was initially developed to overcome tubal blockage, but has also proven suitable for the treatment of other forms of infertility (Jones 1986; Thatcher and De Cherney 1989). One of the techniques is a technique which is used in conjunction with IVF to overcome male factor infertility is intracytoplasmic sperm injection (ICSI) (Palermo etal., 1992).
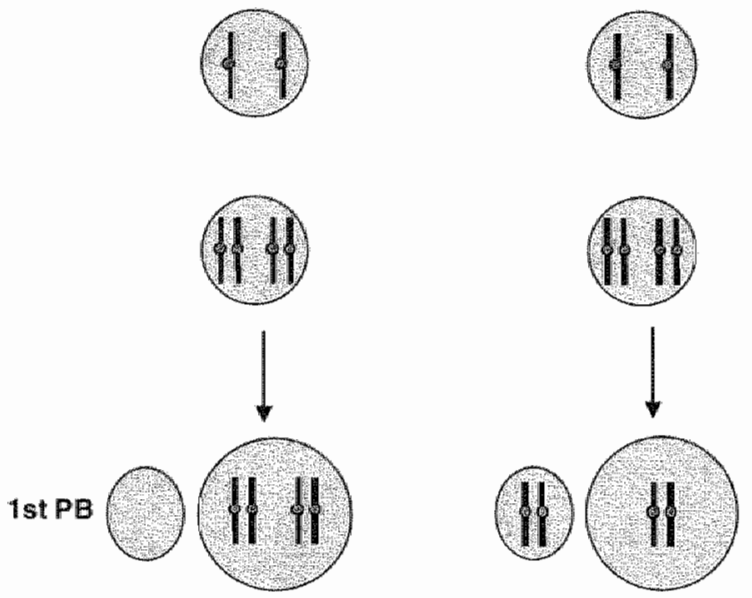

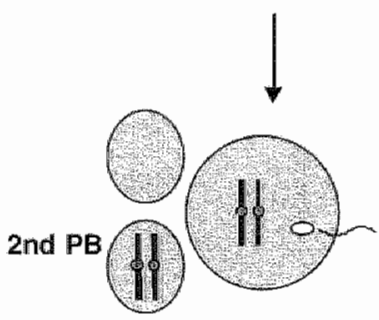

MI Nondisjunction

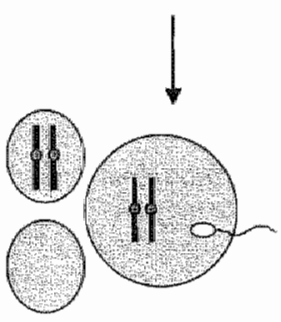

MIII Nondisjunction

Figure 1.4. Two examples of nondisjunction during female meiosis. $\mathrm{MI}=$ melosils 1 , MII = meiosis 11.

Parallel advances in MAR and molecular genetics have now made it possible to study meiotic and mitotic errors which arise diuring oogenesis, spermatogenesis, fertilization and early embryogenesis and to assess the contribution of these errors to chromosomal abnormalities in embryos and fetuses. Genetic studies on single gametes and embryos can provide valuable diagnostic information, which may help couples who require MAR or who are at risk of inheritable diseases (Harper et al., 1994; Munné et al., 1995).

\subsection{Methodological Aspects \\ Spermatozoa}

The earliest studies on chromosomes in human sperm used differential staining of specific regions of chromosomes. In 1970, Pearson and Bobrow (1970) used quinacrine to stain the distal part of the long arm of the $Y$ " chromosome, the so called " $Y$-body". Giemsa and Leishman's staining were used by Bobrow et al., (1972), Pearson et al., (1972) and 


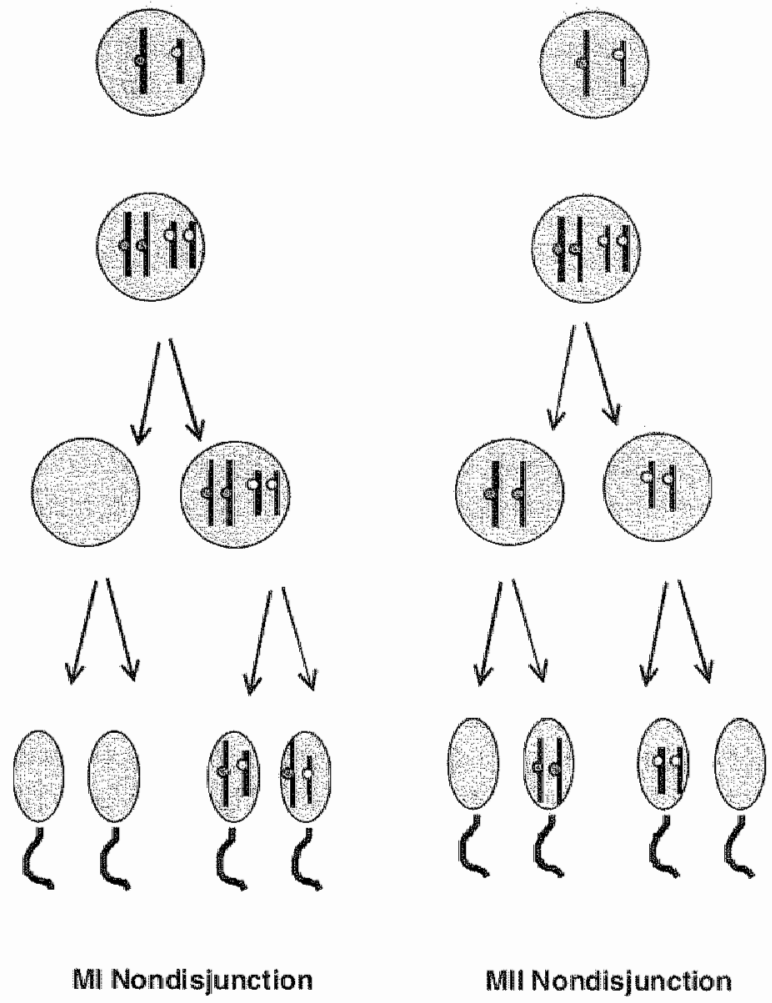

Figure 1.5. Nondisjunction during male meiosis.

Geraedts and Pearson. (1973) to study autosomes. However, due to non-specific staining of chromosomes, these techniques were considered unreliable and were therefore not developed further. Shortly thereafter, Yanagimachi et al., (1976) and Rudak of al. (1978) introduced the direct visualization of human sperm chromosomes after penetration of zonafree hamster oocytes. More than 20,000 sperm chromosome complements have been karyotyped to date using this method (Martin et al., 1993; Brandriff et al., 1985; Estop et al., 1991; Peillestor 1991; Downie et al., 1997 and Guttenbach et al., 1997 for review). This yielded valuable data on the entire chromosome complement of sperm, and the presence of both numerical and structural chromosomal abnormallities can be studied (Martin and Rademaker 1990). However, sperm karyotyping is a laborious and time-consuming procedure and the results may be biased by the fact that only those spermatozoa which were able to fertilize hamster oocytes are karyotyped (Jacobs 1992; Martin et al., 1993; and Guttenbach el al., 1997 for review).

The drawbacks of these earlier methods are overcome by in situ hybridization (ISH) techniques, which permit analysis of both numerical and structural aberrations in metaphase chromosomes as well as in interphase nuclei (Lichter et al. 1991; Tkachuk et al., 1991; Hopman et al., 1991). Since its introduction in 1969 (Gall and Pardue 1969; John et al., 1969), ISH has been used to localize specific DNA sequences in interphase nuclei from many different cell types. This technique enables identification of specific parts of the ge- 
nome (the target DNA) using chemically modified or labelled chromosome-specific DNA probes which hybridize to the target DNA. Following hybridization, the probes can be visualized using fluorochromes (fluorescence $1 \mathrm{SH}$ ) or cytochemical precipitation products (brightfield ISH) as reporter molecules (Speel et al., 1995; Martini et al., 1995).

The first probes used for ISH were labelled radioactively, but poor resolution and long exposure time soon led to their replacement by biotinylated probes (Langer et al., 1981) and later by directly fluorochrome labelled probes. Autoradiography was replaced by fluorescence visualization (Manuelidis et al, 1982) and hitherto routinely used. Although the information obtained by ISH is limited to the DNA targets examined, it has the advantage that virtually every cell is informative, in contrast to conventional karyotyping (Martin et al. 1993; Martini et al., 1995; Martini et al., 1997).

Joseph et al., (1984) reported the first radioactive ISH on spermatozoa, followed by West et al., (1989) and many others (see Downie et al., 1997 for review). Since then these methods were further developed and improved for application on mature spermatozoa. A delicate balance between hybridization efficiency and maintenance of sperm morphology has led to incongruent results (Martin et al., 1993; Williams et al., 1993; Martini el al., 1995; Downie et al., 1997 and Guttenbach et al., 1997a for review). The crucial steps for ISH, in order to obtain efficient hybridization, are to achieve a proper decondensation of the protamines (the proteins which replace in human sperm the nuclear histones) and denaturation of the DNA of the specimen. However, after decondensation the morphology of sperm heads is partly distorted and the majority of the tails are lost. This leads to problems distinguishing hyperhaploid from diploid spermatozoa, and abnormal spermatozoa from somatic cells.

\section{Oocytes}

The chromosomal constitution of human oocytes retrieved for IVF has been studied extensively (see Plachot 1997 for review). For ethical reasons, the usual approach has been to situdy those oocytes that failed to fertilize and remained arrested at metaphase II. This should provide information on the frequency and types of errors that occur in oocytes during meiosis I. However, many of these studies relied on poor quality preparations in which accurate identification of individual chromosomes and the detection of abnormalities was very difficult, besides the spreading method which led to high rates of artefactual chromosomal loss (Warburton 1997; Angell 1997; Plachot 1997). The unusually condensed nature of the chromatids on the metaphase II spindle (Pellestor 1991) has hampered reliable analysis by karyotyping and necessitated the introduction of a modified protocol based on Tarkowski (1966) to spread the chromosomes. This method uses methanol:acetic acid (3:1) fixation and has major drawbacks such as loss of cells and/or loss of morphology, thereby reducing the efficiency, reliability and reproducibility. This is a great disadvantage in the study of aneuploidy, wherein the results must be reliable and accurate. Larger series of studies suggest that a high proportion of human oocytes (25-30\%) are chromosomally abnormal (Benkhalifa et al., 1990; Plachot et al., 1988; Angell et al., 1993; Angell et al. 1994; Edirisinghe et al., 1992; Martin et al., 1991; Pellestor 1991; Roberts and O'Neill 1995).

Coonen et al., (1994b) presented an alternative method for preparing and isolating interphase nuclei from pre-implantation embiyos using $\mathrm{HCl}$ and Tween 20 which offers high reproducibility, good cellular morphology and a high ISH efficiency (Coonenet al., 1994a; Coonen etal., 1994b; Harper et al., 1994; Muggleton-Harris et al. 1995). This technique can be adapted for the spreading of oocyte DNA and when combined with ISH offers an effective alternative to karyotyping (Martini ef al., 1997; Martini et al., 1998b). 


\subsection{Aims of this study}

This study was mainly initiated to develop reliable methods for estimating aneuploidy in human gametes. It was particularly focused on the application of ISH to human spermatozoa and oocytes.

The specific aims of this study were:

* To improve the efficiency, sensitivity and reproducibility of ISH on human gametes.

* To assess whether or not ISH is a valid alternative to estimate the incidence of aneuploidy in spermatozoa and unfertilized oocytes to karyotyping of human gametes, being less time consuming and less labour intensive.

* To analyse the incidence of aneuploidy in spermatozoa and unfertilized oocytes.

* To estimate the risk of transmitting chromosomal aberrations using gametes from males with karyotypic abnormalities. 


\section{Feferences}

Argell $F,(1997)$ Firgthemich-division nondisjunction in thuman oocytes. Am J Hum Genet61: $23-32$.

Aingell $\mathrm{A}$, Xian $\mathrm{J}$, Keith $\mathrm{J}$ (1993) Chromosome anomalies in human oocytes in relation to age. Hum Reprod 8: $1047: \div 054$

Angell $\mathrm{A}$, X Xan J, Keith J, Ledger W, Baird D. (1994) First meiotic division abnomalities in human oocytes: mechanism of trisomy formation. Cytogenet Cell Genet 65: 194-202.

Bellve $A_{,} O$ Brien $D_{1}(1983)$ The mammalian spernatozoon: structure and iemporal assembly. In: Hartmann $J(e d)$ Mechanism and control of anmal fertilisation Academic Press, New York, pp 55-137.

Benkhalifa D. Geneix A, Janny L, Boucher D, Malet P. (1990) Chromosome aberrations in human oocytes Fifth Intternational Congress on Early Fetal Diagnosis, Prague.

Bobrow M. Madan K, Pearson P, (1972) Staining of some specific regions of human chromosomes, particularly the secondary constriction of number 9 . Nature New Biol 238: 122-124.

Boue' J, Boue A, Lazar P, (1975) Relrospective and prospective epidemiological studies of 1500 karyotyped spontaneous human abortions. Teratology $12: 111-26$.

Brandiff $B$, Gordon L, Ashworth L, Watchmaker $G$, Moore II D, Wyrobek $A$, Carrano $A_{\text {. }}$ (1985) Chromosomes of human sperm: variability among normal individuals. Hum Genet 70: 18-24.

Chard $T_{.}(1991)$ Frequency of implantation and early pregnancy loss in natural cycles. In: Sepala $M$ (ed) Factors of importance for implantation. Bailliere Tindall, London, pp 179-182.

Coonen E, Dumoulin J. Ramaekers F, Hopman A, (1994b) Optimal preparation of preimplantation embryo interphase nuclei for analysis by fluorescence in situ hybridization. Hum Feprod 3: 533-537.

Coonen E. Harper J, Ramaekers F, Delhanty J "Hopman A. Geraedis ل. Handyside A (1994a) Presence of chromosomal mosaicism in abnormal preimplantation embryos detected by fluorescence in situ hybridisation. Hum Genet 94:609-615.

De Braekeleer M, Dao T-N, (1990) Cytogenetic studies in couples experiencing repeated pregnancy losses. Hum Aeprod 5: 519-528.

De Grouchy J, Turleau $C_{1}$ (1984) Clinical Atlas of human chromosomes, znd edn, New York.

De Kretser D, Ker J, (1988) The cytology of the testis. In: Knobil E, Neill J (eds) The physiology of repraduction. Raven Press, New York, pp 837-932.

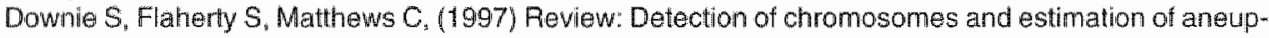
loidy in human sperm using fluorescence in-situ hybridization. Mol Hum Reprod 3: 585-598..

Edirisinghe W. Murch A, Yowich $\mathrm{J},(1992)$ ) Cytogenetic analysis of human oocytes and embryos in an invitro fertilization programme. Hum Reprod 7: 230-236.

Edwards $R$, (1986) Causes of early embryonic lass in human pregnancy. Hum Reprod 1: 185-198.

Eiben B, Bartels I. Bahr-Porsch S, Borgmann S, Gatz G, Gellert G, Goebel R. Hammans W, Hentemann M, Osmers R, Rauskolb R, Hansmann I, (1990) Cytogenetic analysis of 750 spontaneous abortions with the direct-preparation method of chorionic villi and its implications for studying genetic causes of pregnancy wastage. Am J Hum Genet 47: 656*663.

Eslop A, Cleply K, Van Kirk V, Munne" S, Garver K. (1991) Cytogenetic studies in human sperm. Hum Genet $87: 447.451$.

Estop A. Marquez C, Munne' S, Nawarro d, Cleply K, Van Kirk V, Mantorell M, Benet J, Templado C. (1995) An analysis of human sperm chromosome breakpoints. Am J Hum Genet 56: 452-460.

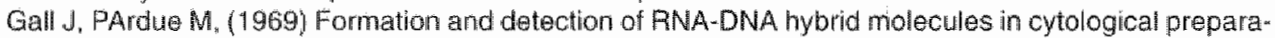
tions. Proc Natl Acad Sci USA 63: 378-383

Gardner $\mathrm{A}$, Sutherland $\mathrm{G}$ (1989) Chromosome abnomalities and genetic counseling. Oxford University Press, New York.

Geraedts $\downarrow$, Pearson $P$, (1973) Specific staining of the human chromosome No. 1 chromosome in spematoza. Humangenetik20: $171-173$.

Goldman $A_{*}$. Hulten M, (1993a) Meiotic analysis by FISH of human male $46, X Y_{11} 1(15 ; 20)(q 11.2 ; 011.2)$ translocation heterozygote: quadrivalent configuration, orientation and first meiotic segregation. Chromosoma 102: 102-111.

Goldman $\mathrm{A}_{4}$ Hulten $\mathrm{M}$, (1993b) Analysis of chiasma frequency and first meiotic segregation in humant male reciprocal translocation heterozygote, $t(1 ; 11)(\mathrm{p} 36.3 ; \mathrm{q} 13,1)$, using fluorescence in situ hybridisation. Cytogenet Cell Genet63: 16-23.

Gutenbach M, Engel W, Schmid M, (1997a) Analysis of structural and numerical chromosome abnormalities in sperm of normall men and carriers of constitutional chromosome aberrations. A review. Hum Genet 100: 1-21.

Harper J, Coonen E, Ramaekers F., Dellhanty J. Handyside A, Winston R, Hopman A, (1994) Identification of the sex of human preimplantation embryos in two hours using am improved spreading method and fluorescence in situ tybridization (FISH) using directly labelled probes. Hum Reprod 4: 721-724.

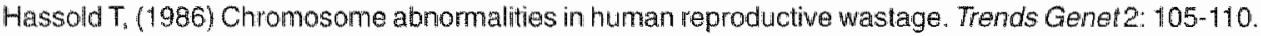
Hassold T, Chen N, Funkhouser J, Jooss T, Manuel B, Matsuura $\Downarrow$, Matsuyama A, Wilson C, Vamane J, 
Jacobs $P_{\mathrm{n}}$ (1980) A cytogenetic study of 1000 spontaneous abortons. Anm Hum Genen 44: 151-164. Hopman A, Van Hooren E, Van de Kaa C, Vooijs GR, FCS Ramaekers, (1991) Detetion of numenical chromasome aberrations using in situ hybridization in paraffin sections of routhely processed bladder cancers. Modern Pathol 4: 503-513.

Jacobs $P_{,}$(1977) Epidemiology of chromosome abnomalities in man. Am J Epidem 105: 180-191. Jacobs $P$, (1992) The chromosome complement of human gametes. Oxford Fev Reprod Biol 4 4: $47-72$. Jacobs P. Hassold T, (1995) The origin of numencal chromosome abnomalities. Adv Genet 33: 101-133.

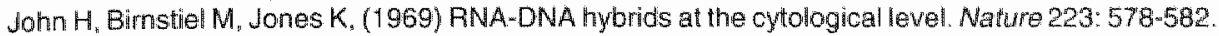
Jones H, (1986) The infertile couple. In: Fishel S, Symonds E (eds) In vitro fertifization. Past-present-future. IRL Press, Oxford Washington DC, pp $17-26$.

Joseph A, Gosden J, Chandley A, (1984) Estimation of aneuploidy levels in human spermatozoa using chromosome specific probes and in situ hybridization. Hum Genet 66: 234-238.

Langer $P$, Waldrop A, Ward D. (1981) Enzymatic synthesis of biotin-labeled polynucleotides: nowel nucleic acid affinity probes. Proc Natl Acad Sci USA 78: 6633-6637.

Lichter $P_{1}$ Boyle $A_{0}$ Cremer $T$, Ward D, (1991) Analysis of genes and chromosomes by nonisotopic in situ hybridization. GATA 8: 24-35.

Lijnschoten van $G$, Arends $J$, Leffers $P$, de la Fuente $A$, van der Looij $H_{3}$ Geraedts $J$, (1993) The value of histomorphological features of chorionic villi in early spontaneous abortion for the prediction of karyotype. Histopathology 22:557-563.

Manuelidis L, Langer-Sater P. Ward D, (1982) High resolution mapping of satellite DNA using biotin-labeled DNA probes. J Cell Bial $95: 619-625$.

Martin R, Ko E, Chan K, (1993) Detection of aneuploidy in human interphase spermatozoa by I Luorescence in situ hybridization (FISH). Cytogenet Cell Genet 64: $23-26$.

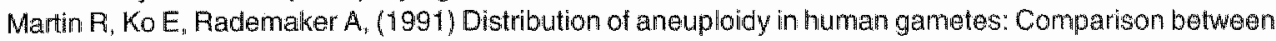
human sperm and oocytes. Am J Med Gener 39: 321-331.

Martin R, Rademaker A, (1990) The frequency of aneuploidy among individual chromasomes in 6281 human sperm chromosome complements. Cytogenet Cell Genet 53: 103-107.

Martini E, Flaherty S, Swann N, Matthews C, Ramaekers F, Geraedts J. (1998b) FiSH analysis of six chromosomes in unfertilised human oocytes after polar body removal submitted

Martini E, Flaherty S, Swann N, Payne D, Matthews C, (1997) Analysis of unfertilized cocytes subjected to intracytoplasmic sperm injection using two rounds of fluoerescence in-situ hybridization and probes to five chromosomes. Hum Reprod 12: 2011-2018.

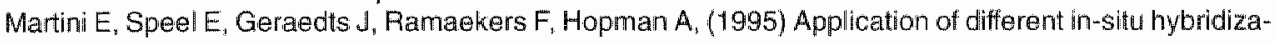
tion detection methods for human sperm analysis. Hum Reprod 10: 855.861.

Martini E, von Bergly A, Coonen E, de Die-Smulders C. Hopman A, Ramaekers. F, Geraedts J, (1998a) Detection of structural abnormalities in spermatozoa of a Iranslocation carrier $1(3 ; 11)(q 27.3 ; 924.3)$ by triple FISH. Hum Gener 102: 157-165.

Moore $H_{\text {s }}$ (1995) Posit-testicular sperm maturation and transpont in the excurrent ducts In: Grudzinskas J, Yovich J (eds) Gametes- The Spermatozoon. Cambridge University Press, Cambridge, pp 140-156

Muggleton-Harris A. Glazier A, Pickering $S$, Wall M, (1995) Genetic diagnosis using polymerase chain reaction and fluorescent in.situ hybridization analysis of biopsied cells from both the cleavage and blastocyst stages of individual cultured human preimplantation embryos. Hum Feprod 10: 183-192.

Munné $S_{s}$ Sultan K, Weier H*U, Grifo J, Cohen J, Aosenwaks Z, (1995) Assessment of numeric abnormalities of $X, Y, 18$, and 16 chromosomes in preimplantalion human embryos belore transter. Am J Obstet Gynecol172: 1191-1199.

Palermo $G$, Joris $H$, Devroey $P$, Van Steirteghem $A$, (1992) Pregnancies after intracytoptasmic injection of single spermatozoon into an oocyte. Lancet $340: 17-18$.

Pearsan $P,(1972)$ The use of new staining techniques for human chromosome identification. J Med Genet 9:264-275.

Pearson $P$, Bobrow $M,(1970)$ Fluorescent staining of the $Y$ chromosome in meiotic stages of the human male. J Reprod Fentil 22: $177-179$.

Pellestor $F$, (1991) Differential distribution of aneuploidy in human gametes according to their sex. Hum Reprod 6: 1252-1258.

Plachot M, (1997) The human oocyte. Genetic aspects. Amn Genet 40: 115-120.

Plachot $M$, Veigla $A$, Montagut J, deGrouchy J, Calderon $G$, Lepretre $S$, Junca A, Santalo J. Carles $E$, Mandelbaum J, Barri P. Degoy J. Cohen J, Egozcue J. Sabatier J. Salat-Baroux J, (1988) Are clinical and biologicaIIVF parameters correlated with chromosomal disorders in earyy life: a multicentric study. Hum Reprod 3: 627 6335 .

Roberts $\mathrm{C}_{3}$ O'Neill $\mathrm{C}$. (1995) Increase in the rate of diploidy with maternal age in unfertilized in witro fertilization oocytes. Hum Reprod 10: 2139-2141.

Rudak $E$, Jacobs $P$, Yanagimach $A$, (1978) Direct analysis of the chromosome constitution of thuman 
spermatozoa. Nature 274: 911.913.

Speet E, Ramaekers F, Hopman A, (1995) Detection systems for in situ hybridization, and the combination with immunocylochemistry - Who is stiff altraid of Red, Green and Blue?". Histochem $ل$ 27: 833-858.

Spriggs E. Rademaker $A_{1}$ Martin $P$, (1996) Aneuploidy in human sperm: the use of multicolor FISH to test various theories of nondisjunction. Am I Hum Genet 58: 356-362.

Tarkowski $A_{1}$ (1966) An alirdrying method for chromosome preparation from mouse eggs, Cylogenetics 5 : $394-400$.

Thatcher $8, D e$ Cherney $A,(1989)$ A critical assessment of the indications for in witro fertilization and ombryo transtier Hum Reprod 4: 11-16.

Tkachuk D, Pinkel D, Kuo W-L, Weier H-U, Gray J, (1991) Clinical applications of fluorescence in situ hybridization. GATAB:67-74.

Warburton D. (1997) Human temale meiosis: new insights into an error-prone process. Am J Hum Genet 61: 1.4 .

Warburton D, Kline J, Stein Z, Hutzler M, Chin A, Hassold T, (1987) Does the karyolype of a spontaneous abortion predict the karyoype of a subsequent abortion? - Evidence from 273 women with two karyotyped spontaneous abortions. Am d Hum Genet 41.

Watt J, Templeton A, Messinis 1 , Bell L, Cunningham $P$, Duncan $R$, (1987) Trisomy in an eight cell human preemnbryo. J Med Genet 24: 60-64.

West $\mathrm{J}$, West K, Aitken $\mathrm{R}$, (1989) Detection of $Y$-bearing spermatozoa by DNA-DNA in situ hybridisation. Mol Reprod Dev 1: $201-207$.

WHO (1993) WHO manual for the standardized investigation and diagnosis of the infertile couple. Cambridge University Press, Cambridge.

Williams B, Ballenger $C$, Malter H, Bishop F, Tucker $M_{*}$ Z Zwingman T, Hassold T, (1993) Nondisjunction in human sperm: results of fluorescence in situ hybridization using two and three probes. Hum Molec Genet2: 1929-1936.

Yanagimachi $\mathrm{A}$, Yanagimachi $H_{2}$, Rogers $\mathrm{B},(1976)$ The use of zona free animal ova as a lest for the assessment of the fertilizing capacity of human spermatoza. Biol Reprod 15:471-476. 


\section{Chapter 2}

\section{Application of different in situ hybridization detection methods for human sperm analysis}

Elena Martini, Ernst Jan M. Speel, Joep P.M. Geraedts,

Frans C.S. Ramaekers and Anton H.N. Hopman 


\section{Abstract}

The detection of some types of aneuploidy in human spermatozoa can be based on the use of fluorescence in situ hybridization technique (F/SH). One of the crucial steps for FISH is to achieve a proper decondensation and denaturation of the DNA in the specimen, so as to obtain efficient hybridization results. However, after DNA decondensation the morphology of sperm heads is partly distorted and the majority of the tails is lost. This situation leads to problems in the distinction between disomic and diploid sperm, as well as between abnormal spermatozoa and somatic cells. Double- and triple-target FISH can partly solve this discrimination problem. To improve these procedures we adapted the steps of decondensation and visualization of the single sperm cells. Firstly, DNA decondensation with $25 \mathrm{mM}$ DTT in $1 \mathrm{M}$ TRIS at pH 9.5 resulted in sperm cells with intact morphology of both the head and the tail and allowed to perform efficient single-, doubleand triple-target ISH. Secondly, we applied a novel detection method, based on enzyme immunocytochemical reactions, with coloured precipitation products. Thirdly, this ISH procedure was combined with Diff-Quik staining and the use of brightfield microscopy. This absorption method has the advantage of a permanent signal, and the adapted cytoplasmatic staining of the sperm plasma membrane allows the visualization of the outline of the single spermatozoa. Using this approach, therefore, it is possible to discriminate between disomic-, diploid-, and abnormal spermatozoa, somatic cells and spermatozoas that overlap, because the morphology of the cells is not distorted and the tails of the spermatozoa are intact and properly visualized.

\section{Introduction}

For several years the detection of numerical chromosome aberrations in human spermatozoa has been performed with karyotyping, a very laborious and time consuming procedure, involving the fusion of one single spermatozoa with a zona pellucida free hamster oocyte (Martin et al., 1990). In recent years, with the advent of interphase cytogenetics, using in situ hybridization (ISH) with specific DNA probes, the interest has focused on the latter. With ISH it is possible to analyse a whole specimen within a few hours. In this respect, the fluorescence $\mathrm{ISH}$ (FISH) technique has become a powerful method used widespreadly for the detection of numerical and structural chromosomall aberrations in metaphase spreads and interphase nuclei. It is used to study the effect of carcinogenic and teratogenic agents as well as in prenatal and preimplantation diagnosis. However, the use of fluorescent ISH on human spermatozoa is more complex, due to the inaccessibility of sperm DNA and the interpretation of the results. Joseph et al. (1984) reported the first ISH on spermatozoa. They used an autoradiographic method on testicular spermatozoa. Since then many other authors have performed fluorescence ISH on mature spermatozoa. Although the hybridization rate has increased, the morphology of the sperm cell, is often lost and the interpretation of the ISH signals has led to different results among different groups (Martin et al., 1993; Williams et al., 1993).

The DNA of human spermatozoa is tightly compacted in the nucleus due to small, arginine rich nuclear proteins, the protamines, which are specific for spermatozoa and replace the nuclear histones of somatic cells. These protamines neutralize the charge of DNA and form a network of molecules in mature spermatozoa interconnecting intra- and interprotamine disulfide bridges. ISH requires denaturation of the chromosome specific DNA probe and of the target cell DNA. Therefore, a proper decondensation of the sperm chromatin, prior to the denaturation step is necessary for positive ISH results. From early studies, the denaturating agent, dithiothreitol (DTT) is known to be an efficient reducing agent (Calvin and Bedford, 1971). It breaks the disulphide bonds between the protamine 
chains and allows proper DNA hybridization, and several different decondensation methods using DTT have been published (Perrault and Zirkin, 1982; West et al, 1989; Wyrobeket al., 1990; Coonen el al., 1991, Han et al., 1992; Holmes el al., 1993; Vidal et al. 1993; Willams ef al., 1993; Miharu et al., 1994). Onty one group (Guttenbach and Schmid, 1990) has claimed the ability of performing 1 SH without previous decondensation of their samples. Another difficulty of the ISH procedure is the recognition of somatic cells and their clistinction from diploid, overlapping or morphologically abnormal spermatozoa. A specific marker that allows the visualization of the outline of the whole spermatozoon is needed.

The aim of this study was to improve $\mathrm{SH}$ on sperm cells, replacing the diverse decondensation procedures by a standard, routinely applicable protocol. Furthermore, the morphology of the whole, single spermatozoa had to be retained in preparations that allowed a correct and reliable evaluation of the ISH signals.

The use of a detection method based on immunocytochemical reactions, using different enzymes as conjugates in combination with precipitating substrates, allows the detection of ISH signals with a brightfield microscope instead of a fluorescence microscope, and has therefore many advantages. No fading of the ISH signals occurs, the signals are permanently and accurately localized and can be examined in relation to cell morphology (Speel et al., 1994). Counterstaining of these preparations with Diff-Quik highlights the outline of the single spermatozoa, and the clear, contrasting staining of the sperm tails, the sperm heads and the somatic cells makes the evaluation reliable (Kruger et al. 1988 ).

\section{Materials and methods}

Preparation of sperm nuclei

Ejaculates from 7 normal males were used in this study. The samples were allowed to liquify at room temperature for 30 min and then routinely analyzed by the IVF-lab of our hospital. The number of sperm cells, their motility and morphology was determined for each sample. The semen samples were washed 3 times in phosphate buffered saline (PBS, $0.15 \mathrm{M} \mathrm{NaCl}, 10 \mathrm{mM}$ sodium phosphate, $\mathrm{pH} 7.2$ ) and centrifuged for 10 min at $1200 \mathrm{rpm}$. The pellet was then resuspended carefully in $1 \mathrm{ml}$ of fresh, cold fixative $\left(-20^{\circ} \mathrm{C}\right)$. (methanol : acetic acid, $3: 1$ ) and stored at $-20^{\circ} \mathrm{C}$.

\section{Decondensation of sperm nuclei}

Sperm cells were cytospun on poly-L-lysine coated slides, washed in $2 \times 5 S C$ C $0.3 \mathrm{M} \mathrm{NaCl}$, $30 \mathrm{mM}$ sodium citrate) to remove the remainders of fixative and incubated for $5 \mathrm{~min}$ in $1 \mathrm{M}$ TRIS/HCl buffer, pH 9.5, containing $25 \mathrm{mM}$ DTT. After decondensation the slides were washed once in $2 \times S_{\text {SC }}$ once in PBS, finally dehydrated through an ethanol series $(70$ 96-96-100-100\%) and air dried (Jones er al, 1987).

\section{DNA probes and labeling procedures}

The DNA probes used in this study recognize the (peri)centromeric regions of the human chromosomes 1 (pUC 1.77, 1.77 kB; Cooke and Hindley, 1979), 7 ( $p 7 t 1,0.68 \mathrm{kB}$; Waye et al, 1987) and 17 (p17H8, 2.7 kB; Waye and Willard, 1986). Further, the centromeric probes for chromosome X (pBam $\times 5,2.0 \mathrm{kB}$; Oncor, Gaithersburg, MD) and $Y(D Y Z 1,3.4 \mathrm{kB}$; Cooke et al., 1982) were used. These DNA probes were labelled with biotin 11-dUTP (Enzo Diagnostics; New York, NY), digoxygenin-11-dUTP or fluorescein-12-dUTP (Boehringer; Mannheim, Germany) or tetramethy/rhodamine-4-dUTP (Amersham International, Little Chalfont, UKK) in a standard nick-translation reaction and used in single-, double- or tripletarget ISH procedures. 


\section{SH procedure}

The DNA probes described above were used at a concentration of $0.4 \mathrm{ng} / \mathrm{\mu l}$ ( $\mathrm{pUC1.77}$ ) and of 1 nigf $\mu$ l for all the other probes, in single- and double-target ISH. In triple-target ISH the autosomal probes $\mathrm{p} 7 \mathrm{t1}$ and $\mathrm{p} 17 \mathrm{H} 8 \mathrm{~s}$ were used at a concentration of $0.25 \mathrm{ng} / \mathrm{\mu l}$, to enable simultaneous localization of three ISH signals in the sperm head. The different probes were hybridized in different combinations (see below) in a hybridization buffer containing $60 \%$ formamide, $2 \times \mathrm{SSC}, \mathrm{pH} 7,0,10 \%$ dextran sulfate, $0.2 \mu \mathrm{g} / \mu \mathrm{l}$ herring sperm DNA as carrier DNA and $0.2 \mathrm{~kg} / \mu$ l yeast $t$-RNA as carrier RNA. $5 \mu$ buffer was added to each slide under a coverslip $(18 \times 18 \mathrm{~mm})$. Denaturation was performed on the bottom of a metal box in a water bath at $73^{\circ} \mathrm{C}$ for $3 \mathrm{~min}$ and hybridization was performed for $4 \mathrm{hrs}$ at $37^{\circ} \mathrm{C}$. The slides were washed twice at $42^{\circ} \mathrm{C}$ with $60 \%$ formamide, $2 \times \mathrm{SSC}, \mathrm{pH} 7.0$, containing $0.05 \%$ Tween 20 , followed by $2 \times 5$ min washes with $2 \times$ SSC, $\mathrm{pH} 7.0$ at $42^{\circ} \mathrm{C}$ and a 5 min wash with $4 \times$ SSC, pH 7.0 , containing $0.05 \%$ Tween 20 at room temperature.

\section{Cytochemical detection procedures}

Detection of signals was performed as described previously (Speell et al., 1994). Briefly, the detection procedures for the avidin conjugates were diluted in $4 \times \mathrm{SSC}, \mathrm{pH} 7.0$, containing $5 \%$ non fat dry milk (NFDM), while all the antibody conjugates were diluted in PBS containing $0.05 \%$ Tween 20 and $2 \%$ normal goat serum (NGS). After each incubation step of 20-30 min at 37 ?C, the slides were rinsed twice in $4 \times S S C$ pH 7.0/0.05\% Tween 20 (Avidin conjugates) or PBS/ $0.05 \%$ Tween 20 (antibody conjugates).

\section{Fluorescent ISH}

Single target fluorescent ISH was performed with the biotinylated probe for chromosome 1 and detected with a 1:100 dilution of FITC-conjugated avidin (Vector, Brunschwig Chemie, Amsterdam, The Netherlands). For double-target fluorescent ISH the directly labelled probes for the sex chromosomes (X-FITC and Y-TRITC) were applied simultaneously and could be detected directly. Slides were dehydrated and mounted in PBS/glycerol $(1: 9, \mathrm{v} / \mathrm{v})$ containing $2.3 \%$ of the anti-fading reagent 1,4 -diazobicyclo- $(2,2,2)$-octane (DABCO, Merck, Darmstadt, Germany) and $0.5 \mu \mathrm{g} / \mathrm{ml}$ of DAPI for nuclear DNA staining. In triple-target FISH with the probes X-FITC, Y-TRITC and biotinylated pUC 1.77, the first two probes were detected directly and the biotinylated probe was detected by means of three subsequent incubation steps of AMCA-conjugated avidin (AV-AMCA, 1:100; Vector), biotinylated goat anti-avidin (BioGaA, 1:100; Vector) and again AV-AMCA. Slides were then embedded as described above without the DAPI counterstaining.

\section{ISH using enzyme precipitates}

Single-, double-, and triple-target ISH using enzyme-conjugated reagents in combination with precipitating substrates were performed as described previously (Speel et al., 1994). Briefly, in single-target ISH the biotinylated pUC 1.77 probe was detected with horse radish peroxidase-conjugated avidin (AV-PO; 1:50; DAKO A/S; Glostrup, Denmark), followed by either the diaminobenzidine (DAB) or the tetramethylbenzidine (TMB) reaction. For alkaline phosphatase-Fast Red (APase-Fast Red) visualization, the probe was detected with two layers of mouse anti-biotin (M $\alpha$ Bio, 1:100, DAKO A/S) and APase-conjugated goat antimouse IgG (GoM-APase, 1:25; DAKO A/S).

In double-target ISH the biotinylated, chromosome $X$-specific probe and the fluoresceinated, chromosome $Y$-specific probe were detected respectively with AV-PO, mouse anti-FITC

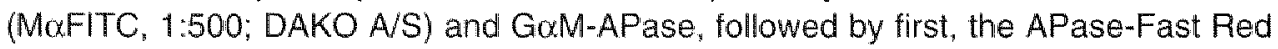


reaction and finally the $\mathrm{PO}-\mathrm{TMB}$ reaction; or $\mathrm{AV}-\mathrm{PO}$, MofFITC and $\mathrm{PO}-\mathrm{conjugated}$ rabbit anti-mouse lgG (RoM-PO, 1:80; DAKO A/S). In this ciase the PODAB reaction was performed after the first detection layer, followed by an incubation of the slides in $0.01 \mathrm{~N}$ $\mathrm{HCl}$ for 10 min at room temperature to inactivate any restactiviy of the PO enzyme. After the last incubation step with RaM-PO the PO-TMB reaction was perfomed.

In triple-target ISH the biotinylated X-probe, the FITC-labelled Y-probe and the digoxigeninlabelled 1-probe or biotinylated 1-probe, the digoxigenin-labelled 7 -probe and the FITClabelled 17-probe, were detected with three incubation steps of AV-PO, a mixture of mouse anti-digoxigenin (MoDig, 1:2000; Sigma, St. Louis, MD) and rabbit anti-FITC (1:2000; DAKO A/S), and a mixture of GoM-APase and PO-conjugated swine anti-rabbit lgG (SW $\alpha \mathrm{R}-\mathrm{PO}, 1: 100 ; \mathrm{DAKO}$ A/S). After the first detection layer the PO-DAB reaction was performed followed by the $0.01 \mathrm{~N} \mathrm{HCl} \mathrm{step.} \mathrm{After} \mathrm{the} \mathrm{last} \mathrm{incubation} \mathrm{step} \mathrm{first} \mathrm{the} \mathrm{APase}$ Fast Red precipitation reaction was performed, followed by the PO-TMB reaction. The individual enzyme reactions have been described previously (Speel et al. 1994).

\section{Counterstaining}

The haematoxylin counterstaining was first used, but than substituted by the Diff-Quik staining procedure. Of the latter we used only the cytoplasmatic staining step, $1 \mathrm{~g} / \mathrm{k}$ xanthene in sodium azide preserved phosphate buffer, $\mathrm{pH} 6.6$ (solution 1) and was obtained from Baxter, Utrecht, The Netherlands.

\section{Embedding}

Embedding dependent on the cytochemicall reactions used:

after a single- or double-target ISH with brown PO-DAB and green PO-TMB precipitates, the slides were embedded in organic mounting media, such as Entellan (Merck "Darmstadt, Germany), since the PO-TMB reaction product is unstable in aqueous mounting media. When a APase Fast Red reaction in single- or double-target (combining PO-DAB and APase Fast Red) ISH was performed, the slides had to be embedded in aqueous mounting media, after counterstaining, since the APase Fast Red precipitation product is unstable in ethanol and organic-based mounting media (Speel et al., 1992). When a triple target ISH was performed, the slides had to be embedded in a thin protein layer, after counterstaining (Speelet al, 1993, 1994), to ensure a permanent stabilization of the enzymo reaction products and optimal visualization of color contrast. The preparations were stored permanently at $4^{\circ} \mathrm{C}$.

\section{Microscopy}

FISH signals were analyzed with a Zeiss Axiophot microscope, equipped with appropriate filters for FITC. TRITC and DAPI fluorescence.

The evaluation of the enzyme precipitate ISH signals was done with a standard Zeiss brightfield microscope. Microphotographs were made on a Zeiss Axiophot microscope. using a Kodak Color Gold 100 ASA film in combination with blue and magenta filters.

\section{Results}

DNA decondensation

The original DNA decondensation protocol of Coonen et al., (1991), where DTT is combined with $0.1 \mathrm{M}$ trypsin treatment, was used for our initial studies. Over and under exposure to the denaturating agent influenced the ISH efficiency, as well as sperm morphology. Overexposure caused a complete loss of morphology and splitting of the ISH 
signals, making evaluation difficult. On the contrary, underexposure resulted in a nonaccessibility of sperm DNA and subsequent ailure of the 1 SH procedure. To improve DNA decondensation without having to assess the correct denaturation time for each individual case, we developed a decondensation procedure with DTT at a high $\mathrm{pH}$.

A proper decondensation of nuclear DNA and protamines was obtained after standard exposure to $25 \mathrm{mM}$ DTT in 1 M TRIS at a pH of 9.5 , for $5 \mathrm{~min}$ (tested in a range of 3 to 10 min) at room temperature. No efficient hybridization was observed without pretreatment of the samples, since only a limited number of sperm cells reacted properly, their number varying between the different samples. With the protocol delineated above all the investigated samples showed an oval, compact shape of the sperm head and tall, together with efficient hybridization.

The problem of clustering and overlapping spermatozoa was partly solved by careful fixation in methanol: acetic acid (3:1), and by cytospinning the samples on poly-L-lysine coated slides. However, sometimes adjacent or overlapping sperm cells and somatic cells could not be easily evaluated.

Single-, double- and triple-target FISH-procedure with differently labelled probes has been used for these tests. Additional counterstaining of the slides with DAPI allowed a better evaluation of the signals and a more reliable recognition of the tail. The FISH spots were discretely localized and bright, while the sperm tail was distinguishable (data not shown). In triple-target FISH a counterstaining was unnecessary since background-fluorescence was strong enough for a faint counterstaining.

\section{Brightfield microscopical analyses}

For brightfield microscopical detection of ISH signals, the enzymatic precipitation reactions were optimized for single target ISH. The optimalisation involved variation of reaction times and composition of the reaction media in order to obtain a proper localization of the ISH signal to enable a reliable evaluation.

Figure 1a illustrates a single target ISH reaction on a sperm preparation with an autosomal probe, performed with a PO-DAB reaction (brown precipitate). Figure $1 \mathrm{~b}$ shows the APase Fast Red reaction (red precipitate), and the $\mathrm{PO}-\mathrm{TMB}$ reaction (green precipitate) in a double-target sex chromosome $1 \mathrm{SH}$. In single-target ISH the oval shape of the head and the tail is clearly visible (Figure 1a). In this case the counterstaining was performed with haematoxylin. Aneuploidies could be detected in the single-target ISH procedure in properly counterstained sperm cells (see Figure 1a). Although in double-and triple-target ISH the different colors and the shape of the sperm-head were recognizable, the staining of the tail was normally inefficient, even after haematoxylin counterstaining (Figures $1 \mathrm{~b}-\mathrm{d}$ ).

\section{Combination of ISH and Diff-Quik sperm counterstaining}

In the first experiments counterstaining was performed with haematoxylin (Figures 1a-d), but it showed to be important to dilute the dye solution properly to allow a correct staining of the sample without covering the ISH signals and prevent mixing with the colored reaction products. However, it was still not possible to distinguish overlapping sperm heads or twisted tails because of the weak and non-contrasting staining that is obtained with haematoxylin.

To overcome these problems and to enable a simultaneous visualization of ISH signals and of the whole spermatozoon, we applied the Diff-Quik staining Kit, routinely used in the IVF lab for the evaluation of sperm morphology (Krugeret al., 1988; Enginsu et al, 1991). It could be combined with all ISH detection systems tested in this study, and we only reduced the standard staining to a 2 sec cytoplasmatic staining step. This was sufficient for a clear 
and contrasting staining of the plasma membrane. Figures 1e g show single-target $1 \mathrm{SH}$ with brown DAB signals, while in Figure $1 \mathrm{~h}$ an example of the green PO-TMB precipitation product is shown. Examples of morphologically abnomal spermatozoa showing abnomalities of chromosome 1 are indicated in Figure ff and Figures $1 \mathrm{~g}$-h, respectively. In Figure 1i a double-target ISH with the sex chromosomes is shown, in spematozoa next to a somatic cell. The sperm head has a small cytoplasm, and is therefore less stained as compared to the tail and to the somatic cells. A rellable evaluation of the ISH signals together with cytogenetic and morphological abnormalities is now possible with the DiffQuik method.

\section{Numerical data}

Sperm samples from 7 normall males were analyzed with the centromeric probe for chromosome 1. For each donor an average of 1600 sperm cells were counted (range from 1200 to 1800 ). The average 1 SH efficiency was $98.7 \%$ (range from $98.0 \%$ to $99.3 \%$ ). The detected aneuploidy rate was $0.69 \%$ (range from $0.40 \%$ to $1.40 \%$ ). The percentage of morphologically abnormal spermatozoa ranged from $3.71 \%$ to $8.21 \%$, with an average of $5.68 \%$

\section{Discussion}

This study was initiated to develop a standardized method for an efficient detection of numerical chromosomal aberrations in human spermatozoa by ISH. The decondensation of the chromatin of the sperm head appeared to be a crucial and essential step for such analyses. Only after proper decondensation the DNA probe is able to penetrate and hybridize to the DNA of the specimen. The denaturation of DNA, both of the probe and of the target cells, concedes the annealing of the first to the complementary sequences of the latter.

\section{DNA Denaturation}

Different denaturation methods are used, based on the reducing quality of DTT. Several buffers and exposure times have been reported, and the methodological approach occasionally varied per sample (for example time of digestion, time of denaturation prior to ISH) in order to obtain optimal results (Coonen et al., 1991; Robbins et al., 1993).

Our study started from a protocol that was based on exposure of the sperm samples to DTT during a carefully assesed denaturation time (Coonen et al., 1991). This crucial timing involved the use of time sequences of the reducing agent and was too much time consuming to be useful for a routine analysis. The exposure to $25 \mathrm{mM}$ DTT and $0.1 \mathrm{M}$ Trypsin resulted in a partial loss of morphology and of the tail. The dilution of DTT in a TRIS/HCl buffer gave a compact morphology, but the pH of the buffer strongly influenced DTT's reducing efficiency. Our experiments revealed a more compact head structure the higher the $\mathrm{pH}$ of the DTT containing buffer was (in a range that varied from $\mathrm{pH}$ 6.0-9.5) (data not shown). Skipping of the enzymatic treatment of spermatozoa resulted in a retainment of the tails. At a pH of 9.5, where DTT is almost completely ionized, 5 min of exposure at room temperature was enough for a proper decondensation of the DNA, without an excessive swelling of the sperm head. The hybridization efficiency in single target ISH showed to be $98.7 \%$ (in a range from $98.0 \%$ to $99.3 \%$ ) with this decondensation protocol. In conclusion, this decondensation method keeps the morpholgy of the whole spermatozoon intact and results in efficient DNA hybridization. 

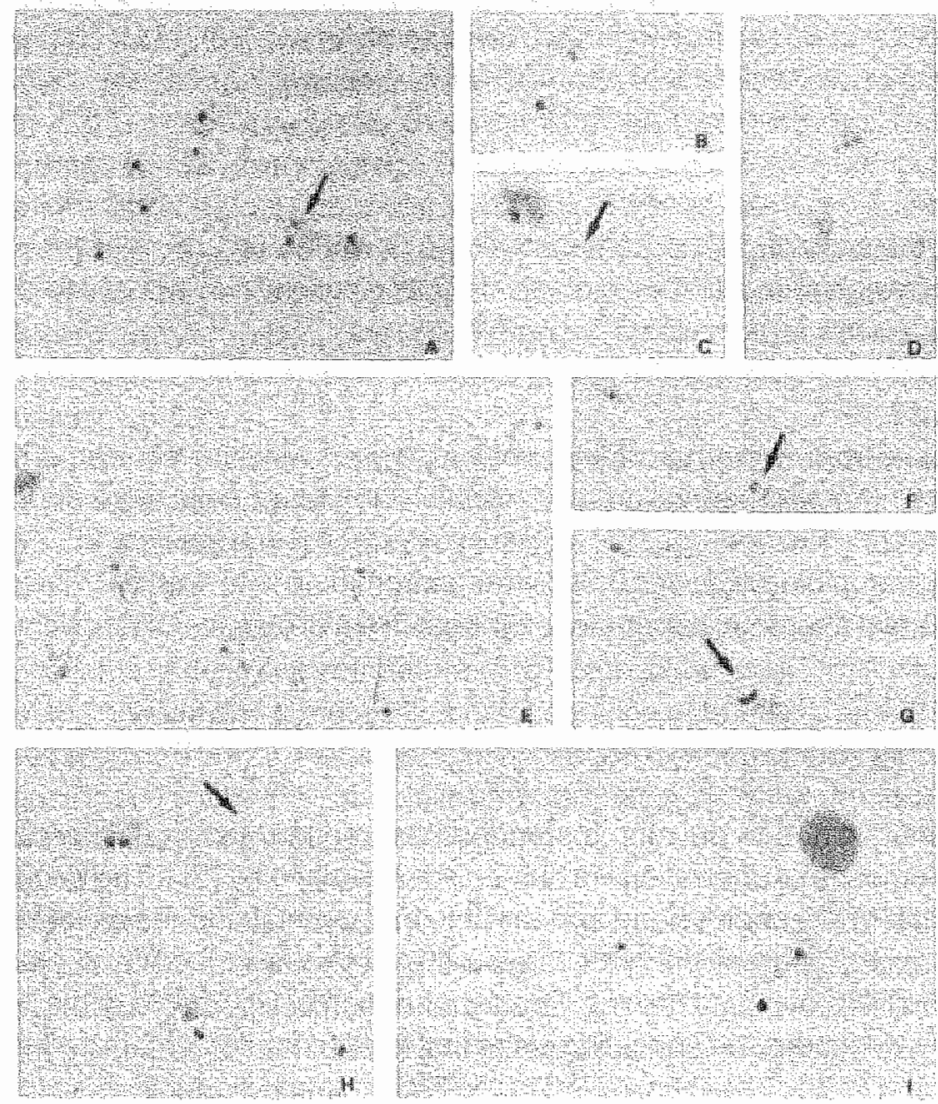

Figure $\|_{n}$ (magnification for Figures $a, b, d, e, f, g, h, i: 1000 X_{n}$ Figure,c: $2000 x$ ) (a.) Single-targel ISH with a biotinylated probe for chromosome 1, detected with the $D A B$ reaction. The arrow indicates a spermatozoa with 2 ISH signals for chrom mosome 1. (b.) Double-target ISH with a biotinylated probe for chromosiome $X$ and a FITC labelled probe for chromosome $\mathrm{W}$. Detected with the Fast-Red and the TMB reactions, respectively. (c-d.) Triple-target ISH with a biotinylated probe for chromosome 1 , a digoxigenin-labeiled probe for chromosome 7 and a FITClalbelled probe for chromosome 17. Detected with DAB, Fast-Ped and TMB, respectively. In Figure 1c the arrow indicates the tail. (a-d.) Counterstaining with haematoxylin. (e-g.) Single-target ISH with a 1-bio probe, detected with DAB. The arrow in ( $f_{.}$) indicates a spermatozoa with 2 ISH signals for chromosome 1. The arrow in (g.) indicates a morphologically abnormal sperm cell. with two heads, two signals, two midpieces, but one tail. (h.) Single-target ISH with 1 bio probe, detected with TMB. The arrow indicates a morphologically abnormal sperm cell with one head but with two ISH signals and two tails. (i.) Somatic cell and double-target $1 \mathrm{SH}$ with a $\mathrm{X}$-bio probe and FITC-labeled probe for chromosome $Y$, detected with DAB and TMB, respectively. (e-1) Counterstaining with Diff-Quik. For colour illustration see page $\$ 13$.

\section{Brightfield microscopical analyses}

The different and partly contrasting ISH results on sperm cells published so far can be explained by the complexity of the FISH procedure, by signal interpretation as well as the morphological evaluation (West et al., 1989; Coonen et al., 1991; Guttenbach and Schmid, 
1994; Martin el al., 1993: Robbins et al., 1993; Miharu et al., 1994). In particular the proper combination of efficient ISH with good morphology of the spem cells is still a problem and not very well documented in the literature. Some authors do not consider and count mor. phologically abnormal spermatozoa, overlapping spermatozoa and spematozoa without an hybridization signal (Martin etal., 1993; Bischoff et al, 1994). This hampers a correct evaluation as much as a controversial signal interpretation does, because aneuploid sper. matozoa are not easily distinguishable from abnormal spermatozoa (two tails, but one head or vice versa), or from diploid somatic cells (see Figures 1a, fi), especially in fluorescent ISH.

Our data show an aneuploidy rate for chromosome 1 of $0.69 \%$, with a range that varies from $0.40 \%$ to $1.40 \%$. This value fits in the range of the published data, where the detected aneuploidy rate with the centromeric probe for chromosome 1 is in the range from $0.06 \%$ to $0.96 \%$ (Holmes and Martin, 1993; Pang et al., 1994). The percentages of morphologi. cally abnormal spermatozoa ( 2 heads one tail or viceversa) were in between $3.71 \%$ and $8.21 \%$, with an average value of $5.68 \%$. This high value of morphologically abnormal spermatozoa can now reliably be excluded from aneuploidy analysis.

The exposure to a reducing agent and detergents leads to swelling of the sperm head. In a single color probe system, disomic and diploid sperm nuclei will produce both two signals for particular chromosomes. In spermatozoa Carothers and Beatty (1975) and Miharu et al. (1994) observed no correlation between cell size or morphology at the one hand and ploidy levels on the other. As a result it is not feasible to differentiate a monosomic sper. matozoa with a split signal from a disomic or a diplaid one on basis of nuclear size with a single target ISH. Secondly, if the tail is lost, it is extremely difficult to separate sperm cells from somatic cells on basis of morphological criteria. Diploid somatic cells are nomally present in an ejaculate and are not completely removed during washing steps designed to discard seminal plasma, which are applied before fixing the samples. These cells can contribute to an erroneous estimation of the ploidy level, or to interpretation problems between different groups, also if care is taken in scoring of the samples (Holmes and Martin, 1993; Miharu ef al., 1994). Some authors have tried to solve this problem with triple-target FISH (Williams et al, 1993). Such a procedure with the sex chromosomal probes and one autosomal DNA probe permits the easy detection of diploid somatic cells. Although multiple target FISH is feasible, the interpretation of the signals, in relation to the morphological recognition of the single spermatozoa, is difficult and therefore brightfield microscopy with multiple color detection procedures is to be preferred.

Moreover the FISH signals, though localized and bright, can be at different levels of focus, due to the size of the interphase nuclei (Miharu et al., 1994), and proper focusing is therefore needed. Added to a splitting of the signal, an inhomogeneous fluorescence intensity. and minor binding sites of the signals, this can lead to misestimations. Furthermore, fading of the fuorescent signals requires a rapid evaluation.

The absorption protocol for multiple $1 \mathrm{SH}$ is routinely used in our lab for the analysis of numerical and structural genomic aberrations of somatic cells (Speel et al., 1994). It is based on immunocytochemical and enzymatic detection reactions, that allow the evaluation of ISH results with a brightfield microscope. This has the advantages of avoiding fading of the signal, partly solves the focusing problem, gives well localized signals and the procedure is relatively easy to perform. We used different enzymatic detection reactions in combination with different substrates, which resulted in stable precipitates with contrasting colors. The use of these different detection colors, allows a correct evaluation of the signals in single-, double-and triple-target ISH reactions. 


\section{Counterstaining}

The time of counterstaining proved to be a crucial point in case of brightfield microscopy. If this was done too long, the ISH signal was not distinguishable from the general counterstaining, because of the mixing of the different colors. On the other hand, if counterstaining was too weak, no correct morphological evaluation of the single spermatozoa was feasible. The presence of the tail was essential for correct evaluation of the single spermato$z_{\text {za }}$ especially in case of morphologically abnormal spermatozoa. It is important to be able to distinguish an abnormal spermatozoa (with two heads, two midpieces but one tail or two tails but one head) from a diploid somatic cell or from a disomic spermatozoa itself (see Figures $1 a_{s} 1 f-i$ ). The cytoplasmatic component of the Diff-Quik protocol stains the membrane that covers the whole spermatozoon. Human sperm has a relatively small amount of cytoplasm, and therefore the head piece is less stained than the tail or than somatic cells, thus allowing a reliable estimation of the aneuploidy rate. Some problems regarding its usefulness in abnormal sperm cells persist, however, for example when the tail is single but thick, when the ISH spot is double but two midpieces and two head membranes are recoginizable or when one sperm head shows two tails. In these cases the single sperm has to be classified on basis of morphological criteria. Our procedure makes it possible to discriminate between morphologically abnormal or immature spermatozoa on one hand, and aneuploid mature spermatozoa on the other.

Our new approach will be applied to evaluate the cytogenetic abnormalities in sperm samples of normal, healthy donors of proven fertility in single target ISH with a repeated probe for the telomeric region of chromosome 1, and a double target ISH using centromeric probes.

\footnotetext{
Acknowledgements

The authors thank Edith Coonen for her helpful suggestions, the IVF lab of the University Hospital Maastricht for the routine analyses, and Professor G. Capitanio for his irreplaceable support.

This work was in part supparted by the E.C. with a COMETT LI.SA. Grant and by the National Research Council (CNA) -Targeted Projects "Prevention and Control Disease Factors" - Subproject "Control of Human Fertility" -grant 91.00265.PFA1
}

\section{References}

Calvin $H_{3}$ Bedford J. (1971) Formation of disulphide bonds in the nucleus and accessory structures of marnmallan spermatozog during maturation in the epididymus. I Reprod Fer, 13, 65-75.

Carothers, A, Beatty $\mathrm{A},(1975)$ The recognition and incidence of haploid and polyploid spermatozoa in man, rabbit, and mouse. J Reprod Fer., 44, 487-500.

Cooke $\mathrm{H}_{\text {, Hindley }} \mathrm{J}$, ("1979) Cloning of thuman satellite lll DNA: different components are on different chromosones. Nucleic Acids Res, 6, 3177-3197.

Cooke H. Schmidtke J, Gosden J. (1982) Characterization of human Y chromosome repeated sequence and related sequences in higher primates. Chromosoma, 87, 491-502

Coonen E, Pieters M, Dumoulin J, Meyer H, Evers J, Ramaekers F, Geraedts J, (1991) Nonisotopic in situ hybridization as a model for nondisjunction studies in human spermatozoa. Mol Reprod Dev, 28, 18-22.

Enginsu $M$, Dumoulin J. Pieters $M$. Bras $M$. Evers J. Geraedts „. (1991) Evaluation of human sperm morphology using strict criteria after Diff-Quik staining: correlation of morphology with fertilization in vitro. Hum Reprod, 6, 854-858.

Guttenbach $M$, Schakowsky $R$, and Schmid $M,(1994)$ Incidence of chromosome $3,7,10,11,17$ and $X$ disomy in mature human sperm nuclei as determined by nonradioactive in situ hybridization. Mum Genet 93, 7-12. 
Guttenbach M: Schmid M, (1990) Determination of Y chromosome aneuploidy in human spem nuciei by nonradioactive in situ hybridization. Am J Hum Gene, $466_{0} 553558$.

Han T, Webb G, Flahery S, Correll A, Matthews $C$, Ford J. (1992) Detection of chromosome 17 - and $X$ bearing human spermatozoa using fluorescence in situ hybridization. Mol Feprod Dev $33,189-194$.

Holmes J, Martin $R_{s}$ (1993) Aneuploidy detection in humam sperm nuliclel using fluorescence in situ hybridization. Hum Genet, 91, 20-24.

Joseph $A$, Gosden J, Chandley A. (1984) Estimation of aneuploidy levels in human spematozod using chromosome specific probes and in situ hybridization. Hum Genet, 66, 234-238.

Kruger T, Acosta A. Simmons K, Swanson J, Malta J, Oehninger S. (1988) Predictive value of abnomat sperm morphology in in wilro fertilization. Fertil Steril, 49, 112-117.

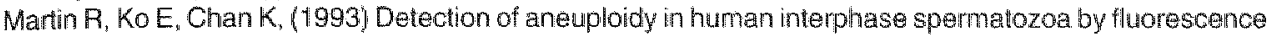
in situ hybridization (FISH). Cytogenet Cell Genet, $64,23-26$.

Martin $\mathrm{F}_{3}$. Rademaker $\mathrm{A}$, (1990) The frequency of aneuploidy among individual chromosomes in 6821 huw man sperm chromosomes complements. Cytogenet Cell Genet, $53,103-107$.

Martini E, Speel E, Coonen E, Ramaekers F, Geraedts J. Hopman A, (1994) Now methodologies for ISH on chromosomal DNA in numan spermatozoa. Hum Reprod, $9 \mathrm{~S} 4,30$.

Mitharu N, Best R, Young S. (1994) Numerical chromosome abnormalities in spermatozoa of fertile and infertile men detected by fluorescence ir situ hybridization. Hum Genet, 93, 502-506.

Pang M, Zackowski d, Ryu B, Moon S, Acosta A, Keams W, (1994) Aneuploidy detection for chromosome $1, X$ and $Y$ by fluorescence in situ hybridization in human sperm from oligoasthenoteratozoospernic piatients. Am J Hum Genet, 55, S., A113.

Perrault S, Zirkin B, (1982) Sperm nuclear decondensation in mammals: role of sperm associated protein. ase in wivo. J Exp ZOOl, 224, 253-257.

Pieters M, Geraedts J, Meyer H, Dumoulin J, Evers J, Jongbloed R, Nederlof P, van der Flier S, (1990) Human gametes and zygotes studied by nonradioactive in situ hybridization. Cytogenet Call Genet. $53,15-19$.

Robbins W, Segraves R, Pinkel D, Wyrobek A (1993) Detection of aneuploid human sperm by fluorescence in situ hybridization: evidence for a donor difference in frequency of sperm disomic for chromosome 1 and Y.. Am. J. Hum. Genet. 52, 799-807.

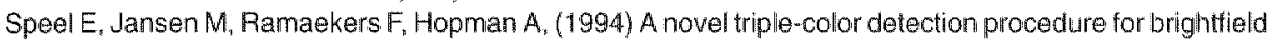
microscopy, combining in situ hybridization with immunocytochemistry. J Histochem Cytochem, 42 , 1299-1307.

Speel E, Kamps M, Bonnel J, Famaekers F. Hopman A, (1993) Multicolor preparations for in situ hybridization using precipitating enzyme cytochemistry in combination with reflection contrast microscopy. Histochemistry, 100, 357-366.

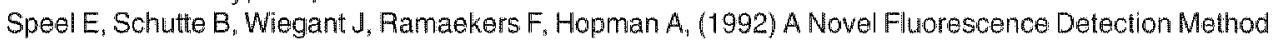
for In Situ Hybridization, Based on the Alkaline Phosphatase-Fast Red Reaction. J Histochem Cylochem, 40, 1299-1308.

Vidal F, Moragas M, Catala" V. Torello $M$, Santalo' J Calderon G, Gimenez C, Barri P, Egozcue J, Veiga $A_{\text {" }}$ (1993) Sephadex filtration and human serum albumin gradients do not select spermatozoa by sex chromosome: a fluorescent in-situ hybridization study. Hum Reprod, 8, 1740-1743.

Wawe J, England S. Willard $H,(1987)$ Genomic organization of alpha satelite DNA on human chronosome 7: evidence for two distinct alphoid domains on a single chromosome. Mor CeN Biol, 7, 349-356.

Waye $J_{*}$ Willard $H_{*}(1986)$ Molecular analysis of a deletion polymorphism in atpha satellite of chromosome 17: evidence for homologous unequal crossing-over and subsequent fixation. Nucleic Acids Fes, 14, 6915-6927.

West J, West K, Aitken R, (1989) Detection of $Y$-bearing spermatozoa by DNA-DNA in situ hybridization. Mol Reprod Dew, 1, 201-207.

Willams B, Ballenger $C$, Malter $H$, Bishop F, Tucker M, Zwingman T, Hassold T, (1993) Non-disjunction in human sperm: results of fluorescence in situ hybridization studies using two and three probes. Hum Mol Genet, 2, 1929-1936.

Wyrobek A, Alhbor T, Balhorn R, Stanker L, Pinkel D. (1990) Fluorescence in situ hybridization to $Y$ chromosomes in decondensed human sperm nuclei. Mol Reprod Dev, 27, 200-208. 



\section{Chapter

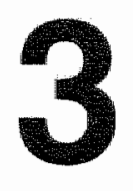

\section{Constitution of semen samples from $X Y Y$ and $X X Y$ males as analyzed by in situ hybridization}

Elena Martini, Joep P.M. Geraedts, Inge Liebaers, Jolande A. Land, GianLuigi Capitanio, Frans C.S. Ramaekers and Anton H.N. Hopman

Human Reproduction (1996), 11: 1638-1643 


\section{Abstract}

A brightfield microscopical in situ hybridization (ISH) lechnique was applied to semen samples of two $47, X Y Y$ males, one $46, X Y / 47, X X Y$ male having fertility problems, and two normal $46, X Y$ men, who served as controls. The use of a standardized nuclear DNA decondensation method, together with double-target ISH and morphological staining, allowed an accurate study of the sex chromosomal content and morphology of spermatozoa. In the males carrying an extra sex-chromosome, we detected $X$-and $Y$-bearing spermatozoa in a ratio which did not differ significantly from the $1: 1$ ratio found in nomal males. Aneuploidy for the sex-chromosomes was found in approximately $15 \%$ of the sperm cell population of both XYY males and in $3 \%$ of the XXY male. The most striking finding was the relatively low percentage of sperm cells in these patients, with an average of $65 \%$ in the $X Y Y$ males and $84 \%$ in the $X X Y$ male. The other cells represented immature germ cells (IGC), like spermatogonia and spermatocytes arrested at various stages of spermatogenesis. Apparently, in XYY or XXY men, these $1 G C$ are shed into the semen to an increased extent as compared to normal, fertile men. The sex chromosome constitution of these IGC was heterogeneous. However, the finding that the majority of spermatozoa in semen of $47, X Y Y$ and $47, X X Y$ males carried a single sex chromosome, strenghtens the hypothesis that a $46, X Y$ germ cell line must be present, apparently with a proliferative advantage over the $47, X Y Y$ or $47, X X Y$ cells.

\section{introduction}

The estimated incidence of chromosomal abnormalities in cells of subfertile men is $4 \%$ to $5 \%$ compared with $0.5 \%$ to $0.7 \%$ in the general population. It has been found that up to $11.9 \%$ of azoospermic-and $4.4 \%$ of oligospermic patients carry a constitutional chromosomal abnormality (Harari et al., 1995). In a study done on 496 infertile males an overall incidence of $7.1 \%$ constitutional abnormalities suggests that a selection criterion based on chromosome studies as routine analysis of infertile men might be advisable (Retief et $a 1 ., 1984$ ).

The most frequent anomalies found in subfiertile malles are sex-chromosome aneuploidies, predominantly $47, X Y Y$ and $47, X X Y$.

Virtually all cases of $X Y Y$ are due to paternal meiosis $I I$ nondisjunction. The frequency of $X Y Y$ conceptuses and liveborns $(0.1 \%)$ coincides with the observed frequency of $Y Y$ sperm in ejaculates of normal males (0.06-0.11\%) (Rothwel, 1983; Bischoff et al., 1994). The first fluorescent quinacrine staining on testicular biopsies of XYY males was performed in 1971 by Hulten and Pearson. In 1988, Benet and Martin analyzed 75 sperm complements of one 47, XYY male by karyotyping and observed no increase in the percentage of spermatozoa with sex-chromosome abnormalities. In 1994 fluorescence in situ hybridization (FISH) was applied to spermatozoa of a $47, X Y Y$ patient (Han et al, 1994). The ratio of Xand $Y$-bearing spermatozoa appeared not to differ from the normal $1: 1$ ratio (Han et al., 1994; Benet and Martin, 1988). The offspring of 47, XYY men does not show an increased frequency of congenital abnormalities, nor a higher frequency of $47, X Y Y$ or $47, X X Y$ children (Stoll et al., 1979).

The 47, XXY karyotype is associated with the Klinefelter Syndrome (KS), and is the most common form of male hypogonadism. It occurs in 1 out of 600 new-born males, and arises from maternal or paternal nodisjunction at meiosis. Jacobs et al., (1988) found no effect of parental age on the conception of $47, X X Y$ males of paternal origin, but a very marked association between increasing maternal age and $47, X X Y$ males of maternal origin. Although males with KS are usually sterile, patients with mosaic karyotypes may have tu- 
bules consisting of cells with a normal chromosomal constitution that produce spermatozoa. Cozzi et al., (1994) studied 543 sperm karyotypes of an XY/XXY mosaic patient and found a significantly increased incidence $(0.9 \%)$ of hyperhapioid $24, X Y$ chromosome sets, in absence of the expected corresponding hypohaploid cells. The results of Cozzi et al, (1994) support the observations of previous studies (Berthelsen et al., 1981; Vidal et al., 1984; Speed et af., 1991) which indicated that $47, X X Y$ cells may be able to undergo meiosis and produce $24, X Y$ spermatozoa. These results are supported by a recent study of Chevret et al., (1996), where FISH analysis was performed on semen of a $46, X Y / 47, X X Y$ mosaic man, and a significantly increased frequency of hyperhaploid $24, X Y$ spermatozoa was found, suggesting that a few $47, X X Y$ germ cells might be able to produce mature spermatozoa.

This study was performed to investigate the morphology and chromosomal constitution of cells present in the semen of infertile men carrying an extra sex chromosome. The ISH procedure is based on an enzymatic-cytochemical detection procedure, and resulted in a stable and non-fading precipitate that can be analysed by brightfield microscopy. The use of Diff-Quik in combination with haematoxylin as a morphological stain allowed the dis crimination between morphologically normal and abnormal spermatozoa, as well as IGC (Martini et al., 1995b).

The combination of an efficient ISH method with an adequate morphologic staining procedure for sperm cells has been introduced recently (Martini et al., 1995a). Untill now, most authors did not take the morphological criteria into account when analyzing aneuploidy in semen. As a result, abnormal spermatozoa (e.g. double heads with one tail) or overlapping spermatozoa could have been confused with somatic cells or diploid sperm cells (Martin et al., 1993; Bischoff et al., 1994; Wyrobek et al., 1994). Therefore, in our opinion, a correct evaluation of the aneuploidy rate is hampered in assays where morphological parameters are not incorporated.

\section{Materials and methods}

\section{Case histories}

Case 1 concerns a 29 years old man, who was referred for intracytoplasmic sperm injection (ICSI) because of oligoasthenospermia. Lymphocyte karyolyping was done, and showed a $47, X Y Y$ constitution in all cells. Before an ICSI appointment was made, his wife conceived on natural way.

Case 2 concerns a 33 years old man, who was refered for ICSI because of severe oligospermia. As part of the clinical work-up for ICSI, karyotyping was done, and revealed a $47, X Y Y$ constitution in all cells.

Case 3 is a 45 years old man, who was refered for ICSI treatment because of previous diagnosis as a $46, X Y / 47, X X Y$ mosaic. After FISH analysis of 200 peripheral blood cells, 5 cells with an $X X Y$ constitution were detected.

Control samples were obtained from 2 men with a normal $46, X Y$ karyotype.

Semen specimens were analyzed using WHO (1993) criteria for concentration and motility, and Kruger's strict criteria for morphology analysis (Kruger et al., 1988). The analysis showed the semen of the patients to have a concentration of $2 \times 10^{6} / \mathrm{ml}, 3.6 \times 10^{6} / \mathrm{ml}$ and $11.8 \times 10 \% \mathrm{ml}$ respectively for case 1,2 and 3 . Motility percentages were $59 \%, 50 \%$ and $1 \%$ respectively for the three cases while the semen of the control men was within the normal value range.

All three patients and the two healthy volunteers gave written consent for the semen samples to be used for research purposes. 


\section{Preparation of Sperm Nuclei}

After routine semen analysis, sperm from patients and controls was prepared for the ISH procedure as described below.

Sperm samples were washed 3 times in phosphate buffered saline (PBS), pH 7.4, and centrifuged at $1200 \mathrm{rpm}$ for $10 \mathrm{~min}$, and then fixed in methanol: acetic acid (3.1). The specimens were stored at $-20^{\circ} \mathrm{C}$ until slide preparation. Sperm cells were cytospun on poly-L-Lysine coated slides and were kept at $+4^{\circ} \mathrm{C}$ for $7-10$ days. Then the slides were washed in $2 x$ standard saline citrate (SSC) and incubated for $5 \mathrm{~min}$ in $1 \mathrm{M}$ TRIS buffer, pH9.5, containing 25mM dithiothreitol (DTT) (Martini et al.,1995a). After decondensation the slides were washed once in $2 \times 5 S C$, once in PBS and finally dehydrated (Jones et al., $1987)$

\section{DNA Probes and Labeling Procedures}

For the detection of the centromeric region of the $X$-chromosome, we used the repetitive DNA probe pBam $\times 5,2.0 \mathrm{~Kb}$ (Oncor, Gaithersburg, MD) and for detection of the $Y$-chromosome, the repetitive DNA probe DYZ1, 3.4 Kb (Cooke el al, 1982). The probes were labelled with biotin-11-dUTP (Enzo Diagnostic, New York, NY) or fluorescein-12-dUTP (Boehringer, Mannheim, Germany) in a standard nick-translation reaction following the manufacturer's instructions.

\section{SH Procedure}

Double target $1 \mathrm{SH}$ with the biotinylated centromeric probe for the $\mathrm{X}$-chromosome and the FITC-labelled probe for the $Y$-chromosome was performed. The probes were used at a concentration of $0.4 \mathrm{ng} / \mu \mathrm{l}$. Hybridization and detection procedures were performed as described previously (Martini et al., 1995a). Briefly, after overnight hybridization, the biotinylated probe was detected with avidin-peroxidase (AV-PO, 1:50; DAKO A/S, Glostrup, Denmark), followed by the diaminobenzidine reaction (DAB, Sigma, St. Louis, MO, USA). The slides were then incubated for $10 \mathrm{~min}$ at room temperature in $0.01 \mathrm{~N} \mathrm{HCl}$ to unactivate peroxidase activity. Subsequently, the fluoresceinated probe was detected with mouse anti-FITC antibodies (1:500; DAKO A/S), and peroxidase-conjugated rabbit anti-mouse $\operatorname{lgG}(1: 80 ; \mathrm{DAKO}$ A/S). After this last incubation step, the peroxidase-tetramethylbenzidine (TMB, Sigma, St. Louis, MO, USA) reaction was performed (Speel et al, 1994).

\section{Counterstaining and embedding}

The slides were first dehydrated, than briefly counterstained in haematoxylin, again dehydrated and finally counterstained with Diff-Quik (DADE AG, Dudingen, CH) as described before (Martini et al., 1995b). We utilized exclusively the cytoplasmic staining step of the Diff-Quik staining procedure, which consists of Eosin $\mathrm{G}$ in phosphat buffer, pH6.6 (1.22 g/ l: solution 1).

Embedding was accomplished with Entellan (Merck, Darmstad, Germany), and slides were stored at $+4^{\circ} \mathrm{C}$ untill evaluation.

\section{Microscopy}

The $\| S H$ signals were ewaluated with a standard Zeiss brightfield microscope. Microphotographs were made on a Zeiss Axiophot microscope, using a Kodak Color Gold 100 ASA film, in combination with blue and magenta filters. 
morphology and their sex chromosome constitution. Spermatozoa showing one head and one tail were defined as morphologically normal. The morphological evaluation according to Krugers strict criteria was not possible after ISH, due to the exposure of the spermatozoa to DTT prior to ISH. Likewise, morphologically abnormal spermatozoa characterized by 2 heads and 1 tail, or vice versa, or showing any other major morphological abnormality were recognized as abnormal, but could not be evaluated properly for their chromosome content (Martini et al., 1995a).

The big, round cells, without tail and brightly stained with the cytoplasmatic component of Diff-Quik, seen in this study are scored as immature germ cells (IGC). Although it cannot be excluded that these cells are somatic cells, it is very unlikely because in routine semen analysis of these samples, the amount of epithelial cells is comparable to normal semen samples, which is very low. A high amount of small, round and brightly coloured cells, which did not show ISH signals were not included in the evaluation.

\section{Results}

The results of the routine semen analysis and ISH of all samples are presented in table 1. The average ISH efficiency of all samples was $97.3 \%$. X-and $Y$-bearing spermatozoa were present in the regular 1:1 ratios in all the samples analyzed. The results of the routine analyses and ISH of control semen specimens were all within the normal range.

Table 1. Constitution of semen siamples of controls, $X Y Y$ and $X X Y$ males.

\begin{tabular}{|c|c|c|c|c|c|}
\hline & $\begin{array}{c}\text { Controlt } \\
X Y\end{array}$ & $\begin{array}{c}\text { Control } 2 \\
X Y\end{array}$ & $\begin{array}{c}\text { Case } 1 \\
\text { XYY } \\
\end{array}$ & $\begin{array}{c}\text { Case } 2 \\
\text { XYY } \\
\end{array}$ & $\begin{array}{l}\text { Case } 3 \\
X X Y \text { mosaic }\end{array}$ \\
\hline cellis scored & 2820 & 2993 & 3300 & 3500 & 3800 \\
\hline USH Efficiency $(\%)$ & 99.4 & 99.4 & 94.5 & 97.3 & 98.7 \\
\hline Morph. Normal Sperm (\%) & 100 & 99.8 & 58.6 & 66.7 & 79 \\
\hline Morph. Abnorm. Sperm (\%) & 0 & 0.1 & 3.4 & 3.3 & 5.0 \\
\hline $1 \mathrm{GO}(\%)$ & 0 & 0 & 38 & 30 & 16 \\
\hline
\end{tabular}

The most revealing finding in the patients" semen samples was that next to mature sper" matozoa, showing a normal morphology after ISH, a population of large, round cells was seen, which we have interpreted as IGC (Figure 1b,c). These cells were present in a substantial proportion: in case $1,38 \%$ of cells were classified as $I G C$, in case 2 we found $30 \%$, and in case $3,16 \%$ IGC. The percentage of IGC in the control semen samples was only $0.02 \%$.

The ISH analysis for sex chromosome constitution in spermatozoa and IGC are given in table 2 and examples of ISH staining results are depicted in Figure1. In control samples $98.4 \%$ of spermatozoa carried either one $X$ - or $Y$-chromosome and $1.1 \%$ were aneuploid. For the patients the frequency of aneuploid cells ranged from $4 \%$ to $15 \%$, with the highest percentage in both the $47, X Y Y$ males (Figure 1d, e, f, g).

Morphologically abnormal sperm was present in the patients in a range of $3 \%$ to $5 \%$ (Figure $1 \mathrm{~h}, \mathrm{i}$, while in control samples only $0.13 \%$ of spermatozoa was classified as being morphologically abnormall. 
Table 2. Sex chromosome content of spem and $I \mathrm{GC}$ of controt, XYY and XXY males" as analyzed by ISH

\begin{tabular}{|c|c|c|c|c|c|c|c|c|c|c|}
\hline \multirow[t]{2}{*}{ Freq. $(\%)$} & \multicolumn{2}{|c|}{$\begin{array}{c}\text { Control } 1 \\
\text { XY }\end{array}$} & \multicolumn{2}{|c|}{$\begin{array}{c}\text { Control } 2 \\
X Y\end{array}$} & \multicolumn{2}{|c|}{$\begin{array}{c}\text { Case } 1 \\
\text { XYY }\end{array}$} & \multicolumn{2}{|c|}{$\begin{array}{l}\text { Case? } \\
\text { xyy }\end{array}$} & \multicolumn{2}{|c|}{$\begin{array}{c}\text { Case } 3 \\
\times X Y \text {-mosaic }\end{array}$} \\
\hline & Spent & $\operatorname{MGC}$ & Sperm & $19 C$ & Sperm & IGC & Sperm & $\operatorname{MGC}$ & Sperm & $16 \mathrm{C}$ \\
\hline$x$ & 51.3 & 0.0 & 49.0 & 0.0 & 43.5 & 6.7 & 45.4 & 7.9 & 46.7 & 10.6 \\
\hline$y$ & 47.7 & 0.0 & 49.5 & 0.0 & 37.5 & 6.6 & 35.0 & 7.6 & 43.5 & 5.7 \\
\hline no signal & 0.6 & 0.0 & 0.6 & 0.0 & 8.2 & - & 3.8 & $=$ & 1.5 & - \\
\hline$X Y$ & 0.4 & 0.0 & 0.4 & 0.0 & 2.3 & 36.2 & 5.4 & 28.1 & 1.3 & 40.8 \\
\hline XYY & 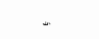 & 0.0 & - & 0.0 & 0.8 & 24.4 & 0.6 & 39.3 & - & 10.7 \\
\hline$X X Y$ & . & 0.0 & . & 0.0 & . & 5.9 & . & 20 & - & 10.0 \\
\hline$x \times$ & - & 0.0 & 0.1 & 0.0 & 2.0 & 9.3 & 2.7 & 49 & 0.5 & 8.8 \\
\hline YY & . & 0.0 & 0.2 & 0.0 & 0.8 & 4.5 & 2.3 & 6.6 & 0.7 & 8.3 \\
\hline$X X Y Y$ & - & 0.0 & - & 0.0 & 0.1 & 5.2 & 0.1 & 1.6 & - & 5.5 \\
\hline XYYY & . & 0.0 & . & 0.0 & . & 1.2 & - & 2.0 & - & - \\
\hline Ictal aneuploid & 0.4 & & 0.7 & & 6.0 & & 11.1 & & 2.5 & \\
\hline
\end{tabular}

"Only the chromosome constitution of apparently normal spematozoa and IGC was evaluated. The morphologically abnormall sperm cells in these preparations could not be analyzed reliably for their chromosome content.

\section{Discussion}

Based on ISH, combined with a morphological staining procedure, a distinction between morphologically normal sperm cells with a normal sex-chromosome constitution on the one hand, and morphologically and/or chromosomally abnormal spermatozoa, somatic cells and immature germ cells (IGC) on the other hand is possible (Martini et al, 1995a). We have applied this technique to the semen samples of three patients with sex chromosome abnormalities and two normal males in order to achieve a reliable estimate of the fraction of normal sperm cells in the semen of these patients. For this purpose we have assessed the proportion of morphologically as well as chromosomally abnormal sperm cells.

Summarizing our findings we can state that (i) the estimated risk of abnormal chromosomal complement in morphologically normal spermatozoa is $14.5 \%$ in $X Y Y$ and $4 \%$ in $X X Y$ patients (depending on the percentage of mosaicism); (ii) the incidence of IGC in semen samples of patients with $X Y Y$ and $X X Y$-mosaic are higher than in normal controls; and (iii) further studies are needed to identify the stages of spermatogenesis, where chromosomally abnormal germ cells are segregated.

Several previous studies showed that $47, X Y Y$ males indeed present this sex chromosome constitution in all their somatic cells, but that a $46, X Y / 47, X Y Y$ mosaicism is found in testicular biopsies (Tettenborn et al., 1970; Berthelsen el al., 1981; Han et al., 1994). XYY cells can have difficulties in completing spermatogenesis, resulting in diminished sperm production (Speed et al., 1991). The offspring of $47, X Y Y$ men is mostly $46, X Y$ (Stoll et al., 1979). which is in agreement with the results obtained from karyotyped sperm cells (Benet and Martin, 1988), sperm cells analysed by means of FISH (Hanet al., 1994) and also with the data of the present study, where no real shift in the $X: Y$ ratio was apparent. In our study the evaluation of the sex chromosomal constitution of the sperm cells in both XYY patients gave comparable results and revealed that the majority of cells was normal for their sexchromosome constitution, however, the data might indicate a slight shift in favour of the $X$ bearing spermatozoa, but our results are too small to perform a reliable statistical analysis. FISH analysis on spermatozoa of a $47, X Y Y$ man did not show any major abnormality or aneuploidy (Han et al, 1994). In contrast, in our study, high percentages of the IGC 


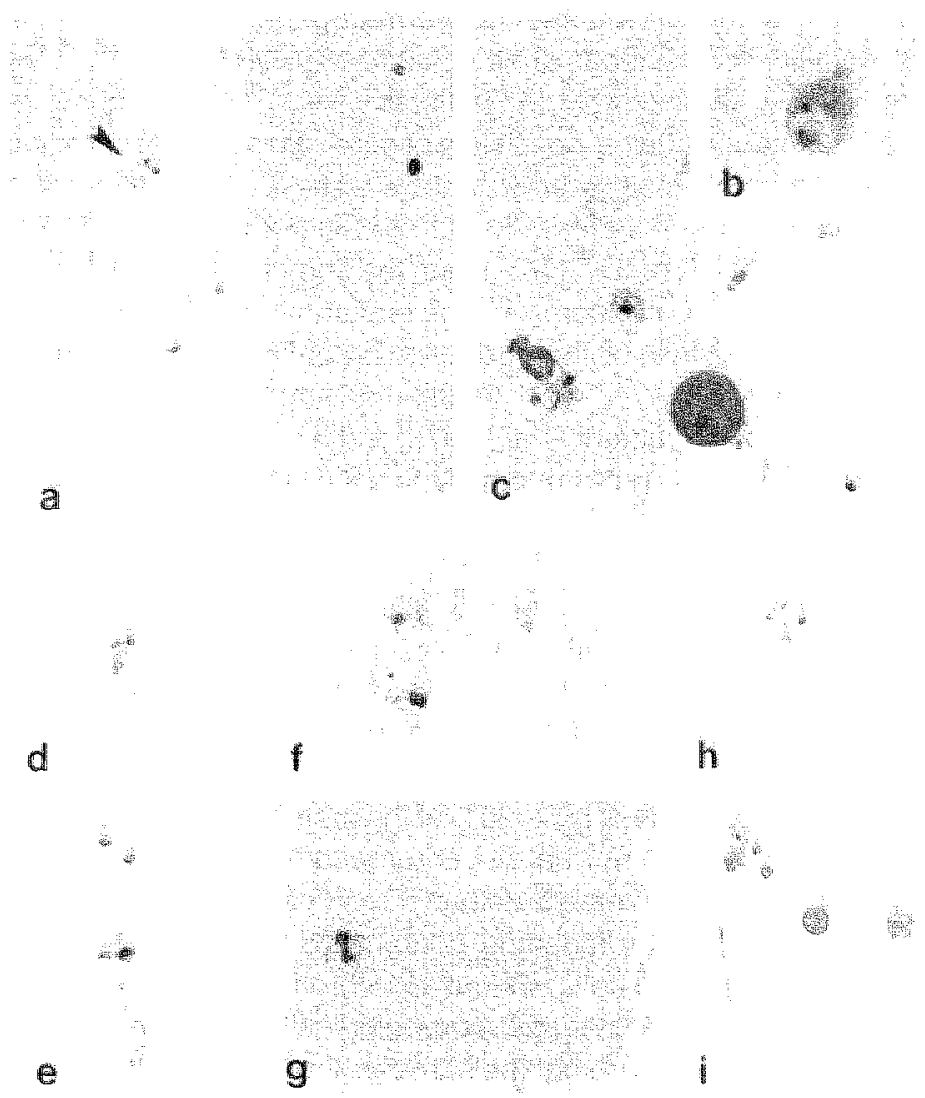

Figure 1. Diff-Quik and Haematoxylin stained semen preparation to which double-target ISH was applied with an X-probe (brown) and a Y-probe (green). (a) Control sample showing an $X X$-bearing spermatozoon. (b, c) limmature germ cells from an $X Y Y$ male (b) and an XXY male (c) showing a XYY-and $X Y$-constitution respectively. Morphologically normal spermatozoa from an $X X Y$ male $(d, e)$ and an $X Y Y$ male $(f, g)$ showing a normal sex-chromosome constitution and $Y Y$ constitution respectively. $(h, i)$ Morphologically abnormal spermatozoa from the $X X Y$ patient. (Magnification $\times 1000$ ). For colour illustration see page 114.

carried an $X Y, X Y Y, X X$ or $Y Y$ constitution. This supports the hypothesis that the extra $Y$ chromosome is lost during spermatogenesis and that the $46, X Y$ germ cell epithelium has a proliferative advantage as compared to the $47, X Y Y$ germ cell line (Berthelsen et al., 1981). Studies of spermatogenesis in $X Y Y$ male confirm the tendency for the germ cells to lose the second $Y$ chromosome but for some $X Y Y$ cells to reach meiosis I. The degenerate category of pachytene and meiosis I spermatocytes seen in the study of Speed et al.. (1991) represent germ cells with an $X$ univalent or cells with an $X Y+Y$ genotype, where the presence of an $Y$ univalent has disrupted cell progression. Probably, spermatogonia and spermatocytes with a $47, X Y Y$ constitution are shed into the seminal fluid and detected as IGC in our study. Indeed, the ISH analysis on IGC confirm a high frequency of combined XY and XYY constitution. Also in the study of Han et al. (1994), a high proportion of IGC and somatic cells are found, though not histologically or cytogenetically confirmed. It might be obvious that a distinction between different stages of germ cell development and somatic 
cells is important for future 1 SH studies on spermatogenesis and for semen diagnosis. and additional identification methods are thus needed (Wyrobek el al., 1994).

$47, X X Y$ men are usually azoospermic, but patients with an $X X Y / X Y$ mosaicism occasionally may show seminiferous tubules, consisting of cells with a normal chromosomal constitution, that produce spermatozoa (Harari et al, 1995). The XY $X X X Y$ patient studied, showed the $X X Y$ cell line in a very small proportion of cells in peripheral blood and the semen contained a lower percentage of $1 \mathrm{GC}(16 \%)$ than the semen samples of the $X Y Y$ patients. This lower percentage of IGC concurs with the explanation of Terzoli et al., (1992), who found that $K S$ patients are fertile when mosaicism is confined to testicular tissue. Studies in patients with a mosaic $46, X Y / 47, X X Y$ constitution suggest that only normal $X Y$-germ cells can complete meiosis (Luciani et al., 1970; Vidal et al., 1984). Cozzi et al.. (1994) and Chevretet al, (1996) using sperm-karyotyping the first and triple-FISH on spermatozoa the latter, found a significantly increased incidence $(0.9 \%$ and $2.09 \%$ respectively) of hyperhaploid $24, X Y$ sets in absence of the expected corresponding hypohaploidy. The results of these studies support the suggestion that some $47, X X Y$ cells are able to go through meiosis and to form spermatozoa. This sugglestion correlates with the relatively high frequency of $X Y$ bearing spermatozoa (1.3\%) found in the $X X Y$ patient, as compared to the percentage found in normal males in our study $(0.4 \%)$, and by Chevret et al. $(0.36 \%)$, (1996).

Our results show that an average of $80 \%-90 \%$ of the morphologically normal spermatozoa of XYY-and XXY-males carry a normal sex chromosome constitution. Based on the re sults of the present study, the average estimated risk of morphologically normal sperm cells having an abnormal seX chromosomal content is $8.6 \%$ in the $X Y Y$ and $2.5 \%$ in $X X Y$ patients, including spermatozoa cells without sex-chromosome. In this respect it should be kept in mind that our criteria to define morphologically normal cells in ISH/Diff-Quik/ haematoxylin stained samples, are not the same as those used in routine semen analyses. Whenever these patients apply for artificial reproductive techniques (ART) the relatively high percentage of aneuploid spermatozoa should be kept in mind. These patients have to be evaluated individually and the risks of ART procedure should be weilghted on basis of the $1 \mathrm{SH}$ results. It is our opinion that after fertilization pre-implantation diagnosis should be performed.

Furthermore, to study the relationship between morphological appearance and genetic/ chromosomal constitution of sperm cells, also cytogenetic studies should be performed. In this respect an additional approach would be to apply ISH analysis to testicular biopsies, in order to study cells with a XYY or XXY genotype, their difficulties in completing spermatogenesis. The possibility that germ cell loss in certain chromosomally abnormal situations could be explained by genetic imbalance (Speed et al., 1991), and whether the stages of spermatogenesis where chromosomal abnormalities are introduced are more likely filtered out, is still a challenging area. Since the number of such studies on ejaculates of $47, X Y Y$ and $47, X X Y$ men is still limited, more studies of larger populations should be pertormed.

\section{Acknowledgments}

The authors wish to thank the patients for their collaboration, E.J.M. Speel for sharing his knowledge on brightfield analysis, the IVF lab of the University Hospital Maastricht for the semen analyses and E. van Assche of the Center for Medical Genetics in Brussels. This work was approwed by the Research Ethics Commiltee of the Academic Hospital Maastricht. This work has been financed by the Dutch "Praeventiefonds" foundation and E.M. has been supported by the Foundation "De Drie Lichten" in The Netherlands. 


\section{References}

Benet $\mathrm{J}_{\text {, Martin }} \mathrm{R}_{1}(1988)$ Spem chromosome complements in a $47, \mathrm{~K} Y \mathrm{Y}$ man. Hum Genet, $78,313-315$.

Berthelsen J, Skakkebaek N. Perboll O. Nielsen J, (1981) Electron microscopical demonstration of the extra $Y$ chromosome in spermatocytes from human $X Y Y$ males, in eds. (eds): Development and function of repraductive organs, No. pp. 328-337 (Excerpta Medica, Amsterdam-Oxford Princeton).

Bischoff F, Nguyen D, Burt K, Shaffer L, (1994) Estimates of aneuploidy using multicolor fluorescence in situ hybridization on human sperm. Oytogenetics Cell Genet, $66,237-243$

Chevret $E$, Rousseaux S, Monteil M, Usson, Gozzi J. Pelletier R, Sele B, (1996) increased incidence of Hyperhaploid $24, X Y$ spermatozoa detected by three-colour FISH in a $46, X Y / 47, X X Y$ malle. Hum Genet, $97,171-175$.

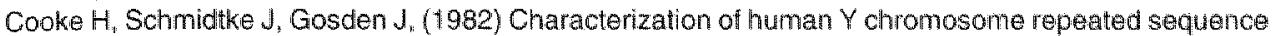
and related sequences in higher primates. Chromosoma, 87, 491-502.

Cozzi J, Chevret E, Rousseaux S, Pelletier R, Benitz V. Jalberk H, Sele B, (1994) Achievement of meiosis in XXY germ cells: study of 543 sperm haryotypes from an XYXXY mosaic patient. Hum Genet, 93. $32-34$.

Han T, Flahery S, Webb G, Matthews $\mathrm{C}_{1}$ (1994) A thorescent in situ thybridization analysis of the chromosome constitution of ejaculated sperm in a $47, X Y Y^{\prime}$ mate. Clin. Genet. 45, 67-70.

Harari $\mathrm{O}_{\text {. Bume }} \mathrm{H}_{\text {, Baker }} \mathrm{G}$, Gronow M, Johnston I, (1995) High fertilization rate with intracytoplasmic sperm injection in mosaic Klinefelter's syndrome. Ferit Steril, 63, 182-184.

Hulten $M$, Pearson $P$. (1971) Fluorescent evidence for spermatocytes with two $Y$ chromosomes in an $X Y Y$ male. Ann. Hum. Genet., 34, 273-276.

Jacobs P, Hassold T. Whittington E, Butler G, Collyer S, Keston M Lee M, (1988) Kinefelter's Syndrome: an analysis of the origin of the additional sex-churomosome using mollecular probes. Ann. Hum. Genet. $52,93-109$.

Jones $K_{*}$ Singh $L_{\text {, Edwards }} \mathrm{R}_{1}(1987)$ The use of probes for the $Y$ chromosome in preimplantation embryo cells. Hum Fieprod, $2,439-445$.

Kruger $T$, Acosta A, Simmons $K$, Swanson J, Malta J, Oelnninger $S_{n}(1988)$ Predective value of abnormal sperm morphology in in-vitra fertilization. Fertil Steris, 49, $112-117$.

Luciani $\mathrm{J}$, Stahl $\mathrm{A}_{\mathrm{*}}$ (1978) Meiotic disturbances related to human male sterility. Ann Biol Anim Biochem Biophys, $18,377-382$.

Martin $\mathrm{A}_{1} \mathrm{~K}_{0} \mathrm{E}$, Chan $\mathrm{K}_{\mathrm{*}}$ (1993) Detection of aneuploidy in human interphase spermatozoa by fluorescence in situ hybridization (FISH). Cytogenefics Cell Genet, 64, 23-26.

Martini E, Speel E, Geraedts J Ramaekers F Hopman A, (1995) Application of different in-situ hybridization detection methods for human sperm analysis. Hum Reprod, 10, 855-861.

Martini E, Geraedts J, Liebaers I Capitanio G, Ramaekers F, Hopman A, (1995) Combined detection of cytogenetic and morphological abnormalities in spermatozoa using in situ hybridization and an improved cell staining method, in eds. (eds:). World Congress on In Vitro Fertilization and Assisted Reproduction, No. 1, pp. 733-736 (Monduzzi Editore, Bologna (Italy) 1995).

Retief $A_{3}$ van Zyl $ل_{3}$ Menkveld $M_{0}$ Fox $G_{1}$ Kotze G, Brunsnicky $J_{3}$ (1984) Chromosome studies in 496 infertile males with a sperm count below 10 million per mi. Hum Genet, 66, 162-164.

Rothwell N, (1983) Sex chromosome anomalies in humans, in (eds:): Understanding Genetics, No.,pp. 113-118 (Oxford University Press, New York 1983).

Speed R, Faed M. Batstone P. Baxby K. Barnetsone W. (1991) Persistence of two $Y$ chromosomes through meiotic prophase and metaphase I in an XYY man. Hum Genet, 87, 416-420.

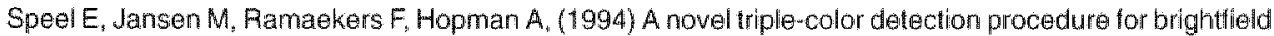
microscopy, combining in situ hybridization with immunocytochemistry. J Histochem Cytochem, 42, $1299-1307$.

Stoll C, Flon E, Clavert A, Beshara D, Buck P. (1979) Abnormal Children of a 47, XYY father. JMed Genet, $16,66-68$.

Terzoli G, Lalatta F, Lobbiani A. Simoni G. Colucci G, (1992) Fertility in a 47,XXY patient: assessment of biological paternity by deoxyribonucleic acid fingerprinting. Forti Steril, 58,821-822.

Tettenborn U, Gropp A, Murken J, Tinnefeld W. Fuhrmann W, Schwinger E, (1970) Meiosis and testicular histology in XY'Y males. Lancef, 1, 267-268.

Vidal F, Navarro J, Templado C. Brusadin S, Egozcue J, (1984) Synaptonemal complex studies in a mosaic 46, XY/47, XXY male. Hum Genet, 66, 306-308.

WHO-Laboratory Manual for the examination of human semen and sperm-cervical mucus interaction. Third edition. (1993) (eds:): Berlin, Heidelberg, New York, Springer Press.

Wyrobek A, Robbins W, Mehraein $W_{\text {, Pinkel }} \mathrm{D}_{\text {. Weier }} \mathrm{H}_{\text {, }}$ (1994) Detection of sex-chromosomal aneuploidies $X-X, Y-Y$, and $X-Y$ in human sperm using two-chromosome lluorescence in situ hybridization. Am J Medic Genet, $53,1-7$. 



\section{Chapter 4}

Comparison of gonosomal aneuploidy in spermatozoa of normal fertile men and those with severe male factor detected by in situ hybridization

Luca Bernardini, Elena Martini, Joep P. M. Geraedts, Anton H. N. Hopman, Silvia Lanteri, Nory Conte and GianLuigi Capitanio

Molecular Human Reproduction (1997), 3: 431-438 


\section{Abstract}

The purpose of the study was to analyse the frequency of sex-chromosome numerical abnormalities in human sperm of infertile men by using a standardized experimental protocol of double target in-situ hybridization (ISH). The experiments were performed on decondensed sperm heads from 15 infertile patients (six cases of unexplained infertility and nine cases of severe oligo-astheno-teratozoospermia). Three men of proven fertility were used as controls. The probes employed recognized the centromeric regions of human $X$ chromosome and the long arm of the $Y$ chromosome. In a smaller number of cases, additional experiments of double ISH were performed using centromeric probes for chromosomes 1 and 17. Signal detection was based on protocols of enzymatic cytochemical reactions. A total of 24508,24679 and 42285 cells were scored in the control, unexplained infertility and severe male factor groups of patients, respectively. In all the patients ISH efficiency result was 98\%. In controls, unexplained infertility and severe male factor patients, the frequency of morphologically normal sperm cells carrying an abnormal chromosome constitution ( $X X$ or $Y Y$ or $X Y$ or $>2$ sex chromosomes signals) was $0.86 \%, 0.75 \%$ and $1.35 \%$, respectively. The value of this last group of patients (severe male factor) was significantly higher than in the other two groups of patients $(p<0.008)$. The same findings were made using the autosomic probes. Our preliminary data support the possibility of an increased risk from paternal origin sex chromosome aneuploidies in children born after intracytoplasmic sperm injection (ICSI). Further investigation of the cytogenetic constitution of spermatozoa from severe male factor patients is warranted.

\section{Introduction}

With the advent of assisted reproduction technology (ART) and especially intracytoplasmic sperm injection (ICSI) combined with epididymal and/or testicular spermatozoa retrieval, men presenting a severely impaired spermatogenesis are currently able tol be treated for infertility. However, available data from cytogenetic analysis on chromosome constitution of newborns from ICSI show that, in comparison with the general population, these liveborns may be at increased risk for sex chromosome aneuploidy ( $1.0 \%$ rather than $0.2 \%$ ) (Liebaers et al., 1995; In't Veld et al., 1995). Since aneuploidy is unlikely to be the product of the ICSI procedure itself, it has been speculated that the incidence of trisomy in embryos and children born following ICSI may be related to a direct injection of disomic spermatozoa (Chandley and Hargreave, 1996). This may be of concern particularly for sex chromosomes since the vast majority of gonosomal aneuploidies in human liveborns and spontaneous abortions are the consequence of meiotic non disjunction during spermatogenesis ( $100 \%$ of $47, X Y Y$ males, $80 \%$ of $45, \times 0$ females, $47 \%$ of $47, X X Y$ males and $10 \%$ of $47, X X X$ females) (Lorda-Sanchezet al., 1922; MacDonald et al., 1994; Jacobs and Hassold et al., 1995; Griffin et al., 1995). Although applying data valid for normal newborns (with normal fathers), to infertile males may be questionable, from a theoretical point view, a paternal origin of gonosomal aneuploidy could be estimated in at least $54 \%$ of the ICSI-liveborns ( $6 / 11$ sex chromosomes abnormalities in 506 newborns) (Liebaers ef al., 1995; In't Velde et al., 1995).

In recent years, fluorescent in situ hybridization (FISH) has been increasingly used as an alternative to sperm karyotyping, being less laborious, less time consuming and allowing the analysis of a whole specimen in few hours. However, despite the abundance of studies using in situ hybridization (ISH), the exact aneuploidy rate for sex chromosomes in spermatozoa of normal healthy men remains controversial (Wyrobek et al., 1994; Martin and Rademaker, 1995). Moreover, in spite of general concern, little is known until now in 
regard to the frequency of aneuploidy in spematozoa of intertile and OAT patients (Moosani ef al, 1995; Chewreter al., 1995).

Our study was undertaken with the purpose to attempt a comparison between fertile and infertile men in terms of gonosomal DNA ploidy (disomy plus diploidy) in spermatozoa using an ISH approach. The ISH method was based on a protocol of immunocytochemi cal reactions resulting in precipitation of signal products of different colour and counterstaining of the cells with Diff-Quik (Martini et al, 1995). This has allowed the correct recognition and distinction of roundish cells (germ cells, somatic cells) and overlapping spepmatozoa and/or morphologically abnormal spermatozoa. Additionally, in order to provide a preliminary estimation of diploidy, experiments of double ISH were performed in a subgroup of patients using probes for autosomes 1 and 17 .

\section{Materials and methods}

Semen samples

Semen samples were obtained from three healthy fertile men, used as controls (C) and 15 patients. Six out of these patients were referred to our laboratory presenting normal semen parameters, normal endocrine profiles, noimal fertility work-up in their female partners and were considered cases of unexplained infertility (U). Three patients of this group underwent ART treatment. Medical records showed for two of them a previous episode of spontaneous abortion. In two cases, despite the achievement of normal in vitro fertilization (IVF) rates (17/25 and $8 / 12)$ and embryos available for cryopreservation (12/17 and $3 / 8$ ), no pregnancy ensued. For the third patient, two successive gamete intra-fallopian tranfer (GIFT) cycles were attempted resulting in a biochemical pregnancy on both occasions. Nine other infertile patients were cases of severe oligo-astheno-teratozoospermia (O) (severe male factor patients). Informed consent was obtained from all the patients. Semen parameters and clinical profiles for the 3 groups of patients are shown in Table 1.

Table 1. Semen parameters and climical characteristics of patients. Ranges are given in parentheses.

\begin{tabular}{|c|c|c|c|c|}
\hline No. cases & age (years) & $\begin{array}{l}\text { Total no. normal } \\
\text { mothe spenalozoa }\left(\times 10^{6}\right)\end{array}$ & Nomal foms & Diagnasis \\
\hline 3 & $36 \cdot(33-37)^{n}$ & $77(42-117)$ & $>40(60-70)$ & Nomal fertile controls (C) \\
\hline 6 & $34(29 \cdot 44)^{5}$ & $50(13 \cdot 122)$ & $>20(45-70)$ & Unexplainod intortility (U) \\
\hline g & $37(30-44)^{\prime \prime}$ & $4.5(0.0+20)$ & $>2010-20)$ & $\begin{array}{l}\text { Oligoasthenoter ato } \\
\text { zoosparmia } 10 \text { ) }\end{array}$ \\
\hline
\end{tabular}

a: Not significant

\section{Sperm nuclei preparation}

Semen samples were routinely analyzed at the Andrology Laboratory of our hospital. Spem cell count, motility and morphology were determined and total normal motille count (TNMC) was estimated for each pre-processed sample (total count $x \%$ of motle $x \%$ normal forms) (Ord ef al, 1993). Sperm preparation prior to ISH followed the protocoll of Martini et al. (1995). Samples were washed 3 times in phosphate buffered saline (PBS, 0.15 M NaCl, $10 \mathrm{mM}$ sodium phosphate, $\mathrm{pH} 7.2$ ) and centrifuged at $280 \mathrm{~g}$ for 10 minutes. The pellet was then resuspended carefully in $1 \mathrm{ml}$ of fresh, cold fixative (methanol: acetic acid, $3: 1$ ) and stored at $-20^{\circ} \mathrm{C}$. Sperm cells were cytospun on poly-L-lysine coated slides, washed in $2 x$ SSC $(0.3 \mathrm{M} \mathrm{NaCl}, 30 \mathrm{mM} \mathrm{Na}$ citrate $)$ to remove excess fixative and incubated for $5 \mathrm{~min}$ utes in $1 \mathrm{M}$ Tris/HCl bufter, $\mathrm{pH} 9.5$, containing $25 \mathrm{mM}$ dithiothreitol (DTT). After decondensation the slides were washed once in $2 \times S S C$, once in PBS, dehydrated through an ethanol series (70-96-96-100-100\%) and air dried. 
Double target in situ hybridization (ISH) procedure

The DNA probes used in this study included an alphoid probe specific for the centromeric region of the human $X$ chromosome ( $\mathrm{pBam} X 5,2.0 \mathrm{~kb}$; Willard et al., 1983), a satellite probe specific for the long arm of the human $Y$ chromosome (DYZ1, $3.4 \mathrm{~kb}$; Cooke et al. 1982) and wo other probes recognizing the (peri) centromeric regions of the human chromosome 1 and 17 (pUC 1.77, $1.77 \mathrm{~kb}$; Cooke and Hindiey, 1979; p17 H8, $2.7 \mathrm{~kb}$; Waye and Willard, 1986). Probes were labelled by either nick translation using biotin-11-dUTP (Enzo Diagnostics; New York, NY, USA) for the $X$ - and 1-specific probes or fluorescein12-dUTP (Boehringer; Mannheim, Germany) for the $Y$-and 17 -specific probes. Probes were dissolved in hybridization mixture containing $60 \%$ formamide, $2 \times \mathrm{SSC}, \mathrm{pH} 7.0,10 \%$ dextran sulfate, $0.2 \mu \mathrm{g} / \mu / \mathrm{l}$ herring sperm DNA as carrier DNA and $0.2 \mu \mathrm{g} / \mu \mathrm{l}$ yeast t-RNA as carrier RNA. A final volume of $5 \mu$ l (corresponding to a concentration of $0.4 \mathrm{ng} / \mu \mathrm{l}$ for each probe) was added to each slide under a coverslip $(18 \times 18 \mathrm{~mm})$. Denaturation was achieved at $70^{\circ} \mathrm{C}$ for 3 minutes and hybridization was performed for 4 hours at $37^{\circ} \mathrm{C}$ in a moist chamber. The slides were washed twice for 5 minutes at $42^{\circ} \mathrm{C}$ with $60 \%$ formamide, $2 \times$ SSC, $\mathrm{pH} 7.0$, containing $0.05 \%$ Tween 20 , followed by two 5 minutes washes with $2 x$ $\mathrm{SSC}, \mathrm{pH} 7.0$ at $42^{\circ} \mathrm{C}$ and one 5 minutes wash with $4 \times \mathrm{SSC}, \mathrm{pH} 7.0$, containing $0.05 \%$ Tween 20 at room temperature. The detection of signals was performed as described previously (Speel et al., 1994; Martini et al., 1995). Briefly, the biotinylated probes for chromosome $\mathrm{X}$ or 1 were detected with horseradish peroxidase-conjugated avidin (AV$\mathrm{PO}$, Dako A/S, Glostrup, Denmark), amplified with biotinylated goat anti-avidin (BioGaA, Vector, Burlingame, CA, USA), followed by a second AV-PO layer and the diaminobenzidine (DAB) reaction. The slides were then incubated for 10 min at room temperature in $0.01 \mathrm{~N}$ $\mathrm{HCl}$ to inactivate peroxidase activity. Subsequently, the fluoresceinated chromosome $\mathrm{Y}$ or 17- specific probes were detected with mouse anti-FITC (MoFITC, Dako A/S) and POconjugated rabbit anti-mouse IgG (RoM-PO, Dako A/S). After this last incubation step, the peroxidase-tetramethylbenzidine (TMB, Sigma) reaction was performed (Speel et al., 1994). Avidin conjugates were diluted in $4 \times$ SSC, pH 7.0, containing $5 \%$ non-fat dry milk, and the antibody conjugates were diluted in PBS containing $0.05 \%$ Tween 20 and $2 \%$ normal goat serum. After each incubation step of $20-30 \mathrm{~min}$ at $37^{\circ} \mathrm{C}$, the slides were rinsed twice in $4 \times$ SSC, pH 7.0, $0.05 \%$ Tween 20 (avidin conjugates) or PBS, $0.05 \%$ Tween 20 (antibody conjugates). Counterstaining was achieved by a combined use of haematoxylin and Diff-Quik (DADE s.p.a., Milan, ltaly) as previously published (Martini et al., 1995). We utilized exclusively the cytoplasmic staining step of the Diff-Quik consisting of Eosin G in phosphate buffer, pH 6.6 (1,22 g/l; solution 1).

Slides were embedded in Entellan (Merk, Bracco s.p.a., Milan, Italy), an organic mounting medium and stored at $+4^{\circ} \mathrm{C}$ until evaluation. The evaluation of the ISH signals was performed with a standard Zeiss bright-field microscope. Microphotographs were obtained using a Leica CCD camera.

\section{Scoring criteria}

Sperm-slides were scored by two independent observers according to the recommendations of Wyrabek et al (1994) and Martin and Rademaker (1995). Both the investigators were blinded as to the origin of the slides being analysed. Results represent the average of the values obtained by the two observers. Sperm nuclei were scored when morphologically preserved, not clumping or overlapping, with well-defined outline and tail and spermhead decondensed to no more than twice the size of normal non-decondensed spermatozoa. The presence of the tail was considered essential for a reliable evaluation. The differentiation of the morphologically abnormal sperm cells (spermatozoa with two heads, two 
midpieces but one tail, two tails but one head micro heads) from somatic cells or nomal spermatozoa was made possible by Diff-Quik staining and their number omitted from the count of the aneuploid cells. The big, brightly stained, round cells showing efficient ISH signals were tecorded as immature germ cells (IGC) (Martin et al., 1996). Three main types of morphologically normal sperm cells carrying an abnomal sex chromosome constitution were observed: (i) sperm cells with both the brown and green signal-products $(X Y)$; (ii) sperm cells with two brown signal-products $(X X)$; (iii) spem cells with two green signal-products $(Y Y)$. For spermatozoa to be recorded as $X X$ or $Y Y$, wo signals of the same color and equal size had to be located at the distance of approximately one diam. eter of the signal-domain. These criteria were not taken into account for sperm cells with XY signals. Sperm cells showing normal decondensation but no signals were scored and considered vallid for calculations of ISH efficiency. The experimental conditions of this study did not allow to differentiate between nullisomic spermatozoa and cells with hybridization failure. Therefore, in order to minmize the subjectivity of the individual observations, our scoring values were compared with the nullisomy rates considered as theoretically equivalent to the incidence of all the aneuploidies (Blanco et al., 1996). In morphologically normal spermatozoa, the evaluation of diploidy and disomy was based upon additional ex: periments of double target ISH for autosomes 1 and 17 . This was posible, within each group, only for a smaller number of patients. An attempt at a realistic estimation of sex chromosomes disomy rate (aneuploidy) was finally achieved by subtracting the diploidy rate, obtained with double ISH for autosomes 1 and 17 , from the total DNA ploidy rate lor sex chromosomes (see table 2).

\section{Data analysis}

Among the three groups of patients, separate comparisons of the proportions observed for single variables (DNA ploidy, nullisomy, immature germ cells, abnormal cells) were performed using univariate statistical analysis by Chi Square test and analysis of variance (ANOVA). In addition, in order to obtain the total information from the data set test, the Principal Component Analysis (PCA) (Forina et al., 1988) was applied for multivariate statistical analysis. PCA is an exploratory and display technique of the data matrix which allows: (i) to reduce the dimensionality of the problem; (ii) to find similarities between samples and/or variables; (iii) to identify directions corresponding to a property or characteristics having a biological meaning. In our case, data matrix was constituted by 18 patients (samples) and 5 variables (DNA ploidy, immature germ cells, abnomal spem cells, morphology and total motile count). Geometrically, each individual sample in the data matrix Was represented by a symbol (C or U or O) in a space of 5 dimensions (one dimension for" each variable). PCA generates a set of axes called principal components. In this way, the maximal amount of variance contained in the starting data set (information) is concen. trated in the first principal component. The coefficients of the original variables defining each principal component are called "loadings" while the projections of the samples on the new axes are called "scores". Data were auto-scaled (subtraction of the mean and division by standard deviation for each variable) betore principal component computation in order to assign the same numerical weight to each variable (Massartet al. 1988).

\section{Results}

Figure la shows morphologically nomal sperm cells with normal hybridization signals (green for spermatozoa carrying $Y$ chromosome and brown for spermatozoa carrying $X$ chromosome). In figure $1 \mathrm{~b}, \mathrm{c}$ and d morphologically normal spermatozoa, carrying an excess of sex 
chromosomes are shown $(X Y, X X$ and $Y Y$, respectively). Fig. 1e shows two different types of abnomal sperm cells (a spematozoon with one tail and two heads and vice versa one head and two tails). In figure $1 f$ the image of an immature germ cell (IGC) is shown.

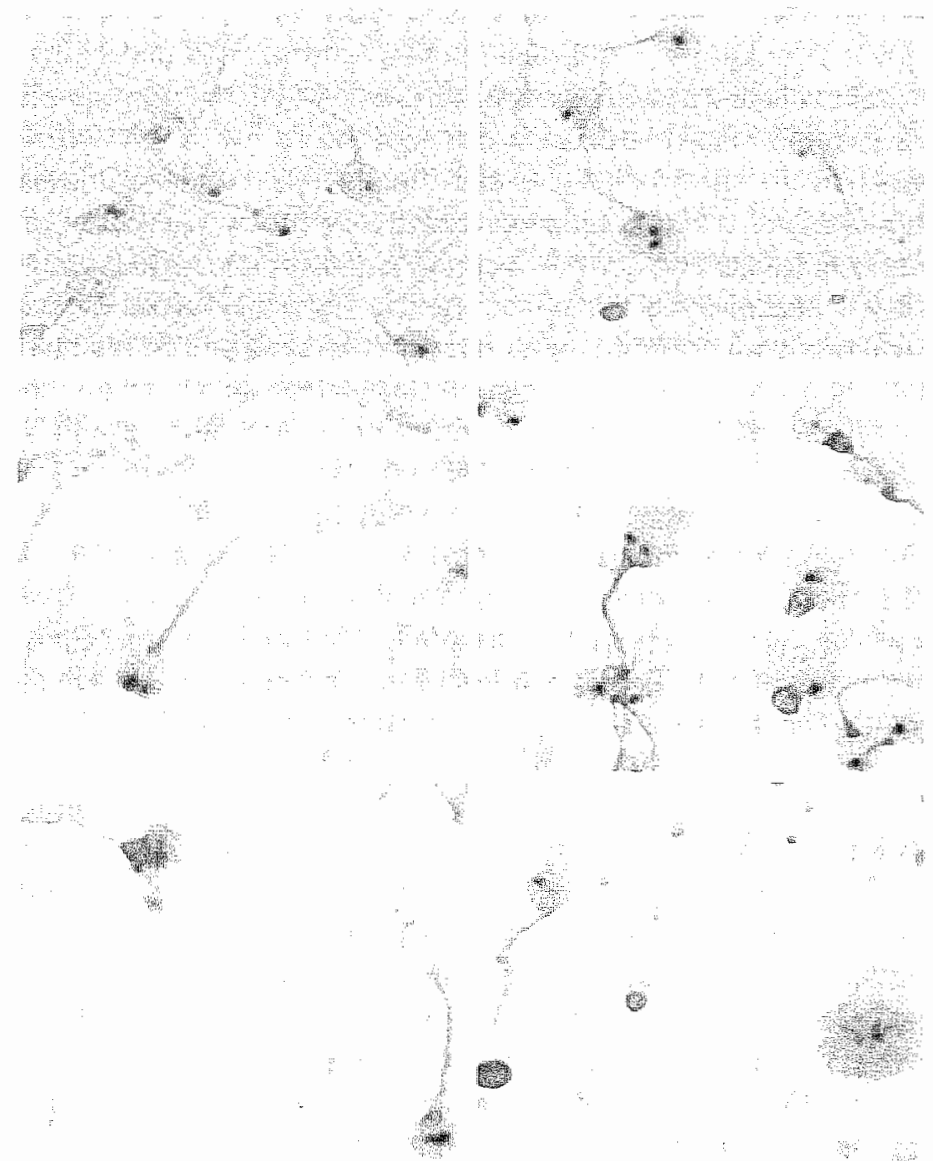

Figure 1. Double target hybridization of semen samples with biotinylated $X$ probe (brown) and fluorescent isothiocyanate (FTC)-labelled Y probe (green). (a-d) Morphologically normal spermatozoa. (a) Control sample showing either $X$ of $Y$ signall; (b) spermatozoa showing an $X Y$ sex chromosome constifution; (c) Sperm cell with an $X X$ sex chromosome constilution; (d) Sperm cell with art $Y Y$ sex chromosome constitution. (e) Morphologically abnormal sperm cells, top left with two heads and wo chromosome X-signals; bottom right spermatozzon with two tails and an $X Y$ chromosome constitution.(f) Irmmature germ cell with hybridization signal for chromosomes $X$ and $Y$, For colour illustration see page 115 .

Table 2 lists the frequencies of morphologically normal cells with an abnormal chromosome constitution ( $X Y, X X, Y Y$ and $>2$ sex chromosomes) among the groups of controls (C), unexplained infertility (U) and severe male factor patients (O). A total of 24508,24679 and 42285 cells were scored for $C, U$ and $O$ groups, respectively. Within these groups, an average of 7500,3100 and 3900 cells were scored per patient respectively. Excluding both nullisomy and diploidy rates from the analysis, the sex chromosome disomy rate (true 
aneuploidy) for the $\mathrm{C}, \mathrm{U}$ and $\mathrm{O}$ groups was $0.46 \%, 0.45 \%$ and $0.82 \%$ respectively. Interobseners differences in counting were small and simlar findings were independently made by both the observers. The data shown in Table 2 and discussed in the lext repre. sent an average of the values recorded by the wo obsevvers. Total DNA ploidy and disomy frequencies for sex chromosomes among the 3 groups were significantly diferent (ANOVA:P<0.008). In particular, the value of disomy found in the severe male factor patients (O group) was higher than in the other two groups of patients. No apparent differences in gonosomal disomy rates were noted between unexplained infertility and control patients $(\mathrm{p}<0.42)$.

Table 2. Constitution of semen samples in controls (C), unexplained infertility (U) and oligoastheno-teratozoospermic (O) patients analysed by in situ hybridization (ISH).

\begin{tabular}{|c|c|c|c|}
\hline Groups of patients & $C$ & $U$ & 0 \\
\hline Noeflis/group & 24508 & 24679 & 42285 \\
\hline Noelis/patient & 7500 & 3100 & 3900 \\
\hline ISH efficiency $\%$ & 99.7 & 98.8 & 97.8 \\
\hline$X: Y$ ratio \% & $49.7: 48.9$ & $50.2: 48.7$ & $49.5: 47.1$ \\
\hline$X Y \%$ & $0.45(0.4-0.52)$ & $0.42(0.24-0.77)$ & $0.70(0.27 \cdot 1.15)^{*}$ \\
\hline$x \times \%$ & $0.15(0.07 \times 0.22)$ & $0.19(0.09 \cdot 0.30)$ & $0.36(0.18 \cdot 0.48)^{*}$ \\
\hline$Y Y \%$ & $0.25(0.14-0.4)$ & $0.14(0.07-0.28)$ & $0.27(0.13-0.43)$ \\
\hline$>2$ sex chrom $\%$ & 0.012 & 0.006 & $0.025^{*}$ \\
\hline DNA ploidy $\%$ & 0.86 & 0.75 & 1.35 \\
\hline Estinated disomy of & 0.46 & 0.45 & 0.82 \\
\hline
\end{tabular}

"O $>C: P<0.000$ and * $O>U: P<0.0001$

b: Disomy abtained by subtraction of the diploidy rate (achieved using double ISH for aulosomes 1 and 17) from tolal DNA ploidy (see table 3 ).

Similar observations were made from results achieved in the same patients for autosomal aneuploidy (Table 3).

Within all three groups inter-individual and inter-chromosome differences of DNA ploidy frequency were observed. In the control, unexplained infertility and severe male factor patient groups frequencies of nullisomic spermatozoa of $0.75,0.67$ and $1.05 \%$, respectively, were scored. These values were not much different from that hypothetically expected on the basis of total DNA ploidy (disomy plus diploidy). Overall, the number of spermatozoa showing no hybridization was small (0.29-1.05\%), emphasizing the level of hybridization efficiency. 
Table 3. Cylogenetic constitution of semen samples in a subset of patients using ISH for aulosomes 1 and 17.

\begin{tabular}{cccc}
\hline Groups & $c$ & $u$ & 0 \\
& $n=2$ & $n=4$ & $n=4$ \\
\hline Cells fpatien & $>3000$ & $>3000$ & $>3000$ \\
Disomy 1 & 0.4 & 0.38 & 0.54 \\
Disomy 17 & 0.35 & 0.37 & 0.74 \\
Diploidy & 0.4 & 0.3 & 0.53 \\
\hline Total & 1.15 & 1.05 & $1.80^{*}$ \\
\hline
\end{tabular}

$" p<0.001$

In figure 2, the relative proportions of DNA ploidy, abnormal spermatozoa and IGC, for each group of patients, are shown. Overall, in the severe male factor patients $(O)$ (normal morphology $<20 \%$ ), the frequencies of gonosomal DNA ploidy, abnormal spermatozoa and number of immature germ cells were higher than in the other groups of patients (chi square test: $p<0.0001)$. Within the group of severe male factor patients $(O)$, those having the poorest semen quality (total normal motile count $<1$ million) $(n=3$ ) also had an almost 10 times higher proportion of immature germ cells $(6 \%$ versus $0.6 \%)$ along with a significantly higher DNA ploidy rate for sex chromosomes ( $1.6 \%$ versus $1.2 \%$ )(data not shown).

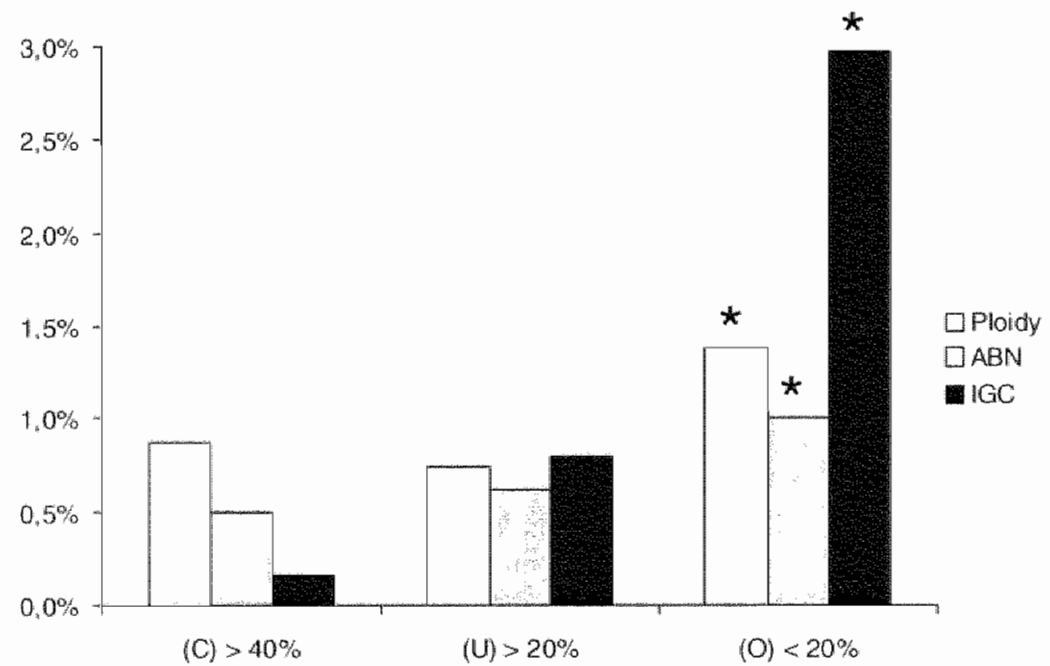

normal morphology

Figure 2. Percentage frequency of DNA ploidy (closed bars), abnormal spermatozoa (ABN; grey bars) and immature germ cells (IGC; open bars) in control groups of palients ( $C$, nomal forms $>40 \%$ ), and groups of patients, with unexplanedinfertility ( $U_{s}$ normal forms $>20 \%$ ), and severe male factor ( $O$; normal forms $<20 \%$ ). Significant difference between $\mathrm{C}$ and $U$ groups $(p<0.001)$.

In figure 3 the results of the PCA are shown. The entire data set can be visualized simultaneously (separate presentation of individual patients according to the 5 variables). The first two principal components retained $77 \%$ of the variance (total information). The first 
principal component represents the direction from the high to the low values of the DNA ploidy rates. Overall, on the PCA graph, the gonosomal DNA ploidy, presence of abnormal spermatozoa and immature cells were distributed in parallel on the area plot and displayed as opposed to the total normal motile count and normal morphology variables. A similar PCA-scatter plot was achieved also when data from double ISH for autosomes were an:

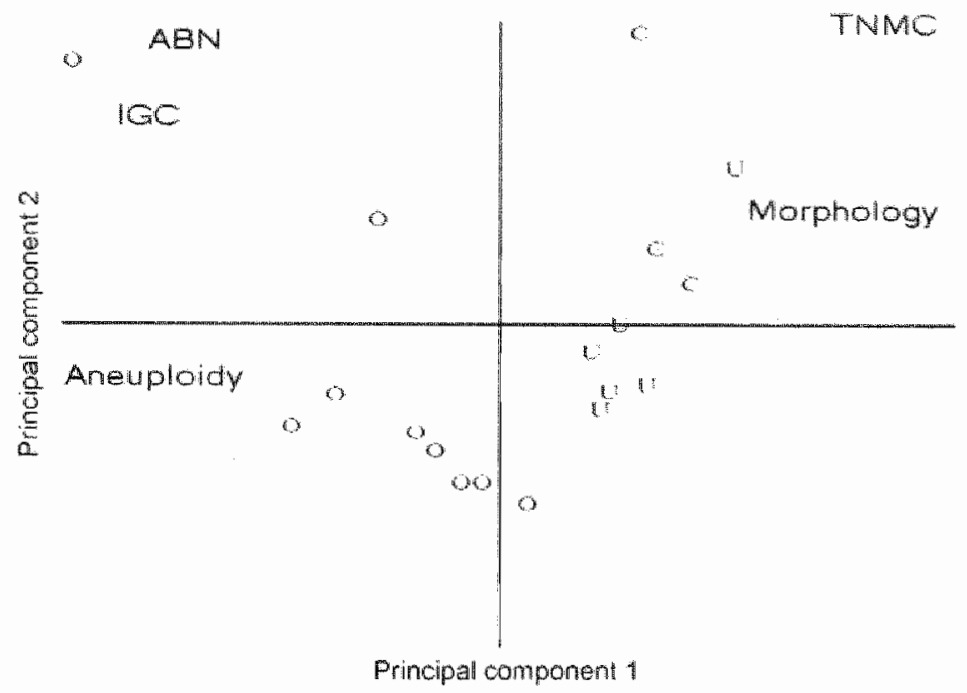

Figure 3. Scatter plot of the principal component analysis ( $P C A$ ) of sample projections ( $\mathrm{C}=$ contro); $\mathrm{U}=$ unexplained infertility; $\mathrm{O}=$ patients with severe male factor) and coefficients of the original variable: $T N M=$ total normal motile count; $\mathrm{IGC}=$ immature germ cells; $\mathrm{ABN}=$ abnormal spermatozoa; aneuploid $y=\mathrm{DNA}$ ploildy.

\section{Discussion}

In this study we applied a standardized method of double in situ hybridization to study frequency of sex chromosome aneuploidy in different populations of men. The validity of this technique is based on a protocol of immunocytochemical detection reactions allowing combination of cytogenetic analysis with a morphological evaluation. As previously reported, this offers several advantages (Martini et al., 1995).

Overall, our values of DNA ploidy for sex chromosomes in spermatozoa of control $(0.86 \%)$ and unexplained infertility $(0.75 \%)$ individuals are within the range of those found in the literature for multiple colour FISH [0.60\%; 0.29-1.06 confidence interval (CI)] (Williams et al., 1993; Schattman et al., 1993; Bischoff et al., 1994; Chevret et al., 1995; Spriggs et al., 1995; Martin and Rademaker, 1995; Moosani et al., 1995; Griffin et al., 1995; Robbins et al., 1995; Martin et al., 1996a; Martin et al., 1996b; Chevret et al., 1996; Spriggs et al., 1996). Other studies using double colour ISH, have reported, on average, lower sex chromosome DNA ploidy rates $[0.45 \% ; 0.14-0.7 \mathrm{Cl}]$ (Han et al., 1993; Goldman et al., 1994; Wyrobek et al., 1994; Chevret et al., 1994; Pang et al., 1995; Martini et al., 1996; Mercier et al., 1996). Methodological differences between all these studies include the number of cases, the scoring criteria, the decondensation methods, the use of a different $Y$ probes and the numbers of scored spermatozoa.

We are aware of the fact that our approach has implicit limitations as it cannot distinguish 
either between diploid and disomic spermatozoa $(46, X Y$ or $24, X Y)$ or between nullisomic spermalozoa and $1 \mathrm{SH}$ efficiency fallure. In order to accurately distinguish between diploidy and disomy a multiprobe FISH including a probe for autosomes would be the best approach (Martinet al. 19960). This notwithstanding, we believe that our protocol of ISH, based on a proper staining of the sperm tail combined with brightfield-microscope evaluation of permanent signals, guarantees, as compared to FISH, a more correct recognition of the normal spermatozod among all the other sperm cells. According to the literature, baseline diploidy rate in normal human spermatozoa corresponds to $0.20 \pm 0.13$ out of 0.60\% (total aneuploidy) (Williams et al, 1993; Schattman et al, 1993; Bischoff et al. 1994; Chevret et al, 1995; Spriggs et al, 1995; Griffin et al., 1995; Robbins et al., 1995; Martin et al, 1996a; Martin et al, 1996b; Chevret et al., 1996; Spriggs et al, 1996). However, it remains to be determined whether, in spermatozoa of infertile men a differential contribution to the total DNA ploidy rather than disomy exists. Our preliminary results achieved using probes for chromosomes 1 and 17 suggest that this contribution should be ascribed mainly to the disomy rates. Further data from our laboratory support this concept (Bernardini et al. 1996).

We attempted a comparison of the aneuploidy rate between different groups of patients estimating the relative proportions rather than providing absolute rates. Though final conclusions cannot be drawn yet, our data suggest that the frequency of DNA ploidy for chromosomes in severe OAT patients is allmost twice as common as that found in normal fertile men. Results achieved using autosomic probes indicate that this is most probably, valid also for other chromosomes and suggest that in spermatozoa of OAT patients a "generalized chromosomal pairing disruption" may accur (Egozcue ef al., 1983).

The value of increasing the size of our control group seems questionable as this would help at the most to achieve baseline aneuploidy rates closer to those found in some of the unexplained infertility patients $(0.5 \%)$, simply reinforcing the level of discrepancy between results.

In men who are partners of couples suffering from unexplained infertility, the chances of finding gonosomal aneuploidy increased above the baseline rates seem reduced. However, this is a heterogenous group of men including perhaps some who are completely healthy (misclassified due to failure of female fertility work up) as well as, at the other extreme those who carry specific types of sperm aneuploidy. In our study, few probes were analysed in a small sample size of patients, so that final conclusions on this regard are definitely hampered.

Other investigators also have reported the frequency of aneuploidy in sperm cells of infertile men. Miharu et al, (1994), using FISH, did not find an increase of gonosomal disomy in a group of 12 infertile men. However, the patient population of this study was quite heterogeneous and the utilization of a single-probe FISH did not allow the determination of the number of spermatozoa carrying a $X Y$ content. In the experience of our own group and that of others, this type of hyperhaploid spermatozoa is prevalent. A significant in. crease of disomic spermatozoa was also found in 4 out of 5 infertile patients described by Moosani et al., (1995). In the same study, the comparison of sperm karyotyping results achieved in 12 sperm donors and 5 infertile patients yielded a conservative estimate of total aneuploidy of $0.84 \%$ and $3.1 \%$, respectively (no changes were seen in terms of structural chromosomal abnormalities).

Very lkely, chromosome aneuploidy increases in cases with greater severity of infertility. Pang ef al. (1995) studying sex chromosomes aneuploidy frequencies by FISH in 9 severe male factor patients (nomal morphology $<4 \%$ ) in comparison with 4 normal men, found a 10 fold difference ( $5.0 \%$ versus $0.5 \%$, respectively). 
Our data also suggest a positive correlation between aneuploidy and the number of morphologically abnormal spermatozoa and immature germ cells observed in cases of decreasing sperm quality. This agrees with the finding of high percentages of immature germ cells $(28 \%)$ and normal spermatozoa carrying abnormal sex chromosomal content in semen of $X Y Y$ and $X X Y$ males $(8.6 \%$ and $2.5 \%$, respectively) (Martini et al., 1996). While these patients are well known to be generally affected by severe oligozoospermia, inuch less is known about the chromosomal constitution of their spermatozoa. The supposition is of a prevalent population of 24, XY disomic cells (Mercier al. 1996; Chevret et al. 1996). It has been suggested that, in some cases, the phenotype of azoospermic men may be normal, while a mosaicism confined to the germ tissue and leading to aneuploid cell lines may occur (Persson et al., 1996). However, even when the karyotype is normal, as in the patients analysed in this study, an elevated frequency of aneuploid spermatozoa still occurs. This finding agrees with the concept that alterations of the recombination and/ or pairing processes might concomitantly lead to a higher rate of aneuploidy along with the decreasing quality of semen (Hassold et al., 1991; Martin, 1996c).

In conclusion, our data show a significantly increased aneuploidy rate for sex chromosomes in OAT patients compared with men with normal semen parameters. These data should be taken into account, and relative risks estimated, whenever an OAT patient is a candidate to undergo ICSI.

\section{Acknowledgements}

This work has been financed by the Dutch "Praeventiefonds", and E.M. has been supported by the Foundation "De Drie Lichten" and by the Training and Mobility of Researchers (TMR) Programme Research Training Grants (ERB 4001 GT 955293) from the European Commission.

\section{References}

Bernadini $L_{*}$ Borini $A_{\text {, }}$ Preti $S$, Conte $\mathrm{N}_{*}$ Capitanio $\mathrm{GL}$ (1996) Detection by in situ hybridization of numerical abnormalities for autosomes 1 and 17 in human spermatozoa from infertile men of different age. Pre-

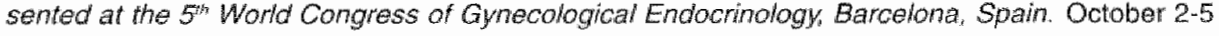
1996. Abstract no. C-07.

Bischoff F, Nguyen D, Burt K, Shaffer L, (1994) Estimates of aneuploidy using multicolor flluorescence in situ hybridization on humam sperm. Cytogenet Cell Genet, 66, 237-243.

Blanco J. Egozcue J. Vidal F, (1996) Incidence of chromosome 21 disomy in human spermatozoa as determined by fuorescent in-situ hybridization. Hum Reprod, 11, 722-72.6.

Chandley A, Hargreave T, (1996) Genetic anomaty and ICSI. Hurm Heprod, 11,930-931.

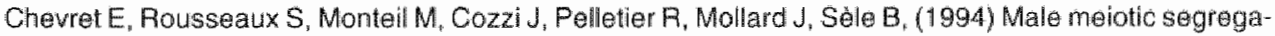
tion of gonosomes analysed by two colour FISH in human unterphase spermatozoa. Hum Genet, 94. $701-704$

Chevret E, Aousseaux S, Molteil M, Pelletier R, Cozzi J, Sele B, (1995) Meiotic segregation of the X and $Y$ chromosomes and chromosome 1 analysed by three-color F1SH in human interphase spermatozoa. Cytogenet Cell Genet, 7\#, 126-130.

Chevret E, Rousseaux S, Molteil M, Usson Y, Cozzi J Pellttier R, Sële B, (1996) Increased incidence of hyperhaploid 24. XY spermatozoa detected by three-colour FISH in a 46, XY/47 XXY male. Hum Genet, $97,171-175$.

Cooke H, Schmidtke J Gosden ل J, (1982) Characterization of human $\gamma$ chromosome repeated sequence and related sequences in higher primates. Chromosoma, $87,491-502$

Cooke $H_{4}$ Hindley $J_{n}$ (1979) Cloning of human satellite III DNA: different components are on different chromo. somes. Nucleic Acios Res, 6, 3177-3197.

Egozcue J, Templado C, Vidal F, Navarro J, Morer.Fargas F, Marina S, (1983) Meiotic studies in a series of 1100 infertile and sterile males. Hum Genet, 65, 185-188

Forina M, Leardi P, Armanino C, Lanteri S, Conti P, Princi P, (1988) Parvus: an extendible package of 
programs for data exploration, classification and correlation. Elsevier Scientfic Sofware, Amsterdam.

Goldman $A$, Fomina A, Knights P. Hil C. Walker A, Hutten M, (1994) Analysis of the primary sex ratio, sex chromosome aneuploidy and diploidy in human sperm using dual colour fluorescence in situ hybridization. Eur I Hum Genet, 1, 325-334.

Griffin D, Abruzzo M, Mille E, Sheean L, Feingold E. Sheman S, Hassold T, (1995) Non-disjunction in thuman sperm: evidence for an effect of increasing patemal age. Hum Mol Genet, 4, 2227-2232.

Han T, Ford J. Webb $G$. Flaherty $S_{3}$ Correll $A$, Mathews $C_{\text {, }}$ (1993) Simultaneous detection of $X$ - and $Y$ bearing human sperm by double fuorescence in situ hybridization. Mol Reprod Dev, 34, 308-313.

Hassold $T$, Sheman $S$. Pettay $D$. Page $D$, Jacobs $P,(1991) X Y$ chromosome nondisjunction in man is associated with diminished recombination in the pseudoautosomal region. Am J Hum Genet, 49,253 260.

In't Veld P, Brandenburg $H$, Verhoeff $A_{1}$ (1995) Sex chromosomal abnormalities and intracytoplasmic sperm injection [letter]. Lancet, 346, 773 .

Jacobs P, Hassold T. The origin of numerical chromosome abnormalities. Advances in Genetics, vol 33, [series: advances in genetics $33(1995)$ ]. pp. 101-133.

Liebaiers I, Bonduelle M, Legoin J, et al. (1995) Follow up of children born after intracytoplasmic sperm injection. In Hedon, B., Bringer, J. and Mares, P (eds), Fertility and Sierility. A Current Overvew. Parthenon Publishing, New York, pp. 409i-412.

Lorda-Sanchez $I_{\text {, Binkert }} F_{1}$ Maechler $M$, Robinson W, Schinzel $A_{*}$ (1992) Reduced recombination and paternal age effect in Kinefelter syndrome. Hum Genet, 89, 524-530.

MaciDonald M, Hassold T, Harvey J, Wang $L$, Morton $N$, Jacobs $P_{1}(1994)$ The origin of $47, X X Y$ and $47, X X X$ aneuploidy: heterogeneous mechanisms and role of aberrant recombination. Hum Mol Gener, $3,1365-$ 1371.

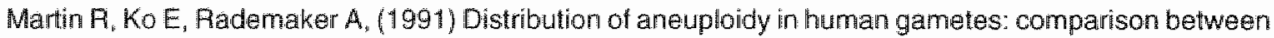
kuman sperm and oocytes. Am J Med Genet, 39, 321-331.

Martin $\mathrm{R}$, Rademaker $\mathrm{A}_{\text {, }}(1995)$ Reliability of aneuploidy estimates in human sperm: result of fluorescence in situ hybridization studies using two different scoring criteria. Mol Reprod Dev, 42, 89-93.

Martin $F$, Spriggs $E, K o, E$, Rademaker $A,(1996 a)$ The relationship between paternal age, sex ratios, and aneuploidy frequencies in human sperm, as assessed by multicolor FISH. Am 1 Hum Genet, 57 , $4395-1399$.

Martin R, Spriggs E, Rademaker A, (1996b) Multicolor fluorescence in situ hybridization analysis of anewploidly and diploidy frequencies in 225846 sperm from 10 normal men. Biol Reprod, 54, 394-398.

Martin $\mathrm{Fi},(1996 \mathrm{c})$ The risk of chromosomal abnormalities following ICSI. Hum Reprod, 11, 924-925.

Martini E, Speel E, Geraedts J, Ramaekers F, Hopman A. (1995) Application of different in-situ hybridization detection methods for human sperm analysis. Hum Reprod, 10, 855-861.

Martini E, Geraedts J, Liebaers L, Land J, Capitanio G, Ramaekers F Hopman A, (1996) Constitution of semen samples from XYY and XXY males as analysed by in-situ hybridization, Hum Reprod, 11, 1638 1643.

Massart D, Vandeginste B, Deming S, Michotte Y, Kaufman L, (1988) Chemometrics: a Textbook. Elsevier. Amsterdam, pp. 395-397.

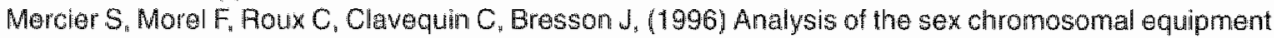
in spermatozoa of a 47, XYY male using mo-colour fluorescence in-situ hybridization. Mol Hum Reprod, $2,485-488$.

Mharu $\mathbb{N}_{\text {, Best }}$ Y Young $S$, (1994) Numerical chromosome abnormalities in spermatozoa of fertile and infertile men detected by fluorescence in situ hybridization. Hum Genet, $93,502-506$.

Moosani N, Pattinson $H_{1}$ Carter M, Cox D, Rademaker A, Martin R, (1995) Clromosomal analysis of sperm from men with idiopathic infertility using sperm karyotyping and fluorescence in situ hybridization. Fertil Sterit, 64, 811-7.

Ord T. Palrizio P, Balmaceda J, Asch $\mathrm{R}_{\text {. }}(1993)$ Can severe male factor infertility be ireated without micro manipulation ? Fertil Sterit, $60,110$.

Pang M. Zackowski J, Hoegeman S, Friedman E, Moon S, Cuticchia A, Acosta A, Kearns W. (1995) Detection by fluorescence in situ hybridization of chromosome $4,6,7,8,9,10,11,12,13,17,18,21, X$, and $Y$ aneuploidy in sperm from oligo-astheno-teratozoospermic patients of an in vitro fertilization program. Abstract $17^{\circ} .680$, Abstractbook of the American Society for Human Genetics, Minneapolis.

Persson ل, Peters G, Saunders D, (1996) Is ICSI associated with risk of genetic disease ? Implications fior counselling, practice and research. Hum Reprod, 11,921-924.

Robbins W, Baulch J, Moore II D, Weier H, Blakey D, Wyrobek A, (1995) Three probe fluorescence in situ hybridization to assess chromosome $X, Y$, and 8 aneuploidy in sperm from 14 men from two healthy groups: evidence for a paternal age effeci on sperm aneuploidy. Feprod Fertil Dev, 7, 799-809.

Schattman G. Munne S, Grifo J, Carton L, Cohen J, (1993) Aneuploidy in spermatozoa using fluorescence in situ hybridization. J Ass Reprod Genei, 10,360-365. 
Speel E, Jansen M. Ramaekers F, Hopman A, (1994) A novel triple-color detection procedure for brightheld microscopy, combining in situ hybridization with immunocytochenistry. 1 Histochem Cytochem. 42 , 1299-1307.

Spriggs $E$. Rademaker A, Martin $\mathrm{F},(1995)$. Aneuploidy in human sperm: results of two-and three-color fluorescence in situ hybridization using centromeric probes for chromosomes $1,12,15,18, X$, and $Y$. Cytogenet Cell Genet, 71, 47-53.

Spriggs $E$, Rademaker A, Martin R, (1996) Aneuploidy in human sperm: the use of multicolor FiSH to test various theories of nondisjunction. Am J Hum Genet, 58, 356-362.

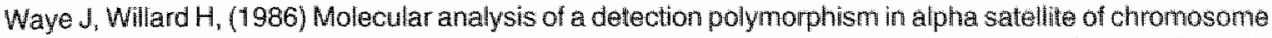
17: evidence for homologous unequal crossing-over and subsequent fixation. Nucleic Aciots Res, 14, $6915-6927$.

Williams $B$, Ballenger $C$, Malter H, Bishop F. Tucker M, Zwingman T, Hassold T, (1993) Non-disjunction in human sperm: results of fluorescence in situ hybridization studies using two and three probes. Hum Mol Genet, 2, 1929-1936.

Wyrobek $A$, Riobbins $W$, Mehraein $Y$, Pinkel D, Weier $H_{3}$ (1994) Detection of sex chromosomal aneuploidies $X-X, Y-Y$, and $X-Y$ in human sperm using two-chromosome fluorescence in situ hybridization. Am J Med Genet, $53,1-7$. 



\section{Chapter 5}

\section{Detection of structural abnormalities in spermatozoa of a translocation carrier $t(3 ; 11)(q 27.3 ; q 24.3)$ by triple FISH}

Elena Martini, Anne R.M. von Bergh, Edith Coonen, Christien E.M. de Die-Smulders, Anton H.N. Hopman, Frans C.S. Ramaekers and Joep P.M. Geraedts 


\section{Abstract}

Structural chromosome abnormalities in spermatozoa represent an important category of paternally transmittable genetic damage. A couple was referred to our centre because of repetitive abortions and the man was found to be a carrier of a reciprocal translocation $\mathrm{t}(3 ; 11)(\mathrm{q} 27.3 ; \mathrm{q} 24.3)$. A taillored fluorescence in situ hybridization (FISH) approach was developed to study the meiotic segregation patterns in spermatozoa from this translocation carrier. A combination of three DNA probes was used, a centromeric probe for chromosome 11, a cosmid probe for chromosome 11q, and a YAC probe for chromosome 3q. The frequency of spermatozoa carrying an abnormal chromosome constitution was compared with baseline frequencies in control semen specimens, and it was found that a significantly higher percentage of spermatozoa carried an abnormal constitution for the chromosomes involved in the translocation. A rormal or balanced chromosome constitution was found in $44.3 \%$ of the analyzable spermatozoa, while the remainder exhibited an abnormal chromosome constitution reflecting different modes of segregation $15.9 \%$, adjacent I segregation; $6.5 \%$, adjacent II segregation; $28.9 \%, 3: 1$ segregation; $0.8 \% 4: 0$ segregation; $3.6 \%$, aberrant segregation). The frequency of aneuploidy for chromosomes $\mathrm{X}$, $Y, 13$ and 21 was assessed using specific probes but there was no evidence of interchromosomal effects or variations in the sex-ratio in spermatozoa from the translocation carrier. In conclusion, structurat aberrations can be reliably assessed in interphase spermatozoa using unique DNA probe cocktails, and this method provides insight into the genetic constitution of germ cells and enables evaluation of potential risks for the offspring.

\section{Introduction}

Balanced chromosome translocations result from an exchange of fragments between two non-homologous chromosomes, without any gain or loss of genetic material. Translocation carriers, although they do not exhibit any particular phenotypes, are often affected by reproductive failures, either due to spermatogenic arrest or to unbalanced progeny. Indeed, during meiosis I, the association of both translocated chromosomes and their normal homologues can lead to an unbalanced pattern of segregation for these chromosomes. Statistical data from imbalances observed at birth have been applied to determine segregational models for the assessment of reproductive risks (Jalbert et al., 1980; Cans et al., 1993). Studies on liveborn offspring or fetuses do not provide accurate information about meiotic segregations, as lethal segregations have already been lost through spontaneous abortions, hence the true mechanisms responsible for determining how structural rearrangements segregate remains unknown. In addition, an increase of aneuploidies involving chromosomes unrelated to the translocation, termed an "interchromosomal effect", has also been suggested, though never proven (Aurias et al., 1978).

To date, 30 different reciprocal translocations in men have been studied by karyotyping sperm after penetration of zona-free hamster oocytes (see Rousseaux et al., 1995; Estop et al, 1995 for review of literature). High baseline frequencies (5-10\%) of structural abnormalities were reported for human spermatozoa (Martin et al., 1987; Estop et al., 1991), however, $90 \%$ of the observed aberrations were unstable chromosome and chromatid aberrations suggesting high degrees of post-meiotic damage or possibly artefacts of inter-species fertilization (Martin 1992). Aneuploidy was estimated to be 1-2\% and hypoploidy was observed at higher frequencies than hyperploidy (Martin and Rademaker 1990). However, this technique is time consuming, labor intensive and does not allow analysis of large numbers of cells (Martin and Rademaker 1990).

In situ hybridization (ISH) and fluorescence ISH (FISH) have been used to study sperm chromosomes in single, double and triple target procedures (see Downie et al., 1997 for 
review). This technique is limited to the detection of abnormalities for the specific chromosomes analyzed, but it allows rapid screening of many spermatozoa. Only few studies exist on men carrying a numerical chromosomal abnormality, like XYY and XXY karyotypes (Han et al., 1994; Martini el al., 1996; Mercier et al., 1996; Guttenbach et al., 1997; Chevret et al., 1997) and on men carrying a structural chromosomal abnormality (Lu et al., 1994; Spriggs and Martin 1994; Rousseaux et al., 1995; Mercier and Bresson 1997). These studies were all based on the detection of meiotic segregation modes using centromeric probes.

The present paper reports a specific FISH approach, developed in order to simultaneously investigate the frequencies of structural and numerical chromosome aberrations in spermatozoa of a translocation carrier $t(3 ; 1))(q 27.3 ; q 24.3)$. Two probes specific to DNA loci on the segregational fragments (a cosmid probe for chromosome region 11 q25 and a YAC probe for chromosome region $3 q 29$ ) and a centromeric probe for chromosome 11 were hybridized simultaneously. Furthermore, the sex ratio and aneuploidy rate for the sex-chromosomes was assessed, and the frequency of aneuploidy for chromosomes 13 and 21 was studied in order to exclude interchromosomal effects.

\section{Materials and Methods}

Case history

Spermatozoa from a 33-year-old man who carries a reciprocal translocation $\mathrm{t}(3 ; 11)(\mathrm{q} 27.3 ; \mathrm{q} 24.3)$ were studied. His sister, mother and maternal grandmother were also carriers of the same transiocation. His wife had at least seven early miscarriages. In the fifth pregnancy an amniocentesis was performed at 16 weeks of gestational age. The kanyotype of the foetus was abnormal: $46, \mathrm{XX},-11,+\operatorname{der}(11), t(3 ; 11)(\mathrm{q} 27.3 ; \mathrm{q} 24.3)$, resulting in partial monosomy $11 \mathrm{q}$ and partial trisomy $3 \mathrm{q}$. On request of the parents the pregnancy was interrupted. A stillborn girl with multiple congenital anomalies was dellivered. The younger sister of the proband also had several spontaneous abortions. Her third pregnancy ended at 24 weeks with the birth of an hydropic foetus (Willekens et al., 1994). A Parvovirus B19 infection and an unbalanced karyotype were found in the abortion material. Reproductive history of the mother and the grandmother of the proband were unremarkable, with no miscarriages or stillbirths known. Both couples asked for a risk evaluation in using their own gametes and pre-implantation diagnosis of embryos.

The study was approved by the Research Ethics Committee of the Academic Hospital Maastricht. The patient and the three healthy control males gave written consent for the semen samples to be used for research purposes.

\section{Sperm preparation}

Semen analysis $(W H O, 1992)$ revealed parameters in the normal range (volume, $4.5 \mathrm{ml}$; sperm concentration $129 \times 106 / \mathrm{ml}$, progressive motility $35 \%$, morphology $49 \%$ ). A swim up iraction was prepared and the sperm were spread on Super Starfrost Plus slides (Maenzel Glaeser( $B$, Braunschweig, Germany). Slides were air dried at room temperature, fixed in methanol/acetic acid (3:1) and stored at $-20^{\circ} \mathrm{C}$. Before processing for $\mathrm{FISH}$, the slides were washed in $2 x$ standard saline citrate (SSC) and incubated for 5 minutes in $1 \mathrm{M}$ Tris buffer, pH 9.5, containing $25 \mathrm{mM}$ dithiothreitol (DTT) (Martini et al., 1995). After nuclear decondensation, the slides were washed once in $2 \times$ SSC, once in $1 \times$ phosphate buffered saline (PBS), dehydrated and air dried. Finally, they were fixed in $1 \%$ paraformaldehyde/0.1M PBS ( $\mathrm{pH} 7.3)$ for 5 minutes at $4^{\circ} \mathrm{C}$, rinsed three times in PBS, dehydrated and air dried (Martini et al., 1997). 
Semen from 3 normal, healthy men with a $46, X Y$ karyotype were used as controls. These men were partiers of women with an IVF indication and normal IVF results and had semen parameters in the normal range (WHO, 1992). These samples were analysed and processed in an identical manner.

\section{Lymphocyte preparation}

interphase nuclel obtained from methanol-acetic acid ( $3: 1$ ) fixed preparations of peripheral blood cells of the patient and from a healthy $46, X Y$ control were used to test the quality of the DNA probes, the efficiency of the labelling and the FISH procedure.

\section{DNA probes}

Seven different DNA probes were used in this study (Table 1).

Three probes were required for the translocation study: (i) CEP11 labelled with Spectrum Orange(B) (Vysis, Inc., Downers Grove, IL), specific for the repetitive centromeric region of chromosome 11; (ii) a cosmid probe, D11S-477, specific for chromosome 11q25, insert size approximately $40 \mathrm{~kb}$, (Tokino et al., 1991, remapped - personal observations), labelled by nick translation with digoxigenin-12-dUTP (Boehringer Mannheim, Mannheim, Germany; (iii) a YAC clone, TYAC162, specific for chromosome 3q29, insert size $250 \mathrm{~kb}$ (VoceroAkbani et al.s 1996), Alu-PCR-labelled with biotin-11-dUTP (Enzo Diagnostic, New York). Sex-chromosome probes were used: (i) pBam $\times 5$, alphoid, insert size $2.0 \mathrm{~kb}$, (Willard et al., 1983), specific for the centromeric region of human chromosome $X$; (ii) DYZ1, satellite II, insert size $2.1 \mathrm{~kb}$ (Cooke et al., 1982), specific for the long arm of human $Y$ chromosome. These probes were direct-labelled with FITC-12-dUTP (Boehringer Mannheim) and Rhodamine-4-dUTP (TRITC) (Amersham, Buckinghamshire, UK), respectively.

In order to study the baseline frequencies of aneuploidy and to exclude an interchromosomal effect, probes specific for chromosome 13q14 (LSI13) and chromosome 21q22.13-21q22.2 (LS21) were used (Vysis Inc.). The probes were direct-labelled with Spectrum GreenB and Spectrum Orange(B), respectively.

Table 1. Specificity, labelling, signal color and usage of probes.

\begin{tabular}{|c|c|c|c|c|c|}
\hline Probe & Specificity & Label & Color & $\begin{array}{l}\text { Combination } \\
\text { (controls) }\end{array}$ & $\begin{array}{l}\text { Combination } \\
\text { (carrier) }\end{array}$ \\
\hline CEP 11 & alphoid 11 & Specirum Orange & orange & & triple \\
\hline TYACIBZ & 3929 & Biolin: & green & double & \\
\hline$D 115-47^{\circ}$ & $14 q 25$ & Digoxigenin & $\mathrm{red}$ & riple & \\
\hline $\operatorname{LS} 13$ & $13 q 14$ & SpestrumGreen & green & double & double \\
\hline LSI 21 & $\begin{array}{l}2 \lg 2213 \\
2 \lg 222\end{array}$ & Spectrumorange & orange & & \\
\hline pBam $\times 5$ & alphoid $x$ & FITC & green & double & double \\
\hline DYZII & long am $Y$ & TAITC & red & & \\
\hline
\end{tabular}

*remapped on 11 q25, personal observations

\section{FISH procedure}

Triple target $F \mid S H$ was performed with the probe cacktail for the translocation chromosomes (figure 1a-e). Sperm were denatured by immersion in $70 \%$ formamide (FA)/ $2 \times S S C$ at $70^{\circ} \mathrm{C}$ for 3 minutes, dehydrated through a cold ethanol series and air dried. A $10 \mu \mathrm{l}$ sample of hybridization mix (60\% FA, $10 \%$ dextran sulfate) containing 200 ng of cosmid 11 q 25,10 
ng of CEP11, $100 \mathrm{ng}$ of $Y A C 3 q 29,40 \mu \mathrm{g}$ of salmon sperm DNA and $20 \mu \mathrm{g}$ of human Cot DNA (Gibco, BRL) was heated at $70^{\circ} \mathrm{C}$ for 5 minutes and then pre-annealed at $37^{\circ} \mathrm{C}$ for 20 minutes. The mixture was then applied to the specimen. The slides were covered with a $20 \times 20 \mathrm{~mm}$ coverslip and hybridized overnight in a moist chamber at $37^{\circ} \mathrm{C}$. Coverslips were then removed and slides were washed twice in $2 \times S S C / 0.05 \%$ Tween 20 for 5 minutes at $42^{\circ} \mathrm{C}$, once in $0.1 \times S S C$ for 5 minutes at $60^{\circ} \mathrm{C}$ and twice in $4 \times S S C / 0.05 \%$ Tween 20 for 5 minutes at room temperature. Specimens were then pre-incubated for 15 minutes in $4 \%$ non-fat dry milk (NFDM). To detect the biotinylated probe, the following series of incubations was used: (i) 20 minutes at $37^{\circ} \mathrm{C}$ with avidin-FITC, (ii) 20 minutes at $37^{\circ} \mathrm{C}$ with anti-avidin, (iii) 20 minutes at $37^{\circ} \mathrm{C}$ with avidin-FITC. Between incubations, slides were washed for 5 minutes in $4 \times$ SSC/ $0.1 \%$ Tween 20 at room temperature. Slides were washed 5 minutes in PBS/0,1\% Tween 20 at room temperature, then incubated for 30 minutes at $37^{\circ} \mathrm{C}$ with mouse anti-digoxigenin followed by 30 minutes at $37^{\circ} \mathrm{C}$ with $\mathrm{Cy} 3$-labelled goat anti-mouse to detect the digoxigenin labelled probe. Slides were rinsed in PBS, dehydrated through an ethanol series and mounted in Vectashield antifade (Vector laboratories, Burlingame, CA, USA) containing $0.01 \mathrm{mg} / \mathrm{ml}$ 4,6-diamidino-2phenylindole (DAPI) to counterstain the DNA.

Double target FISH using probes for the sex-chromosomes and chromosomes 13 and 21 was performed as described above except that only one 5 minute wash was used between each step.

\section{Microscopy}

Slides were analyzed with a Leica DMRBE fluorescence microscope equipped with separate filters for FITC, Rhodamine and DAPI. Microphotographs were taken using a Metasystem Image Pro System (CCD S30 camera, Sandhausen, Germany). Images were captured using green, red and blue filters and processed for sharpness in Adope Photoshop 3.0 (120 pixels/inch) (figure 1).

\section{Evaluation criteria}

Strict scoring criteria from Hopman et al., (1988) and Martin et al., (1995) were used. Only individual and well delineated spermatozoa were scored. Two signals of the same color were scored as two when they were clearly distinct and of the same size and intensity. In the triple FISH, the centromeric probe for chromosome 11 (CEP11) and the cosmid probe for $11 \mathrm{q} 25$ (D11S-477) were of very different sizes (figure 1a-e) and were therefore distinguished although both yielded red signals. Coded slides (2 per sample) were scored by two observers (E.M. and A.vB.).

\section{Statistical analysis}

A chi-squared test was performed to compare the hybridization efficiencies of CEP11. TYAC162 and D11S-477. Statistical significance was considered when P values were $<0.01$.

\section{Results}

\section{Triple FISH on lymphocytes}

Probes were tested on lymphocyles to determine the characteristics and hybridization efficiencies of the probes. Once the probes worked efficiently in single and double FISH (data not shown), triple FISH was performed (figure $1 \mathrm{a}-\mathrm{b}-\mathrm{c}$ ) and $600 \mathrm{control}$ and carrier lymphocytes were scored. Overall, $97.2 \%$ of the cells displayed the expected, normal dip. loid constitution while the remaining cells showed either loss (hypoploidy or technical artifact) or gain (hyperploidy or split spots) of signals (figure 2a). 

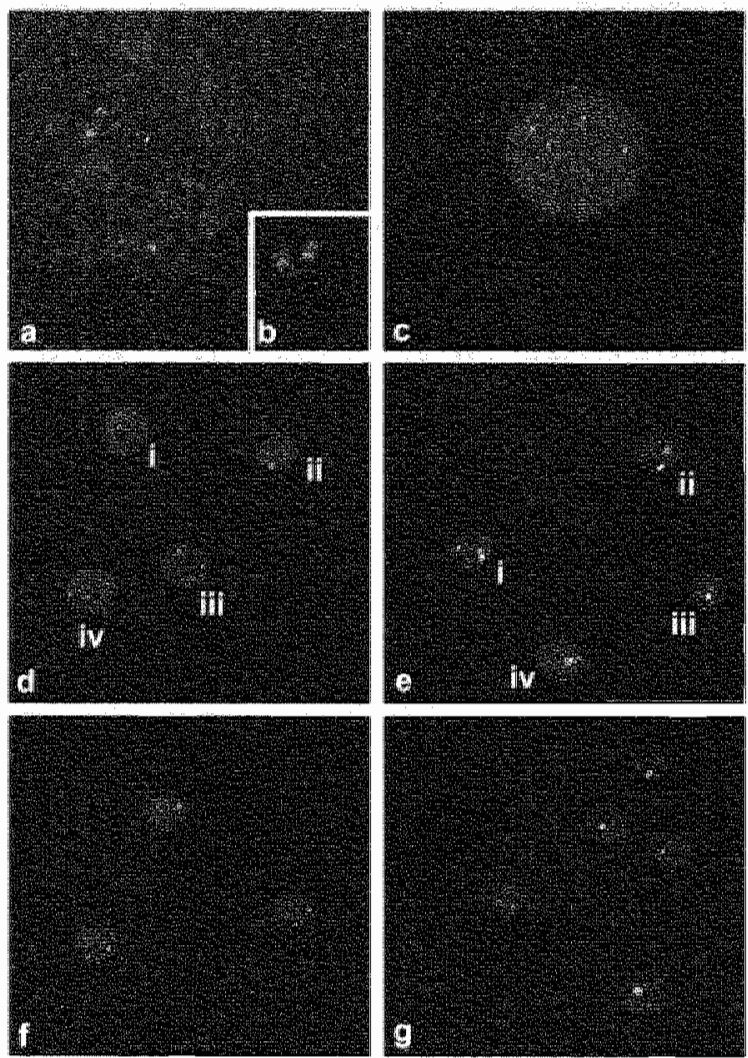

Figure 1. FISH results on peripheral blood cells (a-c) and spermatozod (d-g) of the patient. (a) Triple target hybridization to metaphase spreads with the probes CEP11, TYAC 162 and D11S-477, respectively in orange, green and red. (b) Particular of the chromosomes inwolved in the translocation and the probes applied. (c) Lymphocyte, hybridized with triple FISH, showing the difference in signal size for the centromere and the locus specific probe used. (d) Spermatozoa of the patient hybridized with triple FISH (for explanation see figure 3). (i) Adjacent II segregation mode, signals for CEP11 and TYAC162; (ii) 3:1 seg.w regation mode, signals for CEP11 and D $115-477$; (iit) Alternate segregation, nomal or balanced sperm with signals for CEPII. TYAC 162, D11S-477; (iv) Aberrant segregation mode, two signals for CEP11. (e) Spermatozoa of the patient hybridized with triple FISH (for explanation see figure 3). (i) Adjacent I segregation, signals for CEP11 and twice for TYAC 162; (ii) and (iii) Alternate segregation mode, normal or balanced spermatozoa: (iv) 3:1 segregation mode, signals for CEP11, TYAC 162 and twice for D11S-477. (t): double FISH with chromosomal probes for chromosomes 13 (green) and 21 (red). All spermatozoe show a normal, haploid, chromosomal constittition. (g): double FISH with the sex-chromosomal probes. In green the $X$-probe, in red the $Y$-probe. At the bottom, right corner, a sperm cell carrying an $X Y$ constitution is visible. For colour illustration see page 116. 
Double FISH on control spermatozoa

Probes were tested on control spermatozoa using a double FISH and different probe combinations (CEP11 and TYAC162; CEP11 and D115-477; TYAC162 and D11S-477). A total of 3000 spermatozoa were scored for each combination. The results were as follows: (i) CEP11 and TYAC162: $98.87 \%$ of cells exhibited a signal for both chromosomes. More loss (CEP 11, 0.03\%; TYAC162, 0.7\%) than gain (CEP 11, 0.07\%; TYAC162, 0.33\%) was registered. (ii) CEP11 and D11S-477: $98.67 \%$ of spermatozoa were haploid, with loss (CEP 11,0.03\%; D11S-477, 0.83\%) and gain (CEP 11, 0.20\%; D11S-477, 0.20\%) and $0.07 \%$ diploidy. (iii) TYAC162 and D11S-477 $98.73 \%$ of cells exhibited signals for both probes with loss (TYAC162, 0.07\%; D11S-477, 0.7\%) and gain (TYAC162, 0.17\%; D11S-477, 0.20\%). Loss and gain for individual probes is illustrated in figure $2 \mathrm{~b}$.
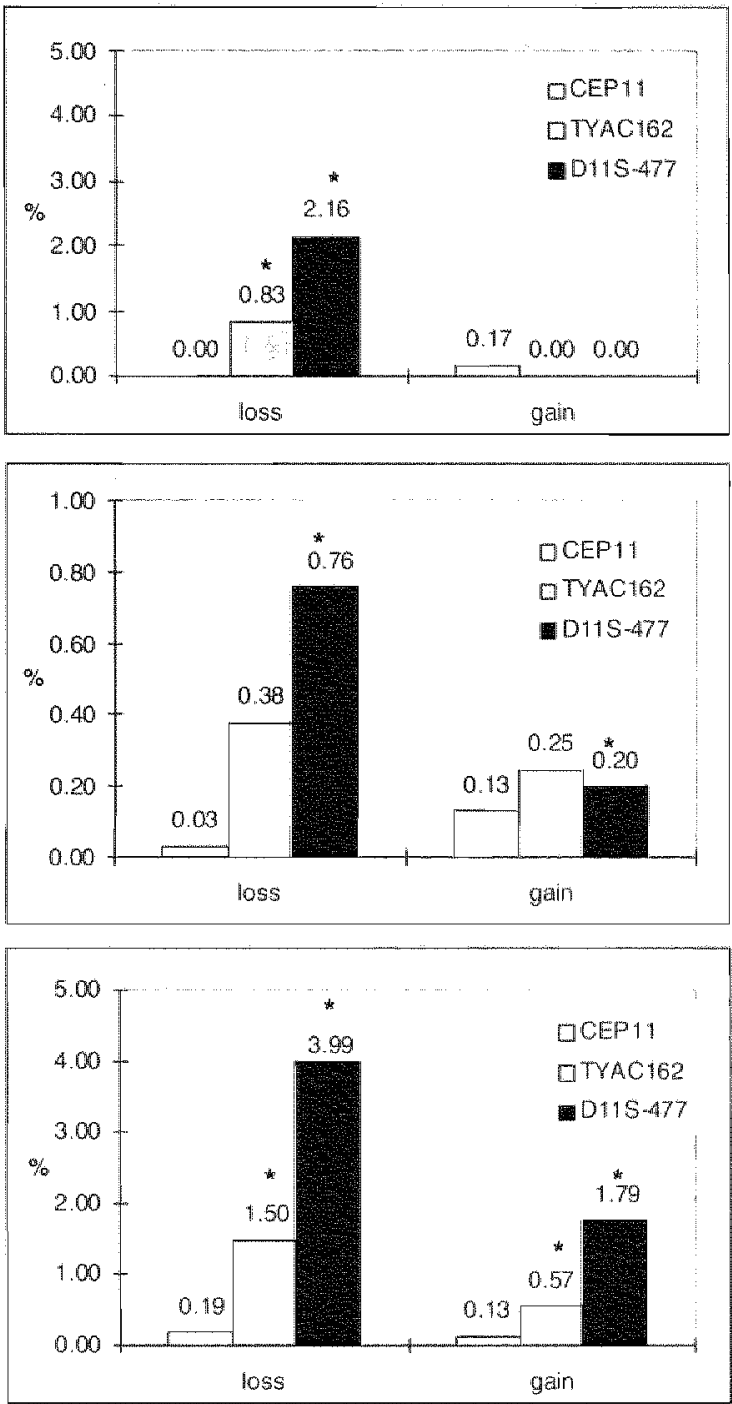

Figure 2. Efficiencies of the single probes (CEP11, TYAC162, and D11S-477) on lymphocytes as determined by triple FISH (2a) and double and triple FISH on spermatozoa of controls (2b and $2 c$, respectively). Loss and gain of the probes is shown in the bars. Description in the text. ": p<0.01 
Triple FISH on spermatozoa from controls and translocation patient

A total of 8316 control spermatozoa were scored. The hybridization efficiencies were as follows: CEP11, 99.81\%; TYAC162, 98.5\%; D 11 S- $477,96.01 \%$. The frequency of normal spermatozoa (carrying one signal for each probe) was $91.55 \%$, and diploidy occurred at a frequency of $0.08 \%$. Loss and gain for individual probes is illustrated in figure $2 \mathrm{c}$. Moreover, $1.05 \%$ of the cells displayed an aberrant chromosome constitution, not classifiable in any of the above categories.

Analysis of 4029 spermatozoa from the translocation carrier by triple FISH yielded a hybridization efficiency of $99.6 \%$. Spermatozoa resulting from the different segregation modes were present at different frequencies "figure 1d-e, 3). During meiosis, a quadrivalent is formed and, depending of the segregation mode, the resultant gametes carry different chromosomal segregations. Of these, only the alternate segregation mode seems to be compatible, in our case, with life. Analysis showed that $44.3 \%$ of the spermatozoa originated from an alternate segregation mode and carried a normal or balanced chromosome constitution. The frequencies of adjacent $I$, adjacent $11,3: 1,4: 0$ and aberrant segregation modes were $15.9 \%, 6.6 \%, 28.9 \%, 0.8 \%$ and $3.6 \%$, respectively. These patterns are shown in figure 3.

Segregation of chromosomes $X$ and $Y$

Chromosomes $X$ and $Y$ were simultaneously detected in 7032 and 5702 control and carrier spermatozoa, respectively. Both the sex ratio and the aneuploidy rate were similar in the two groups (Table 2, figure 1g).

Table 2. Sex ratio and sex chromosome aneuploidy in control and translocation carrier sperm. Values are percentages.

\begin{tabular}{llllllll}
\hline & $X$ & $Y$ & $X Y$ & $X X$ & $Y Y$ & $X X Y$ & $X Y Y$ \\
\hline Control & 49.04 & 50.18 & 0.40 & 0.28 & 0.09 & 0.0 & 0.0 \\
Carrier & 48.05 & 51.57 & 0.23 & 0.02 & 0.12 & 0.02 & 0.0 \\
\hline
\end{tabular}

Segregation of chromosomes 13 and 21

The segregation of chromosomes 13 and 21 was studied in 5612 control spermatozaa and 5016 carrier spermatozoa to determine any interchromosomal effect. No significant variation in aneuploidy rate was detected for these two chromosomes (Table 3 , figure 1f).

Table 3. Chromosome 13 and 21 aneuploidy in control and translocation carrier sperm. Walues are percentages.

\begin{tabular}{cccccccccc}
\hline & $13 / 21$ & $13 /-$ & -121 & $13,13 / 21$ & $13 / 21,21$ & $13,13 / 21,21$ & - & $13,13 \%$ & $-121,21$ \\
\hline Control & 98.66 & 0.23 & 0.29 & 0.07 & 0.37 & 0.11 & 0.25 & 0.02 & 0 \\
Carrier & 98.33 & 0.4 & 0.7 & 0.0 & 0.26 & 0.06 & 0.24 & 0.0 & 0.02 \\
\hline
\end{tabular}

\section{Discussion}

Approximately $30 \%$ of embryonic and fetal deaths are associated with chromosomal abnormalities, in a ratio of 1 to 9 structural versus numerical defects (Hook 1985). A ballanced carrier of a reciprocal translocation can produce a variety of gametes by meiotic 

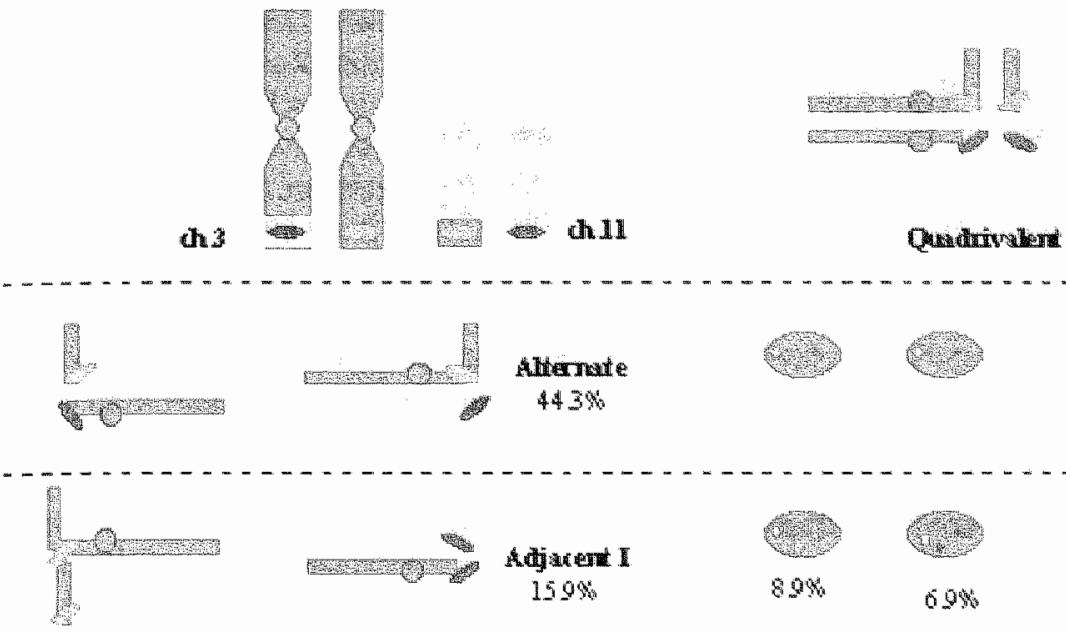

$159 \%$

89

$69 x$
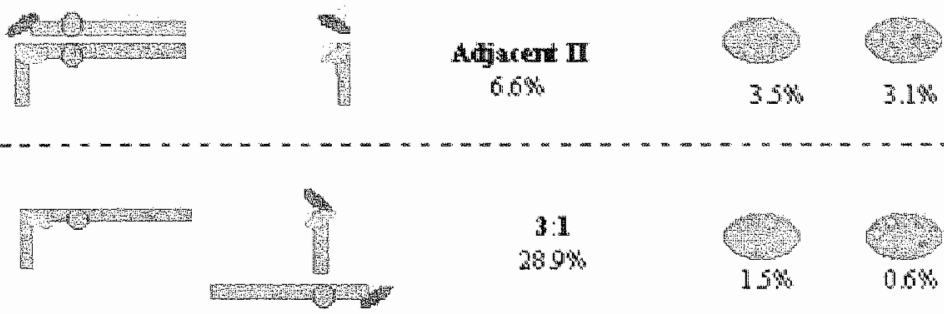

\section{1}

$289 \%$

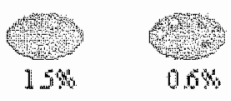

4tond
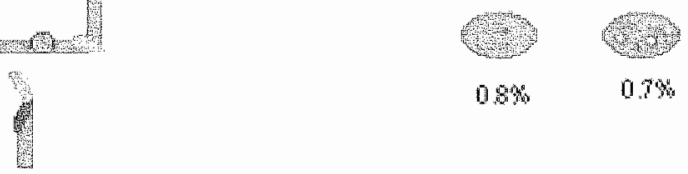

0.96

$0.7 \%$

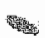
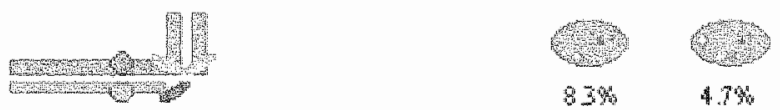

83

$4.7 \mathrm{H}$
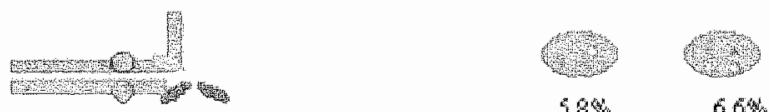

$58 \%$

$6 \%$

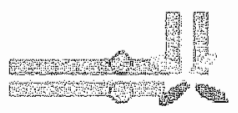

\section{0}

$0,3 \%$
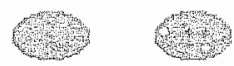

0.45

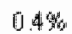

\section{Marand}

$36 \%$

Figure 3. Schematical explanation of the chromosomes involved in the translocation $1(3 ; 11)(q 27,3 ; 024,3)$ and the probes used. The quadrivalent and the various segregational modes are shown. The corresponding resulting gametes are illustrated. For simplification the CEP1 signal, which is detected in red, is here illustrated in yellow. CEP $11=$ Yellow. TYAC $162=$ Green, and D11S-477 $=$ Red. For colourillustration see page 117. 
segregation, whereby the reproductive significance of any particular structural rearrangement depends on the proportion of unbalanced gametes produced and the post zygotic lethality arising from them (Goldman and Hulten 1993a; Goldman and Hulten 1993b).

Generally, information for genetic counseling is obtained from empirical studies or sperm karyotyping (Estop et al., 1995), however, none of these techniques enables correct knowledge of the chromosome constitution in sperm cells and a reliable risk estimation for the patient (Van Hummelen et al., 1996).

Some studies used FiSH on testis biopsies from a translocation carrier (Goldman and Hulten 1993a; Goldman and Hulten 1993b), on epididimal spermatozoa from Robertsonian translocation-bearing mice (Lowe et al., 1996) and on ejaculated spermatozoa from translocation carriers (Spriggs and Martin 1994; Luet al., 1994; Rousseaux et al., 1995; Mercier and Bresson 1997). However, until now, the analysis of spermatozoa of translocation carriers by FISH using centromeric probes could not discriminate gametes originating from an alternate or adjacent I segregation mode. Simultaneous detection of structural and numerical abnormalities in spermatozoa requires multicolor FISH and an appropriate choice of DNA probes (Van Hummelen et al., 1996). In our approach, we used two locus-specific probes and one centromeric probe to differentiate between segregation modes (figure 3 ). We found that $44.3 \%$ of spermatozoa from a translocation carrier $t(3 ; 11)(q 27.3 ; q 24.3)$ carried a normal or balanced genetic constitution, while the remaining spermatozoa showed a chromosomal composition deriving from different segregation modes of the quadrivalent at meiosis. We have shown that although co-hybridization of different DNA probes can influence the hybridization outcome, the present approach can detect structural aberrations in human interphase spem. These results offer a risk estimation which is reliable enough to be used for genetic counselling of trans/ocation carriers.

\section{Meiotic segregation}

The actual risk of producing unbalanced live births differs greatly from one reciprocal translocation to another (Vauhkoen et al., 1985) and unbalanced offspring produced by carriers of a particular reciprocal translocation are nearly always the result of the same mode of translocation.

Factors such as the size of the translacation segments, the presence or absence of heterochromatin, and the centromere index all play a role in defining quadrivalent orientation and first meiotic segregation (Sybenga and Rickards 1987). However, the true mechanisms responsible for determining the segregation of structural rearrangements remains unknown. Ailternate segregation yields chromosomally normal gametes and gametes carrying both translocated chromosomes. Information from most of the translocations studies suggests that meiosis produces an equal ratio of chromosomally balanced and normal spermatozoa (Guttenbach et al., 1997). However, with FISH in interphase, and locus specific probes, it is not possible to distinguish between these two forms. Most unbalanced liveborn offspring from reciprocal translocation heterozygotes are the result of adjacent 1 segregation (Jalbert ef al., 1988). In abortion material obtained from the couple described in this paper, this chromosome constitution was found and in the present study we found $15.9 \%$ of spermatozoa with this particular genolype.

Exchanges of interstitial chiasmata between the centromere and translocation breakpoint render alternate and adjacent I segregation products cytologically indistinguishable (Sybenga and Rickards 1987). This can be bypassed using a specific probe cocktail which hybridizes to the specific fragments involved in the translocation, as in our tailored approach (figure 3).

Data arising from sperm chromosome studies (see review by Estop et al., 1995) suggest 
that in male meiosis, adjacent II segregations are more prevalent than $3: 1$ segregations. However, this was not observed in our case, where the frequency of $3: 1$ segregations was $28.9 \%$ whereas adjacent 11 segregation occurred at a frequency of $6.6 \%$ only. Jalbertet al., (1980) hypothesized that the features of preferential $3: 1$ segregation were (i) unequal sizes of the translocated segments and (ii) participation of acrocentric chromosomes. In our study, $28.9 \%$ of spermalozoa were the result of a $3: 1$ segregation. However, this frequency may have been biased by technical artefacts as discussed later. Additionally, 4:0 and aberrant segregation modes were detected at frequencies of $0.8 \%$ and $3.57 \%$, respectively (figure 3).

\section{Interchromosomal effects}

The possibility of an increased frequency of chromosomal abnormalities unrelated to the specific translocation, an interchromosomal effect, has been postulated (Aurias et al., 1978). This is still controversial, however, and there is little if any evidence to support the concept (Rousseaux et al, 1995). Verily, when analyzing spermatozoa with alphoid or satellite probes for chromosomes $X$ and $Y$ and locus specific probes for chromosomes 13 and 21, we found neither alteration of the sex-ratio nor differences in aneuploidy. The aneuploidy rate found for the sex-chromosomes was in agreement with data from the literature (see Downie et al., 1997 for review; Martini et al., 1996; Bernardini et al., 1997). Few studies have simultaneously assessed chromosomes 13 and 21 in spermatozoa, and all reported higher disomy rates than the present study (see Downie et al., 1997 and Gultenbach et al., 1997; both for review). However, when using a single probe for chromosome 21, Blanco et al., (1996) reported similar frequencies to our study, whereas Rousseaux and Chevret (1995), with the same probe, reported lower aneuploidy rates. In order to completely exclude an interchromosomal effect, the segregation of other autosomes should be studied.

\section{Technical limitations}

Like all the techniques, however, there are some limitations to the approach used in this study. The use of FISH and the consequent identification of "spots" in interphase nuclei is not as convincing as the clear identification of chromosomes by cytogenetic analysis. The same analysis performed on lymphocytes and on control spermatozoa revealed hybridization rates of $97.17 \%$ and $91.55 \%$, respectively. These data indicate that the efficiency hybridization was reduced in the triple FISH procedure, especially in spermatozoa, where the DNA is compacted by disulfide bonds between protamines which have to be reduced (Martini et al., 1995). Moreover, the individual probes themselves showed different properties.

The fact that we found a high level of loss and/or gain of signals in control spermatozoa can be explained by one or a combination of the following theories. First, the combined use of small locus-specific probes with a large centromeric probe can either mask the signal of the smaller probes by superposition or, second, the smaller probes cannot hybridize as efficiently due to sub-optimal conditions of the protocol. Indeed, excesses of nullisomies for chromosomes $3 \mathrm{q} 29$ and $11 \mathrm{q} 25$ compared to the corresponding disomies were observed in controls, and technical artefacts are likely to explain these discrepancies. The superposition of green (TYAC162) or red (D11S-477) signals by the large signal for CEP11 (or overlapping signals) could have led to mis-scoring of some cells with a normal constitution (see also efficiency of each probe in triple hybridization). The reduced hybridization efficiency of the probes for 11q25 and 3q29 (probably due to the insert size, the non-optimal co-hybridization situation) could also have contributed to the mis-scoring of some cells. Moreover, an apparent gain of a fluorescence signal might indeed be a split 
kybridization domain due to overdecondensation of the sperm DNA. (Wyrobek et al., 1994) or to a physical chromosome break within the targeted region of the probe accompanied by a small migration (Van Hummelen et al., 1996).

Finally, the material analyzed has to be considered. It is known from previous studies that analysis of aneuploidy in spermatozoa yields a high variation among different laboratories (Downie et al., 1997). The reason for these variations may be several fold: the quality of the spermatozoa, the decondensation protocol used, single, double or triple FISH protocols, the (im)possibility to identify the sperm tail, the morphological criteria used for the identification of spermatozoa, and the stringency of signal scoring criteria (Martin et al., 1995; Martini et al., 1995; Van Hummelen et al., 1996; Downie et al., 1997).

Hence, this method still presents some limitations due to the hybridization efficiency of the smaller probes, and these preliminary data should therefore be considered with some caution. Nethertheless, the data give a reasonable estimate of the possible risks for the offspring and should enable more effective genetic counselling.

The couple described in this study will be offered preimplantation genetic diagnosis. From the data obtained it is clear that about one in two pre-embryos is likely to be rejected after the treatment because of imbalanced genomic constitution.

\section{Acknowledgments}

We would like to thank the patient for his cooperation and the laboratory staff of the IVF lab at the University Hospital in Maastricht and John Engelen for cytogenetic analysis. A special thanks to Seain Flaherty for his critical appraisal of the manuscript. This study was supported by the Dutch "Piraeventiefonds" (28-2582) and by the Training and Mobility of Researchers (TMR) Program Research Training Grants (ERB 4001 GT 955293) from the European Community to E.M.

\section{References:}

Aurias A, Prieur M, Dutrillaux $B$, Lejeune J, (1978) Systematic analysis of 95 reciprocial translocations of autosomes. Hum Genet, 45:259-282.

Bernardini L. Martini E, Geraedls J. Hopman A, Lanteri S, Conte N, Capitanio G. (1997) Comparison of gonosomal aneuploidy in spermatozoa of normal lertile men and those with severe male factor detected by in-situ hybridization. Molec Hum Reprod, 3: 431-438.

Bianco J. Egozcue J, Vidal $F,(1996)$ Incidence of chromosome 21 disony in human spermatozoa as determmed by thorescent in-situ hybridization. Hum Reprod, 11: 722-726.

Cans C, Cohen O. Mermet M. Demongeot J, Jalbert P. (1993) Human reciprocal translocations - is the unbalanced mode at birth predictable. Hum Genet, $94: 228-232$.

Chevrêt E, Rousseatix S, Monteil M, Usson Y, Cozzi J, Pelletier R, Sele B, (1997) Meiotic behaviour of sex chromosomes investigated by three colour F1SH on 35142 sperm nuclei from two $47, X Y Y$ males. Hum Genet, $99: 407-412$.

Cooke H, Schmidtke J, Gasden J, (1982) Characterisation of a human Y chromosome repeated sequence and related sequences in higher primates. Chromosoma, 87: 491-502.

Downie S, Flaherty S, Mathews C. (1997) Review: Detection of chromosomes and estimation of aneuploidy in human sperm using fluorescence in-situ hybridization. Mol Hum Reprod, 3: 585-598.

Estop A, Cieply K, Varn Kirk V. Munne' S, Garver K. (1991) Cytogenetic studies in human sperm. Hum Genet, $87 ; 447-451$.

Estop A, Marquez C, Munne" S, Navarro J, Cieply K, Van Kirk V, Martorell M, Benet J, Templado C, (1995) An analysis of human sperm chromosome breakpoints. Am w Hum Genet, 56: 452-460.

Goldman A, Hulten M. (1993a) Meilotic analysis by FISH of human male $46, X Y, t(15,20)(c 11.2 ;, q 11.2)$ translocation heterozygote; quadrvalent configuration, orientation and first melotic segregation. Chromosoma, 102: $102 \cdot 111$.

Goldman $A_{n}$ Hulten $M_{4}$ (1993b) Anaiysis of chiasma frequency and first meiotic segregation in human male 
reciprocal translocation heterozygote, $t(1,11)(p 36.3,913.1)$, using fuorescence in situ hybridisation. Cytogenet Cell Genet, 63: 16-23.

Guttenbach M. Engel W. Schmid M, (1997) Analysis of structural and numerical chromosome tbmomalities in sperm of normal men and carriers of constitutional chromosome aberrations. $A$ review. Hum Genet 100: 1-21.

Han T. Ford J.Flaherty S, Webb G, Mathews C. (1994) A fluorescent in situ hybridization andysis of the chromosome constitution of ejaculated sperm in a $47 . X Y Y$ male. Clin Genet; $91: 20-24$.

Hook $E_{1}$ (1985) The impact of aneuploidy upon public health: mortality and morbidity associated with human chromosome abmomalities. In: Dellarco V, Voytec P, Hollaender A (eds) Aneuploidy" ethiology and mechanisms. Plenum Press, New York, pp 7-34.

Hopman A, Ramaekers F, Raap A, Beck J, Devilee P, van der Ploeg J, Vooijs G, (1988) in situ hybridization as a tool to study numerical chromosome aberrations in solid bladder tumors. Histochemistry: 89 : $307-316$.

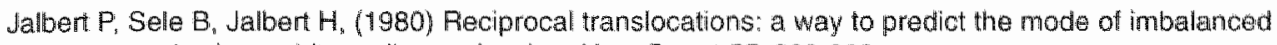
segregation by pachitene digram drawing. Hum Genet, 55 : 209-222.

Jalbert $P$, Jalbert H, Sele B, (1988) Types of imbalances in human reciprocal translocations: risks at birth. Im: Daniel A (ed) The Cytogenetics of Mammalian Autosomal Rearrangements. Alan R Liss, New York.

Lowe X, OHogan S, Moore II D, Bishop J, Wyrobek A, (1996) Aneuploid epididymal sperrm detected in chromosomally normal and Robertsonian translocation-bearing mice using a new three-chromosome FISH method, Chromosoma, 105: 204-210.

Lu $Y$, Hammit D, Zinsmeister A, Dewald G, (1994) Dual color fluorescence in situ hybridization to investigate aneuploidy in sperm from 33 normal males and a man with a $(2 ; 4 ; 8)$ (q23;q27;p21). Fertil Steril, 62: 394-399.

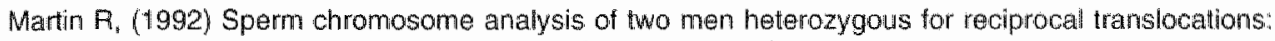
$t(1 ; 9)(q 22 ; q 31)$ and $t(16 ; 19)(q 11.1 ; q 13.3)$. Cytogenel Cell Genet $60: 18-21$.

Martin $\mathrm{A}_{\text {, Rademaker }} \mathrm{A}$, (1990) The frequency of aneuploidy among individual chromosomes in 6281 human sperm chromosome complements. Cytogenet Cell Genet, 53: 103-107.

Martin R. Rademaker A, Hildebrand K. Long-Simpson L, Peterson D, Yamamoto J, (1987) Variation in the frequency and type of sperm chromosomal abnormalities among normal men. Hum Genet, 86: $33-39$.

Martin R, Spriggs E, Ko E, Rademaker A, (1995) The relationship between paternal age, sex ratios, and aneuploidy frequencies in human sperm, as assessed by multicolor FISH. Am J Hum Genet, 57 .

Martini E, Speel E, Geraedts J "Ramaekers F, Hopman A, (1995) Application of different in-situ hybridization detection methods for human sperm analysis. Hum Reprod, 10: 855-861.

Martini E, Geraedts J, Liebaers I, Land J, Capitanio G, Ramaekers F, Hopman A, (1996) Constitution of semen samples from $X Y Y$ and $X X Y$ males as analyzed by in-situ hybridization. Hum Feprod, 11: 1638* 1643.

Martini E, Flaherty S, Swann N, Payne D, Matthews C, (1997) Analysis of unfertilized oocytes subjected to intracytoplasmic sperm injection using two rounds of fluorescence in-situ hybridization and probes to fwe chromosomes. Hum Reprod, 12: 2011-2018.

Mercier S. Morel $F_{1}$ Roux $C_{n}$ Clavequin M. Bresson J, (1996) Analysis of the sex chromosomal equipment in spermatozoa of a 47, XYY male using two-colour FISH. Mol Hum Reprod, 2: 485-488.

Mercier S, Bresson J, (1997) Analysis of chromosomal equipment in spermatozoa of a $46, X Y, 4 / 4, X Y /+8$ male by means of multicolor fuorescent in situ hybridization: contirmation of a mosaicism and evaluation of risk for offspring. Hum Genet, $99: 42 \times 46$.

Rousseaux $S_{\text {, }}$ Chevret $E_{\text {. }}(1995)$ In-vitro decondensation of human spermatozoa for fluorescence in-situ hybridization. Mol Hum Reprod, 1: 2209-2213.

Rousseaux S, Chevret E, Monteil M, Cozzi J, Pelletier R, Devillard F, Lespinasse J, Sele B, (1995) Meiotic segregation in males heterozygote for reciprocal translocations: analysis of sperm nuclei by two and triple collour fluorescence in situ hybridization. Cytogenet Cell Genet, $71: 240-246$.

Spriggs E, Martin A, (1994) Analysis of segregation in a human male reciprocal translacation carrier. $1(1 ; 11)($ (a) 36.3.q13.1), by two colour fluorescence in situ hybridization. Mol Reprod Dev, 38: $247-250$.

Sybenga w, Fickards $G$. (1987) The orientation of multivalents at meiotic metaphase l: a workshop report. Genome, 29:621-620.

Tokino T, Takahashi E, Mori M, Tanigami A, GlaserT, Park J, Jones C, Hori T, Nakiamura Y, (1991) Isolation and mapping of 62 new RFLP markers on human chromosome 11. Am J Hum Genet, 48: 259268 .

Van Hummelen P, Lowe X. Wyrobek A, (1996) Simultaneous detection of structural and numenical chromosome abnormalities in sperm of healthy men by multicolor fluorescence in situ hybridization. Hum Genet, 98: 608-615.

Vauhkoen $A_{\text {, Sankila }} \mathrm{E}_{\text {: Simola }} \mathrm{K}$, de la Chapelle $\mathrm{A}_{\text {, }}$ (1985) Segregation and fertility analysis in an àutosomal reciprocal translocation $1(1 ; 8)(q 41 ; q 23$. 1). Am J Hum Genet, 37: 533-539.

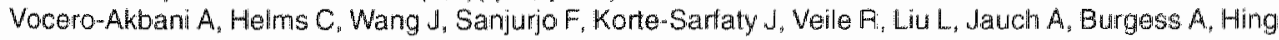




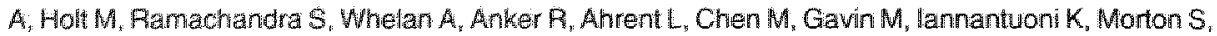
Pandit S, Read C. Strinbrueck T, Warhick $C_{n}$ Smoller D, Donis-Keller H. (1996) Mapping human telomere regions with $\mathrm{YAC}$ and $\mathrm{P} 1$ clones: chromosome-specific markers for 27 telomeres including 149 STSs and 24 polymorphisms for 14 proteminal regions. Genomics, 36: 492-506.

WHO Laboratory Manual lor the Examination of Human Semen and sperm-Cervical Mucus Interaction. (1992) $3 \mathrm{rd}$ edn. The Press Syndicate of the University of Cambridge, Cambridge.

Willard $H$, Smith $K$, Sutherland $d,(1983)$ Isolation and characterisation of a major tandem repeat family from the human X chromosome. Nucl Acid Res, 19: 3237-3241.

Willekens $C_{i}$ Poumen $F_{i}$ Van Elsanker-Niele $A_{i}$ Welland $H$, Vemey-Keers $C$, Van Kriekens $J$, De DieSmulders C, Hamers G, Wass-Pelters G. (1994) Human Parvovirus B19 infection and unbalanced transtoctation in a case of hydrops fetalis. Prenatal Diagnosis, 14:181-185.

Wyrobek $A_{,}$, Robbins $W_{s}$ Menraein $Y$, Pinkel $D$, Weler $H_{5}(1994)$ Detection of sex chromosomal aneuploidies $X-X, Y-Y$ and $X-Y$ in human sperm using two-chromosome fluorescence in situ hybridization. Am JHum Genet, $53: 1-7$. 

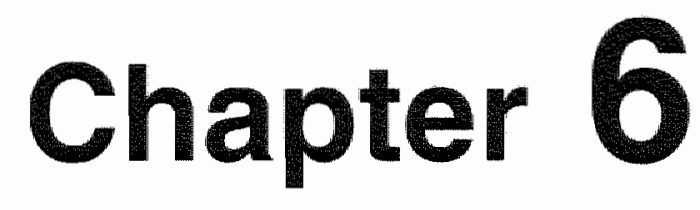

\section{Analysis of unfertilized ICSI oocytes using two rounds of FISH and probes to five chromosomes}

Elena Martini, Sean P. Flaherty, Nicholas J. Swann, Dianna Payne and Colin D. Matthews 


\section{Abstract}

Chromosomal aberrations are the maior cause of pre- and post- implantation embryo wastage and some studies suggest that half of all human concepti have a chromosomal abnormality. Analysis of gametes provides information on the origin of these chromosomal aberrations. The purpose of this study was to develop a reliable multi-probe FISH procedure that would enable us to investigate aneuploidy in unfertilized ICSI oocytes. Oocytes were spread with $\mathrm{HCl}$ and Tween 20 solution, and then two rounds of triple-probe FISH were performed on each oocyte using directly-labelled centromeric probes: (I) chromosomes $1,7,15$ (overnight hybridization); (II) chromosomes $1, X, Y$ (2 h hybridization). After the first round, the slides were counterstained and evaluated, and the positions of FISH signals were recorded. For the second round, the counterstain was removed and the second probe cocktail was applied. The chromosome 1 probe was an internal control for the two hybridization procedures, while the $Y$ chromosome probe was used to detect sperm DNA. To evaluate the method, a total of 79 oocytes from 27 patients were studied. Of these, $67(85 \%)$ were successfully spread and $97 \%$ of these oocytes exhibited discernibie FISH signals. Upon lysis, oocytes exhibited one or more DNA fragments (mean 1.9, range $1-3)$. Of the 65 analysable oocytes, $17(26.2 \%)$ displayed a normal haploid chromosome constitution with paired spots for the two chromatids. A further 23 oocytes ( $35.4 \%)$ showed an ambiguous chromosome complement due to an abnormal number of DNA fragments which may have resulted from loss of DNA during spreading or to an abnormal oocyte, while 25 oocytes ( $38.4 \%$ ) displayed aneuploidy for one or more of the chromosomes studied. In conclusion, this new approach is a quick and efficient method with which numerical chromosomal abnormalities in human oocytes can be studied, although interpretation of the patterns of DNA fragments and FISH signals requires further clarification.

\section{Introduction}

Aneuploidy has been observed for almost every chromosome in human spontaneous abortions (Hassold et al., 1980), whereas in human live born infants, aneuploidy is generally only seen for chromosomes 13,18 and 21 and the sex chromosomes (De Grouchy and Turleau, 1984). Some estimates suggest that up to $50 \%$ of all human concepti have a chromosomal abnomality (Boue ef al., 1975), and chromosomal aberrations which arise during gametogenesis and early embryonic development play a significant role in foetal loss (Chard, 1991). The introduction of in-vitro fertilization (IVF) has made it possible to study meiotic and mitolic errors during oogenesis, spermatogenesis, fertilization and early embryogenesis and assess the contribution of these errors to chromosomal abnormalithes in embryos and foetuses.

Many chromosome studies on human gametes have been performed by karyotyping, a technique which is considered by many to be the gold standard. Chromosomal abnormalities in human oocytes have been studied by karyotyping (Martin et al., 1991; Edirisinghe et al., 1992; Angell et al., 1993; Angell, 1994; Roberts and O'Neill, 1995) and it has been suggested that a high proportion of human oocytes $(25-30 \%)$ are chromosomally abnormal (Plachot et al., 1988; Benkhalifa et al., 1990; Pellestor, 1991b). The two main difficulties encountered while studying chromosomes in human oocytes are first, the scarcity of oocytes, and second, the unusual, condensed nature of the chromatids on the metaphase II spindle (Pellestor, 1991b). The condition of the chromatids hampered reliable analysis by karyotyping and necessitated the introduction of a modified protocol based on Tarkowski (1966) to spread the chromosomes. This method uses methanol:acetic acid (3:1) fixation and has major drawbacks such as loss of cells and/or loss of morphology, which reduces 
the efficiency, reliability and reproducibility. This is a great disadvantage in the study of aneuploidy, where the results must be reliable and accurate.

In recent years, fluorescence in-situ hybridization $(\mathrm{FISH})$ has also been used to study chromosomes in human gametes. FISH has been used on biopsied blastomeres and polar bodies for pre-implantation genetic diagnosis (PGD) of $X$-linked diseases and aneuploidy (Griffin et al., 1992; Harper et al., 1994; Veiga et al., 1994; Munné et al."1995), as well as to study early embryogenesis (Benkhalifa el al., 1993; Munné of al., 1994b; Muggleton-Harris et al., 1995; Sultan et al., 1995). FISH has also been used to imvestigate aneuploidy in sperm from healthy donors and infertility patients (reviewed by Downie of al., 1997) and in the study of oocytes (Benkhailia et al., 1996; Dyban et al., 1996; Wall et al., 1996).

Coonen et al. (1994) presented an alternative method for preparing and isolating interphase nuclei from pre-implantation embryos using $\mathrm{HCl}$ and Tween 20 which offers high reproducibility, good cellular morphology and a high FISH efficiency (Coonen et al., 1994; Harper et al., 1994; Muggleton-Harris et al, 1995).

Since its introduction in 1992 (Palermo et al., 1992), intracytoplasmic sperm injection (ICSI) has revolutionized the treatment of male factor infertility. However, the overall fertilization rate is only $60-70 \%$ and so a considerable number of oocytes are potentially wasted. Flaherty et al. (1995) documented that $82 \%$ of unfertilized ICSI oocytes were still at metaphase II and the majority $(7 \| \%)$ of these contained a swollen sperm head, indicating that fertilization failure was due to defective oocyte activation and not to the injection technique. Similar results were obtained by Dozortsev et al. (1994), Sousa and Tesarik (1994), and Wall et al., (1996). Furthermore, it has been shown that these injected but unactivated oocytes can be activated using calcium ionophore (Tesarik and Sousa, 1995) or sperm extracts (Palermo et al., 1997) and in many cases this resulted in development of pronuclei. The safety of this approach has not been proven and it would be imprudent to use this procedure clinically until the safety of the method has been has been properly assessed. The aim of this study was to develop and assess a reliable FISH method for studying chromosomal anomalies in unfertilized, metaphase II ICSI oocytes. We used the spreading technique of Coonen et al. (1994) and a novel FISH procedure involving two tripleprobe hybridizations to enable a larger number of chromosomes to be studied. Directlylabeiled centromeric probes for chromosomes $1,7,15, X$ and $Y$ were used. The chromosome 1 probe was included in both rounds as an internal control for the speciricity, senst tivity and efficiency of the FISH procedure.

\section{Materials and Methods}

Source of oocytes

Unfertilized oocytes were obtained from 27 couples undergoing ICSI in the Reproductive Medicine Units at The Queen Elizabeth Hospital and Waketield Clinic. The study was approved by the Ethics of Human Research Committee at The Queen Elizabeth Hospital. Our protocols for patient selection, ovarian stimulation, collection and preparation of sperm and oocytes, and ICSI have been described by Payne et al. (1991; 1994) and Payne and Matthews (1995). Of the 343 oocytes recovered from the 27 patients (mean age: 31.3 ; range: $21.3-40.8) 263$ were inseminated and $147(56 \%)$ fertilised normally. The oocyles used in this study $(n=79)$ had all been injected with a spermatozoon, but failed to show any evidence of fertilization when examined $17 \mathrm{~h}$ post-injection using differential interference contrast (DIC) optics. They all possessed a first polar body (PB) or a fragmented PB. 


\section{Spreading of oocytes}

Oocytes were spread about $1-2 \mathrm{~h}$ after the fertilization check (18-20 $\mathrm{h}$ post-injection) using the method developed by Coonen et al. (1994). Using a fine glass pipette, oocytes were transferred in a minimal volume of culture medium to microdrops $(1-2 \mu l)$ of $0.01 \mathrm{~N} \mathrm{HCl}$ and $0.1 \%$ Tween 20 in bi-distilled water on Super Starfrost Plus slides (Maenzel Glaeser ${ }^{(2)}$, Germany). The spreading solution caused the zona pellucida to dissolve, the oolemma to Iyse immediately, and the cytoplasm to dissolve, leaving intact the metaphase II DNA of the oocyte and, if present, the DNA of the first PB. Once all the cytoplasm had been removed by gently adding fresh spreading solution, the individual DNA fragments remained attached to the slide. During the whole procedure, oocytes were watched constantly using an inverted microscope (Figure 2a-c). Photographs were taken using Fujichrome 400 ASA Sensia film. Slides were subsequently air dried, washed with phosphate buffered saline (PBS, $\mathrm{pH} 7.0$ ) for 3 min and dehydrated through an ascending ethanol series. Slides were stored at room temperature (RT) up to one week or processed immediately for FISH.

\section{DNA probes}

Five centromeric probes were used: (i) pUCC 1.77 (satellite III, insert size $1.77 \mathrm{~kb}$ ), specific for the centromeric region of human chromosome 1 (Cooke and Hindley, 1979); (ii) $\mathrm{p} 7 \mathrm{t1}$ (alphoid, insert size $0.68 \mathrm{~kb}$ ), recognises a tandem repeat in the centromeric region of human chromosome 7 (Waye et al, 1987); (iii) pBam X5 (alphoid, insert size $2.0 \mathrm{~kb}$ ), specific for the centromeric region of human chromosome $X$ (Willard et al., 1983); (iv) DYZ1 (satellite II, insert size $2.1 \mathrm{~kb}$ ), specific for the long arm of human $Y$ chromosome (Cooke et al. 1982); and CEP15, a human chromosome 15 probe labelled with Spectrum Orange ${ }^{\circledR(B)}$ (Vysis, Downers Grove, IL, USA). Probes other than CEP15 were labelled by nick translation with either FITC-12-dUTP (Boehringer Mannheim, Mannheim, Germany) or TRITC-4-dUTP (Amersham International plc, Buckinghamshire, UK). Probes were dissolved in hybridization mixture (60\% formamide [FA], $2 \times$ SSC buffer) and used at a final concentration of $1 \mathrm{ng} / \mu \mathrm{l}$ in hybridization solution ( $60 \% \mathrm{FA}, 2 \times \mathrm{SSC}, 10 \%$ dextran sulfate, tRNA, SSDNA).

\section{FISH protocol}

Two rounds of FISH were applied to each oocyte. The first round used a probe cocktail for chromosomes 1,7 and 15. After screening, evaluation and recording of the slides, the second round was performed with a probe cocktail for chromosomes $1, X$ and $Y$. The human chromosome 1 probe was used as an internal control for FISH efficiency, sensitivity and specificity, while the $Y$-chromosome probe was used as a control for sperm DNA. Slides were pretreated using a protocol adapted from Harper et al. (1994). Briefly, they were treated with pepsin $(100 \mu \mathrm{g} / \mathrm{ml})$ in $0.01 \mathrm{~N} \mathrm{HCl}$ for $15 \mathrm{~min}$ at $37^{\circ} \mathrm{C}$ to remove any remnants of cytoplasm and make the nuclei accessible to the probes. The slides were rinsed twice in bi-distilled water, followed by PBS, then fixed in $1 \%$ paraformaldehyde in PBS for 5 min at $4^{\circ} \mathrm{C}$. After fixation, the slides were rinsed twice in PBS followed by one rinse in bi-distilled water, and dehydrated through an ethanol series. Ten $\mu$ l of hybridization mixture containing the first 3 probes (1-FITC and 1-TRITC, 7-FITC and 15-Spectrum Orange ${ }^{(2)}$ was added to the slide and sealed under a coverslip. The nuclear and probe DNA were denatured simultaneously for $3 \mathrm{~min}$ at $72^{\circ} \mathrm{C}$, then incubated overnight in a moist chamber at $37^{\circ} \mathrm{C}$. After hybridization, the slides were washed twice in $2 \times \mathrm{SSC}, 0.05 \%$ Tween 20 for $5 \mathrm{~min}$ at $42^{\circ} \mathrm{C}$, then twice in $0.1 \times \mathrm{SSC}$ for $5 \mathrm{~min}$ at $60^{\circ} \mathrm{C}$, twice in $4 \times \mathrm{SSC}$, $0.05 \%$ Tween 20 for 5 min at RT, then dehydrated through an ethanol series and mounted in Vectashield antifade (Vector laboratories, Burlingame, CA, USA) containing $0.01 \mu \mathrm{g} / \mathrm{ml}$ 
4,6-diamidino-2-phenylindole (DAPI) to counterstain the DNA.

Slides were examined using an Olympus Vanox-AHBT3 fluorescence microscope equipped with a triple band-pass filter. After analysis and recording of results from the first FISH round, and on the same day, DAPI was removed with two washes in $4 \times \mathrm{SSC}, 0.05 \%$ Tween 20 for $5 \mathrm{~min}$ at RT. The slides were dehydrated, and the probes for the second FISH round were applied (1-FITC and 1-TRITC, X-FITC and Y-TRITC). A coverslip was sealed on the slide, and the denaturation and hybridization steps were performed as described for the first round, except that hybridization proceeded for only $2 \mathrm{~h}$ at $37^{\circ} \mathrm{C}$. The slides were washed as described above but with only one $5 \mathrm{~min}$ wash at each step, then they were counterstained with DAPI and analysed. Photographs were taken using Fuji 400 ASA film (Figure 2d-i).

\section{Evaluation and scoring criteria}

The specificity of each FISH probe was tested concurrently on interphase nuclei obtained from ethanol-fixed suspensions of male leucocytes. Using the conditions described above. the hybridization efficiency was optimal and there was only limited non-specific binding. Analysis of the FISH signals was performed according to the criteria set by Hopman et al. (1988) and adapted by Munné et al. (1995). Minor hybridization spots that had much lower fluorescence intensity were not scored, and spots found in close proximity to one another, interconnected or in paired arrangements, were counted as one signal. Minor hybridization spots were considered to be cross-hybridization to non-target chromosomes, while paired arrangements were interpreted as sister chromatids or split signals. Due to the compact nature of the DNA, we considered the occurrence of two single spots for a chromosome to be disomy anly if a single signal was present for the other chromosomes. The opposite situation in which all the chromosomes examined showed two signals except one, was interpreted as monosomy for the latter chromosome.

\section{Results}

Efficiency of the protocol

79 of the unfertilized oocytes were used for this study. Twelve were lost during the spreading procedure and 67 were successfully spread and fixed onto clean slides, giving a spreading efficiency of $84.8 \%$. After the first FISH round, 2 of the 67 cells were unanalysable due to the presence of cytoplasmic remnants covering the DNA, but the remaining 65 oocytes were analysed successfully in both FISH rounds. The overall FISH efficiency was $97.0 \%$. The signals for chromosome 1 were identical in both FISH rounds for every oocyte (Figure 2d-ii).

\section{FISH results}

Oocytes exhibited one or more DNA fragments and were categorised into three groups based on the pattern of DNA and the number and arranglement of hybridization signals (Figure 1).

Group 1 consisted of 17 oocytes (26.2\%) which displayed two DNA fragments and a normal haploid chromosomal constitution with paired spots for the two chromatids of each univalent chromosome, except the Y chromosome if present (Munné et al., 1995; Wall et al., 1996) (Figure 1). A normal metaphase ll oocyte has a single univalent chromosome from each pair, and all the chromosomes should appear as two close spots representing the two chromatids; the same pattern should occur in the first PB, both in interphase and metaphase (Figure 1, patterns i-ii; Figure 2d,e). 
FISH on Unfertilized MII Oocytes

\section{Groupl}

Nont haplotid chiromosom constitutut on

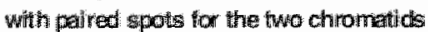
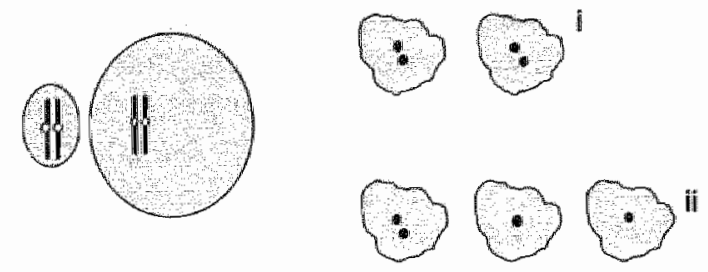

\section{Group II}

Ambiguous chromosome constitution due to incorrect number of DNA fragments

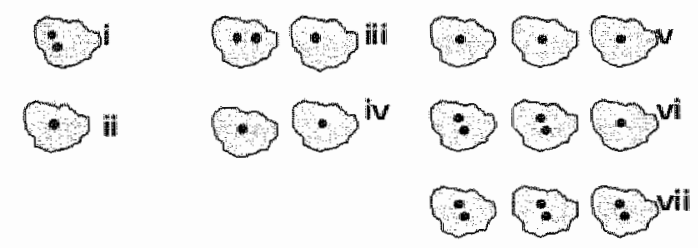

\section{Group III}

Aneuploid chromosome constitution
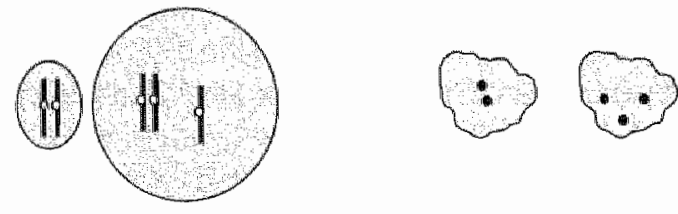

Figure 1. Classification of oocytes into groups in relation to DNA paltems and hybridization results. The different pattern(s) of DNA fragments and signals in group I. II and III oocytes are shown. Subgroups are shown individually (groupl: I and il; group 1:: I-vii) and each spot repiesents one signal for a given chromatid.

Group II consisted of 23 oocytes (35.4\%) which displayed an ambiguous chromosome complement due to an abnormal number of DNA fragments (Figure 1, categories i-vii). These oocytes lysed into one to three DNA fragments (mean 1.9, range 1-3), which probably represents artefactual loss or breakage of the DNA or unidentified sperm DNA. These oocytes displayed either paired signals, indicating normal, univalent metaphase II chro- 
mosomes, or only one small spot which was interpreted as a single chromatid signal, or a combination of the two patterns (Figure 1, pattems i-vil, group II). Nonetheless, each DNA fragment exhibited paired or single signals for all the chromosomes analyzed without any aneuploidy. Some of these fragments might have been disrupted PB or metaphase II DNA in which a pre-division of the chromatids had begun (Angell, 1994) (Figure 2f,g).

Group III consisted of 25 aocytes $(38.4 \%$ which exhibited aneuploidy for one or more of the chromosomes studied, regardless of the number of DNA fragments present (Figure 1; Figure $2 \mathrm{~h}, \mathrm{i})$. Interestingly, a heterogenous chromosome constitution was lound in this group. and it was possible to relate aneuploidy to the DNA fragment patterns of Groups I and II. We found that $47 \%$ of the oocytes which had a normal DNA pattern (two fragments, from the metaphase II and PB, equivalent to Group I) were aneuploid, while $74 \%$ of the oocytes with one to three DNA fragments (equivalent to Group II) were aneuploid. The relative frequency of hyperhaploidy and hypohaploidy for chromosomes $1,7,15$ and $X$ is pre. sented in Table 1. Hypohaploidy for chromosome $X$ and hyperhaploidy for chromosome 1 were common.

Table 1. Number of oocytes with single chromatid hyperhaploidy and hypohaploidy.

\begin{tabular}{cccc}
\hline Chromosome & Hyperhaploidy & Hypohaploidy & Total chromatids \\
\hline 1 & 11 & - & 221 \\
7 & 3 & 3 & 209 \\
15 & 3 & 3 & 193 \\
$x$ & 1 & 16 & 192 \\
\hline
\end{tabular}

An undecondensed sperm head was seen in 10 oocytes, although a $Y$ signall was present in only 3 of these oocytes. This low frequency might have been due to limited decondensation of sperm DNA (Martini et al., 1995) which hampers efficient hybridization, or to the unrecognized presence of sperm DNA (carrying lor example a single set of chromatids and the $X$-chromosome) which was misclassified into group Il.

\section{Discussion}

About $60 \%$ of oocytes owulated in women over 40 years of age may be chromosomally unbalanced (Hassold and Jacobs, 1984). Plachot et al (1988) found an increasing rate of aneuploidy in oocytes from women $>35$ years, whereas Eichenlaub-Ritter el al. (1988) reported similar rates of anomalies in oocytes from young $(<35$ years) and older $(35-39$ years) women. There is evidence that predisposition to non-disjunction (NDل) is corre. lated to a shortened cell cycle in oocytes from aged female mice (Eichenlaub Ritter and Boll, 1989). At a molecular level, these alterations in maturation could result from disturbances in protein phosphorylation and alleration in the phosphorylated status and activity of the catalytic subunit of maturation promoting factor (MPF) (Choi et al. 1991). The high rate of chromosomal abnomalities in oocytes might be explained by two hypotheses, the first that abnormalities are triggered by exogenous homone induced-ovulation, and the second that in-vitro ageing of oocytes induces spindle instability and a subsequent loss or scattering of chromosomes. To date, no evidence has been obtained for the first hypothesis (Pellestor, 1991 b; Edirisinghe et al, 1992), and the second one has also been ques. tioned (Pellestor, 1991a; Roberts and O'Neill, 1995; Macas et al., 1996). Nevertheless, it should be kept in mind that anomalies in metaphase 11 oocytes contribute to aneuploidy at later cleavage stages. 

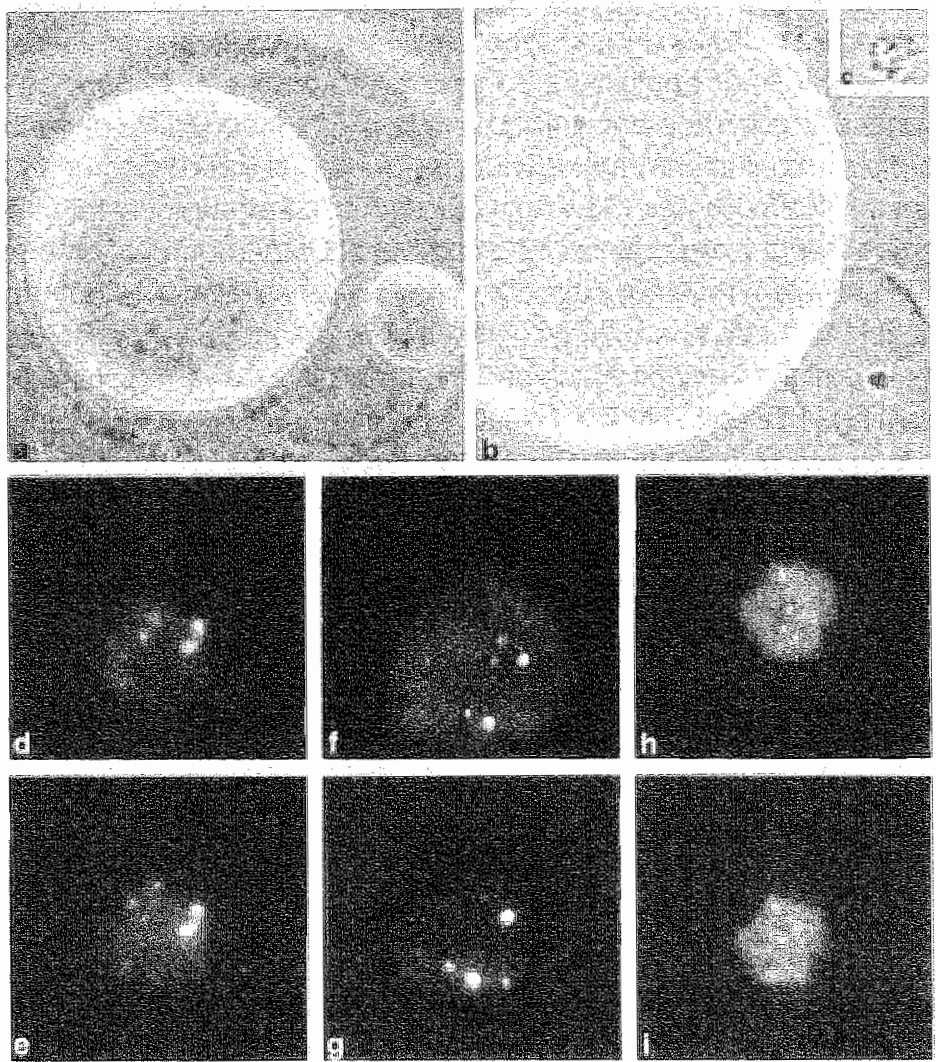

Figure 2. Spreading of the oocyte (a-c): (a) Oocyte with first polar body (PB) and no pronuclei. At the beginning of spreading, the oolemma is still presemt. (b) Lysis of the PB, the DNA is visible. (c) Isolated metaphase DNA. FISH results (d-i): Directly labelled probes for chromosome 1 (yellow), 7 (green), 15 (red) in the first FISH round (d, $f, h$ ), and chromosome 1 (yellow) and $X$ (green) in the second FISH round ( $(\mathrm{g}, \mathrm{g}, \mathrm{l})$, hybridized to DNA (blue) of unfertilized $\| \mathrm{CSH}$ oocytes. First and second FISH rounds respectively on the same DNA (d,e): In (d) signals for the chromatids are close to each other, representing dyads. In (e), the X-chromosome is clearly distinguishable from the remnants of the first hybridization. The signals for chromosome are at the same location as in the first round. First and second FISH rounds respectively on the same DNA $(f, g)$ : Example of predivision of the dyads. The chromatids are cllearly separated from ach other in (f) and are almost at opposite poles. In (g), the $X$ chromatids are at the same pole. First and second FISH rounds respectiwely on the same DNA $(h, i)$ : Example of aneuploidy for all the chromosomes analyzed. in (h) three chromatids of chromosome 1 are visible, three for chromosme 7 and four for chromosame 15 . In (i), three chromatids for chromosome 1 are evident and four copies of chromosome $X$. For colour illustration see page 118.

Angell et al. (1993) studied human oocytes by karyotyping and reported that the major type of chromosomal abnormality was single chromatids replacing whole chromosomes. This suggests that precocious division (pre-division) of a chromosome univalent during the first meiotic division might be the most common mechanism of trisomy formation, and not NDJ of whole bivalents as generally believed. Paired chromosome signals corresponding to the expected metaphase II pattern were reported in FISH studies on human oocytes 
(Benkhalifa el al, 1996; Dyban et al, 1996; Wall et al, 1996), but only single probe FiSH was applied to a small number of oocytes ir these studies.

In the present study, we applied a mutti-probe FISH procedure 1065 oocytes which had been spread using the improved method of Coonen ef al (1994). A combination of 5 different chromosome probes gave a good insight into the genelic constitution of these oocytes. We found that the paired signals for a chromosome were not always tightly adjoined and, in mary cases, one signal was quite distant from the other (Figure $2 \mathrm{~d}, \mathrm{e})$. We scored a pair of similar signals as one chromosome complement and estimated the number of chromatids in accordance with the number of individual stgnals. Palred chromosome signals reflect the unique nature of the oocyte's chromosomes at this stage of the second meiotic division; highly contracted, with sister chromatids widely separated and loosely adjoined in the centromeric region (Dyban et al., 1996).

Two biological events might influence the interpretation of FISH signals in oocytes. First, it has been suggested that pre-division of dyads into two single chromatids is a frequent phenomenon prior to the first meiotic division (Angell, 1991; Angell el al., 1994; Munne ef al. 1995; Dyban et al., 1996). In this case, two discrete signals for a chromosome would be observed instead of two conjoined signals (Figure 2f,g). However, this interpretation might be ambiguous due to pre-division of the chromatids before metaphase lor overlap of the signals for the two chromatids (Munne et al., 1995). Second, chromatid overlap would produce a dyad with only a single hybridization signal instead of a pair. Munné et al. (1995) presented preliminary results which showed that when the DNA in the first PB was very condensed, all the chromosome-specific signals appeared as single signals instead of as paired signals. In this study, we applied the same scoring criteria as Munne at al. (1995) and scored a DNA fragment with single signals as normal, because the probability of having a monosomy for all 5 chromosomes due to pre-division of all the chromatids is remote ('Munné et al, 1995).

The results for Group II oocytes (35.4\%) were difficult to interpret because the chromosome constitution appeared to be haploid, and either dyads or single chromatids were present, however, the number of DNA fragments was inconsistent with the expected number that should derive from the first PB and the metaphase III DNA. We found a sub-group containing only one DNA fragment which may have been due to artefactual Ioss of DNA during spreading. However, another sub-group contained three DNA fragrnents, which might indicate an unrecognised decondensed sperm head, fragmented PB DNA or a potentially polyploid oogonium.

The inclusion of a $Y$ chromosome probe to detect Sperm DNA was olless use uhan expected. Sperm heads were recognised in 10 oocytes; 3 displayed a signal tor the $Y$ chro. mosome, but the sperm head was undecondensed in the other 7 oocytes which would have hindered efficient hybridization of the $Y$ probe (Martini ef al, 1995). Moreover, decondensed sperm heads which yielded hybridization signals (single chromatids), but were $X$-bearing, might not hawe been recognised as such and consequently those oocytes could have been misclassified as Group 11 oocytes. Schmialy et al. (1996) recently reponted a variable degree of chromosome condensation during premature chromosome condensation (PCC) of the sperm nucleus in unfertilized ICSI oocytes, and the occurrence and variation in sperm PCC might influence the rate of misclassification of sperm nuclei as oocyte DNA.

Considering that fertilization failure after ICSI is typically associated with a complete failure of oocyte activation, rather than with incomplete activation or premature initiation of the block to polyspermy (Dozortsev et al, 1994; Sousa and Tesarik, 1994; Faherty etal., 1995), there might be a genetic imbalance in some oocytes which predisposes them to 
this maturation arrest. DNA repair systems are least effective in dealing with chromosome imbalances in the resting stage of meiric oocytes (Ashwood-Smith and Edwards, 1996). The most common anomaly in human oocytes is disomy or nulisomy for various chromosomes, and this probably arises during the first meiotic division (Angell et al, 1994; Griffin, 1996). The presence of a univalent chromosome can affect the alignment and segregation of other chromosomes in the complement (Hunt et al, 1995), presenting an increased risk of NDJ, aneuploidy and trisomy in an embryo (Hassold and Jacobs, 1984; Soewarto el al., 1995). Indeed, we found oocytes in which some of the chromatids were a considerable distance apart and this might represent the beginning of anaphase lag or pre division of dyads that could lead to an abnormal separation of the chromatids and consequently to arieuploidy (Angell et al., 1994).

The high level of chromosome $X$ hypohaploidy found in this study (Table 1) can be explained by one or more of the following theories. First, the use of FISH enables one to identify chromosome-specific aneuploidies, whereas karyotyping mostly classify aneuploidy using the broad Denver classification which does not allow classification of chromosome-specific aneuploidies. For example the high rate of chromosome $X$ hypohaploidy we report might correspond to the hypohaploidy rate reported for group $C$ chromosomes by karyotyping (Macas et al., 1990; Martin et al., 1991, Pellestor et al., 1991b; Roberts and O'Neill, 1995). Second, our sample population might not have been representative of the general gamete population. Third, pre-division of chromatids and subsequent loss of DNA material increases with time in culture and has been proposed as a major mechanism of aneuploidy by Dailey et al., (1996). Finally, we cannot exclude loss of chromatids due to technical artifact, although if this were to occur it should be equal for all the chromosomes analysed and not specific for the X chromosome. On the other hand, the high frequency of hyperhaploidy for chromosome 1 is surprising, since this is the only chromosome that has not been observed as a trisomy in spontaneous abortions. However, trisomy 1 has been observed in an 8-cell human pre-embryo (Watt er al, 1987) and it is therefore possible that trisomy 1 is common in human conceptuses but they are lost at an early pre-implantation stage.

The fact that we found a higher percentage of aneuploid cells $(38.4 \%)$ compared to karyotype studies (25-30\%), (Plachot et al., 1988; Benkhalifa et al, 1990; Pellestor, 1991b) might be due to the small number of oocytes we analysed, but it might also more accurately reflect the true situation. The spreading technique we used enabled us to analyse a very high percentage (85\%) of the oocytes, and FISH on interphase and metaphase cells is more sensitive and more efficient than karyotyping because the DNA probes used for FISH are chromosome-specific. In contrast, only about half of the oocytes karyotyped prior to 1991 yielded results, and in those, very few chromosome-specific aneuploidies were identified (Pellestor, 1991a). Aly additional limitation of karyotyping is that the arrangement and morphology of the chromosomes is critical for obtaining a diagnosis, and many oocytes do not meet these criteria and therefore remain unanalysed even though they were not lost during spreading. The protocol used in this study gave high spreading and FISH efficiencies and enabled us to simultaneously investigate up to six different chromosomes in each oocyte.

Like all techniques, however, there are limitations to the approach used in this study. For instance, spreading and FISH always encompass a risk of losing the oocyte, although this is the same with any technique. The identification of two "spots" in an oocyte is not as reassuring as the clear identification of two chromosomes by cytogenetic analysis, nor can FISH results easily be verified. Perhaps a combination of the two techniques, FISH on previously karyotyped oocytes (Wall et al, 1996) would provide more accurate verification 
of results in individual oocytes. It would also be helpful to be able lo identify, with centainty: whether a particular DNA fragment onginated trom the metaphase ll chromosomes of the oocyte, the first $\mathrm{PB}$, or a decondensed spem head. This would clarify the dilemma we encountered with Group II oocytes. Further studies will help to clarify the stringent scoring criteria needed to achieve this and to correctly distinguish between paired and single chromatids. It is unrealistic to think that this FISH procedure will ever provide error-free estimation of aneuploidy in oocytes, however, it is much quicker and easier lo perform than karyotyping, and it enables rapid and reliable accumulation of information about the chromosome constitution of large numbers of human oocyles.

\section{Acknowledgments}

We would like to thank the patients, laboratory staff, clinical staff and nursing staff of the Reproductive Medicine Units at The Queen Elizabeth Hospital and Wakefield Clinic for participating and/or assisting with this study. We would also like to thank Graham Webb. Edith Coonen and Maurice Jansen for technical assistance and Prof. Dr. J. Geraedis for his aritical appraisal of the manuscript. This study was supported by the Dutch "Praeventiefonds", and by two grants to E. Martini, a joint grant from the Netherlands Organisation for Scientific Research and Australtan Research Council (NWO-ARC) and an EC grant (ERB4001GT955293).

\section{References}

Angell $F$, (1991) Predivision in human oocytes at meiosis 1: a mechanism for trisomy formiation in man. Hum Genet, 86, 383-387.

Angell $\mathrm{R}$, (1994) Possible pitfalls in preimplantation diagnosis of chromosomaldisorders based on polar body analysis. Hum Reprod, $9,181-182$.

Angell R, Xian J, Keith J, (1993) Chromosome anomalies in human oocytes in relation to age. Hum Reprod, $8,1047-1054$.

Angell $R$, Xian J, Keith J, Ledger W, Baird $D_{3}(1994)$ First meiotic division abnormalities in human oocytes: mechanism of trisomy formation. Cytogenet Cell Genet, 65, 194-202.

Ashwood-Smith M, Edwards R, (1996) DNA repair by oocytes. Hurn Reprod, 11, 46-51

Benkhalifa D. Geneix A, Janny L, Boucher D, Malel P, (1990) Chromosome aborrations in human oocytes. Fifth Intermational Congress on Early Fetal Diagnosis.

Benkihalifa M, Janny L, Vye P. Malet $P$, Boucher P, Menezo Y, (1993) Assessment of polyploidy in humen morulae and blastocysts using co-culture and fluorescent in-situ hybridization. Hum Rioprod, 8, 895. 902.

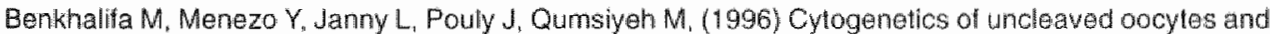
arrested zygotes in IVF programs. I Assist Feprod Genet, 13, 140-148.

Boue J, Boue A, Lazar P. (1975) Retrospective and prospective epiderniological studies of 1500 karyolyped spontaneous human abortions. Teratology, $12,11-26$.

Chard T. (1991) Frequency of implantation and early pregnancy loss in natural cycles. In Factors of importance for implantation. (ed. M. Sepala), p. 179-182. Bailliere Tindall, London.

Choi T. Aolki F. Mori M, Yamahita M. Nagahame Y, Kohmoto $K_{\text {. }}$ (1991) Activation of p34cde2 protein kinase activity in melotic and mitotic cell cycles in mouse oocyles and embryos. Development, 113, 789-795.

Caoke H, Hindley $₫$, (1979) Cloning of the human satellite III DNA: Different components are on different chromosomes. Nucl Acid Res, 6, 3177-3179

Cooke $\mathrm{H}$, Schmidtke J, Gosden J, (1982) Characterisation of a human $Y$ chromosome repeated sequence and related sequences in higher primates. Chromosoma, $87,491-502$.

Coonen E. Dumoulin d. Ramaekers F. Hopman A. (1994) Optimal preparation of preimplantation embryo interphase nuclei for analysis by fluorescence in situ hybridization. Hum Fieprod, 9. 533-537.

Dailey T, Dale B, Cohen J, Munné S. (1996) Association between nondisjunction and maternal age in meiosis-11 human oocytes. Am J Hum Genet, 59, 176-184.

De Grouchy J, Turleau C, (1984) Clinical Atlas of human chromosomes. (ed. J.W. \& Sons), p. New York. 
Downie S, Flahery $\mathrm{S}_{\text {. Matthews }} \mathrm{C},(1997)$ Review: Detection of chromosomes and estimation of aneuploidy in human sperm using luorescence in-situ hybridization. Mol. Hum. Reprod. 3 , in press.

Dozortsev D, De Sutter P. Dhont M, (1994) Behaviour of spermatozoa in human oocytes displaying no or one pronicleus after intracytoplasmic sperm injection. Hum Reprod, 9, 2139-2144.

Dyban A, Freidine $M$, Severowa $E$, Cleslak J, Ivakhnenko $V$, Verlinsky $Y$, (1996) Detection of aneuploidy in human oocytes and corresponding first polar bodies by fluorescent in situ hybridization. I Assist Feprod Genet, $13,73-78$.

Edirisinghe W, Murch A, Yovich d. (1992) Cytogenetic analysis of human oocytes and embryos in an in-vitro fertilization programme. Hum Reprod, $7,230-236$.

Eichenlatub-Ritter U, Boll I, (1989) Nocodazole sensitivity, age-related aneuploidy and alterations in the cell cycle of maturing mouse oocytes. Cytogenet Cell Genet, 52, 170-176.

Eichenlaub-Ritter U, Stahl $A_{*}$ Luciani J (1988) The microtubular cytoskeleton and chromosomes of unfertilized human oocytes aged in witro. Hum Genet, 80, 259-264.

Flaherty S, Payne D, Swann N. Matthews C. (1995) Assessment of fertilization fallure and abnormal fertilization after intracytoplasmic sperm injection (ICSI). Feprod Fertil Dev, 7, 197-210.

Griffin, D. (1996) Incidence, origin and etiology of trisomy. Int Fev Cytol, 167, 262-296.

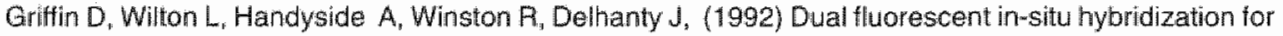
the simultaneous detection of $X$ and $Y$ chromosome specific probes for the sexing of human preimplantation embryonic nuciei. Mum Genet, 89, $18-22$.

Harpe J, Coonen E. Ramaekers, F, Delhanty J, Handyside A, Winston R, Hopman A, (1994) Identification of the sex of human preimplamtation embryos in two hours using an improved spreading method and fluorescence in situ hybridization (F/SH) using directly labelled probes. Hum Reprod, 9, 721-724.

Hassold T, Chen N, Funkhouser ل, Jooss T, Manuel B, Matsuura J, Matsuyama A, Wilson C, Yamane J, Jacobs $P$, (1980) A cytogenetic study of 1000 spontaneous abortions. Ann Hum Genet, 44, 151-164.

Hassold T, Jacobs P, (1984) Trisomy in man. Annu Rev Genet, 18, 69-97.

Hopman A. Ramaekers F, Raap A, Beck d, Devilee P, van der Ploeg J, Vooijs G, (1988), in situ hybridization as a tool to study numerical chromosome aberrations in solid bladder tumors. Histochemistry, 89 , $307-316$.

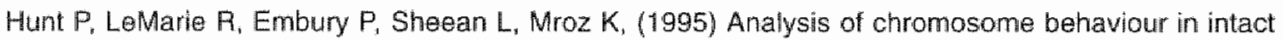
mammalian oocytes: monitoring the segregation of a univalent chromosome during female meiosis. Hum Mol Genet, 4, 2007-201:2.

Macas E, Imthurn B, Roselli M, Keller P. (1996) Chromosome analysis of single- and multipronucleated human zygotes proceeded after the intracytoplasmic sperm injection procedure. I Assist Reprod Genet, $13,345-350$.

Martin $\mathrm{R}_{2}$ Ko $E_{*}$ Rademaker A, (1991) Distribution of aneuploidy in human gametes: Comparison between human sperm and oocytes. Am I Med Genet, 39, 321-331

Martini E, Speel E, Geraedts d, Ramaekers $F$, Hopman A, (1995) Application of different in-situ hybridization detection methods for human sperm analysis. Hum Reprod, 10, 855-861.

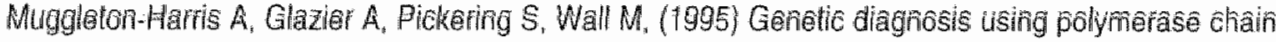
reaction and fluorescent in-situ hybridization analysis of biopsied cells from both the cleavage and blstocyst stages of ind ividual cultured human preimplantation embryos. Hum Reprod, 10, 183-192.

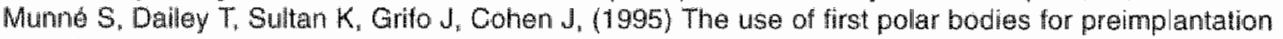
diagnosis of aneuploidy Mol Hum Reprod, 1, 1014-1020.

Munné S, Grífo J, Cohen J, Weier HH, (1994) Chromosome abnormalities in human arrested preimplantation embryos: a multiple probe FISH sludy. Am J Hum Genet, 55, 150-159.

Munné S, Sultan K. Weier H, Grifo J, Cohen J, Rosenwaks Z, (1995) Assessment of numeric abnormalities of $X, Y, 18$, and 16 chiomosomes in preimplantation human embinos before transfer. Am $J$ Obstel Gynecol, 172, 1191-1199.

Palermo G. Joris H, Devroey P, Van Steirteghem A, (1992) Pregnancies after intracytoplasmic injection of singlespermatozoon into an oocyte. Lancet, 340, 17-18.

Palermo $G$. Avrech $O$. Colombero $L$. Wu H, Wolny $Y$, Fissore R, Fosenwaks Z, (1997) Human sperm cytosolic factor triggers Caz+ oscillations and overcomes activation failure of mammalian oocytes. Mol Hum Reprod, 3, 367-374.

Payne D. Flaherty $S$, Jeffrey $A$, Warnes G, Matthews G, (1994) Succesful treatment of severe male factor infertility in 100 consecutive cycles using intracytoplasmic sperm injection (lCSI). Hum Reprod, 9 , $2051-2057$.

Payne D. Matthews $C_{n}(1995)$ Intracytoplasmic sperm injection - Clinical results from the reproductive medicine unit, Adelaide. Reprod Fertil Dev, 7, 219-227.

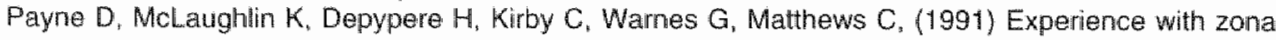
drilling and zona cutting to improve fertilization rates of human oocytes in vitro. Hum Reprod, 6, 423431. 
Pellestor F. (19919) Differential distribution of aneuploidy in human gemeles according to their 3 . Hum Reprod, 6, 1252-1258.

Pellestor F. (1991b) Frequency and distribution of aneuploidy in human female gametes. Hum Gene", 86. 283-288.

Plachot M, Veiga A, Montagut J, deGrouchy $d$, Calderon $G$, Lepretre $S$, Junca $A$, Santalo $J$, Garles $E$, Mande lbaum J, Barri P. Degoy d, Cohen J, Egozcue J, Sabatier J, Salat-Baroux J. (1988) Are clinical and biological IVF parameters correlated with chromosomal disorders in early itfe: multicentric study. Hum Reprod, 3, 627-635.

Roberts $\mathrm{C}, \mathrm{O}^{\prime}$ Neill $\mathrm{C}$. (1995) Increase in the rate of diploidy with maternal age in untertilized in-vitro fertilization aocytes. Hum Reprod, $10,2139 \mathrm{~m} 2141$.

Schmiady $H_{3}$ Tandler-Schneider A, Kentenich, H. (1996) Premature chromosome condensation of the sperm nucleus after intracytoplasimic sperm injection. Hum Reprod, $11,2239 \cdot 2245$.

Soewarto D, Schmiady H, Eichenlaub-Fitter U, (1995) Consequencesof non-extrusion of the first polar body and contral of the sequential segregation of homologues and chromatids in mammalian oocytes. Hum Reprod, 10, 2350-2360.

Sousa M, Tesarik J, (1994) Ultrastructural analysis of fertilization failure after intracytoplasmic sperm injection. Hum Reprod, 9, 2374-2380.

Sultan K, Munné S, Palermo G. Alikani M "Cohen J. (1995) Ploidy assessment of embryos derived firom single-pronucleated human zygotes obtained by regular IVF and intra-cytoplasmic sperm injection (ICSI). Hum Reprod, 10, 132-136.

Tarkowski A, (1966) An air-drying method for chromosome preparation from mouse eggs. Cytogenetics, 5 , $394-400$.

Tesarik $J_{*}$ Sousa M. (1995) More than $90 \%$ fertilization rates after intracytoplasmic sperm injaction and artificial induction of oocyle activation with calcium ionophore. Fertil Steril, 63, 343-349.

Veiga A, Santalo J, Vidal F, Calderon G, Gimenez C, Boada M, Egozcue J, Barri P. (1994) Case report: Twin pregnancy after preimplantation diagnosis for sex selection. Hum Aeprod, 9, 2156-2159.

Wall M. Marks $K_{\text {, Smith }}$, Gearon $C_{4}$ Muggleton-Harris $A_{3}$ (1996) Cytogenetic and fluorescent in-situl hybridization chromosomal studies on in-vitro fertilized and intracytoplasmic sperm injected "falledfertilized" human oocytes. Hum Reprod, $11,2230-2238$.

Watt J, Templeton A, Messinis I, Bell L, Cunningham P, Duncan $R$, (1987) Trisomy 1 in an eight cell human pre-embryo. J Med Genet, 24:60-64.

Waye J, England S, Willard H, (1987) Genomic organization of alpha satellite DNA on human chromosome 7: evidence for two distinct alphoid domains on a single chromosome. Mol Cell Biol, 7, 349.

Willard $\mathrm{H}$, Smith $K$, Sutherland $\mathrm{J}$, (1983) Isollation and characterisation of a major tandem repeat family from the human X chromosome. Nucl Acid Res, 19, 3237-3241. 



\section{Chapter 7}

\section{FISH analysis of six chromosomes in unfertilised human oocytes after polar body removal}

Elena Martini, Sean P.Flaherty, Nicholas J.Swann, Colin D.Matthews, FCS Ramaekers and Joep P.M.Geraedts 


\section{Abstract}

We recenty reported a two round, multi-probe luorescence in situ hybridization (FISH) procedure for detecting aneuploidy in human oocytes. In the present study, we have improved the technique by removing the first polar body (PB) before the cocytes were spread so that only the metaphase II chromosomes were evaluated by FISH. We also investigated whether there was an association between aneuploidy and precocious division (predivision) of chromosomal bivalents. Unfertilised oocytes which were still af metaphase II 18-20 h after insemination or intracytoplasmic sperm injection (ICSI), were treated with pronase to remove the zona pellucida and $\mathrm{PB}$ and then spread on slides using $\mathrm{HCl}$ and Tween 20. Two rounds of FISH were performed using direct-labelled probes: chromosomes $1,13,21$ (round 1); chromosomes $X, 7,18$ (round 2). Of the 63 oocytes from 18 patients (mean age: 32 years), $48(76 \%$ ) had one DNA complement as expected, $9(14 \%)$ had 2 DNA complements, $3(5 \%)$ gave incomplete FISH signals and $3(5 \%)$ were not analysable. Of the 48 oocytes with one set of DNA, $48 \%$ were haploid, $44 \%$ were aneuploid for one or more chromosomes, and $8 \%$ were polyploid. We analysed the position of the chromatids (dyad or pre-division) and found a prevalence of dyads in thaploid oocytes and an increased frequency of pre-division in aneuploid oocytes, especially for chromosome 21. This method enables analysis of multiple chromosomes in human oocytes without interference by DNA from the PB.

\section{Introduction}

The introduction of assisted reproductive techniques (ART) such as in vitro fertilization (IVF) and ICSI has madie it possible to study early events in human reproduction and the contribution of spermatogenesis, oogenesis, fertilization and early embryogenesis to the generation of chromosomal abnormalities.

Unfertilised oocytes from ART cycles are the only readily-available source of human aocytes for research. The oocytes which fail to fertilise after IVF insemination or ICSI can be used for chromosomal analysis. Various lines of evidence imply that oocyte meiosis is sensitive to endogenous or exogenous factors and that the incidence of abnormalities is correlated with female factors. For instance, women with tubal of unexplained infertility have a higher rate of oocyte chromosomal abnormalities than women whose partners are infertile (see Plachot, 1997 for review). The incidence of chromosomal aberrations in uninseminaled human oocytes has been reported to vary between $8-50 \%$ (Plachot, 1997) and the rate of chromosomaly abnormal oocytes appears to be relatively high in cases of fertilization fallure after IVF $(26.5 \%)$. Furthermore, aberrations arising de-novo from meiotic non-disjunction (NDJ), especially paternal NDJ, contribute to chromosomal abnormalities in newborns after ICSI (Plachot, 1997; Liebaers et al., 1995). Studies on metaphase II human oocytes by Angell (Angell, 1994a; Angell, 1994b; Angell, 1997) revealed an unexpected class of chromosome abnormalities which manifest as single chromatids rather than whole chromosomes comprising a dyad of chromatids. These studies also revealed a close correlation, with respect to frequency, distribution and maternal age, between oocyte data and trisomies in aborted foetuses and live newborns (Angell, 1997). Several groups have reported results from large samples of oocyte karyotypes which suggest that a high proportion of human oocytes (25-30\%) may be chromosomally abnormal (Plachotet al., 1988; Benkhalifa el al., 1990; Pellestor, 1991a; Pellestor; 1991b). The two main difficulties encountered while studying chromosomes in human oocytes are first, the scarcity of oocytes and second, the unusual, condensed nature of the chromatids on the metaphase II spindle (Pellestor, 1991a; Pellestor, 1991b). The condition of the chromatids 
has hampered reliable analysis by karyotyping and necessitated the introduction of a modified protocol based on Tarkowski (1966) to spread the chromosomes. This method however has major drawbacks such as loss of cells and/or loss of morphology, which reduces the number of analysable oocytes and compromises the efficiency and accuracy of the analysis.

We recently developed a reliable method for studying chromosomal anomalies in unfertilised, metaphase 11 oocytes using the spreading technique of Coonen et al. (1994) and a novel FISH procedure involving two triple-probe hybridisations to enable a larger number of chromosomes to be studied (Martini et al., 1997). This new approach allowed us to analyse $85 \%$ of the oocytes, compared to the $30.50 \%$ routinely obtained by karyotyping (reviewed by Plachot 1997; Angell, 1997). However, it was not always possible to differentiate between DNA from the first PB and the metaphase II chromosomes, which hindered interpretation of the results. The aim of the present study, therefore, was to bypass this problem by removal of the PB prior to spreading the oocyles so that only oocyte chromosomes were studied. Two rounds of FISH and direct-labelled probes for chromosomes $1,7,13,18,21$ and $X$ were used, enabling study of six different chromosomes in each oocyte. Furthermore, since precocious division (pre-division) of bivalents at meiosis I may be responsible for trisomy formation (Angell et al., 1993; Angell. 1997), we also studied the position of chromatids to determine whether or not there was an association with the ploidy status of the oocyte.

\section{Materials and methods}

Source of oocytes

Unfertilised oocytes were obtained from 18 couples undergoing ICSI $(n=8)$ or IVF $(n=10)$ in the Reproductive Medicine Unit. The mean female age was 32 (range: 26-39). Our protocols for patient selection and treatment have been described in detail by Payne et al. $(1991 ;$ 1994) and Payne and Matthews (1995). The study was approved by the Ethics of Human Research Committee at The Queen Elizabeth Hospital.

Of the 344 recovered oocytes, $200(58.1 \%)$ fertilised normally and 111 of the unfertilised oocytes were suitable for study. They all failed to show any evidence of fertilization when examined $17-20 \mathrm{~h}$ post-injection (ICSI) or post-insemination (IVF) and possessed a first $\mathrm{PB}$, which was either normal or fragmented.

\section{Zona pellucida removal}

A $0.5 \%$ (w/v) solution of pronase (from Streptomyces griseus, specific activity $7000 \mathrm{U} / \mathrm{g}$; Boehringer-Mannheim, Castle Hill, Australia) was prepared in HEPES-buffered HTTF culture medium (Quinn et al., 1985) and frozen in aliquots at $-20^{\circ} \mathrm{C}$. On the day of use, aliquots were thawed, vortexed and then clarified by centrifugation for $20 \mathrm{sec}$ at $14000 \mathrm{~g}$.

Oocytes were processed individually, 20-24 hours post-insemination. Zona removal was performed in $50 \mu l$ microdrops, and oocytes were transferred between drops using fine drawn glass pipettes (inner diameter slightly larger than the oocyte). Each oocyte was transterred firstly into a drop of HEPES-HTF containing $0.1 \%$ human serum albumin (HSA), then into a drop of pronase solution. It was drawn in and out of the pipette 4-5 times, incubated in pronase for 30-60 sec, then aspirated again until the zona was partially removed. It was then transferred into a fresh drop of HEPES.HTF containing $0.1 \% \mathrm{HSA}$ after which final removal of the zona and PB was achieved by further aspiration. The oocyte was then rinsed in a fresh drop of HEPES-HTF containing HSA and spread on a slide. 
Spreading of oocytes

Oocytes were spread on stides using a modification of the method reported by Coonen ef al. (1994), as detailed in Martini et al. (1997). Slides were subsequently air dried, washed and dehydrated through an ascending ethanol series. They were stored at $-20^{\circ} \mathrm{C}$ in Adelaide before being shipped to Maastricht at room temperature. The slides were then kept at room temperature for up to one month before being processed for $\mathrm{FISH}$.

\section{DNA probes}

Six probes were used: (i) pUCC 1.77 (satellite III, insert $1.77 \mathrm{~kb}$ ), specific for the centromere of human chromosome 1 (Cooke and Hindley, 1979); (ii) p7t1 (alphoid, insert $0.68 \mathrm{~kb}$, which recognises a tandem repeat in the centromere of human chromosome 7 (Waye et al., 1987); (iii) LSI13, specific for chromosome $13 q 14$ and labelled with Spectrum Green( (Vysis, Downers Grove, IL, USA); (iv) L1.84 (alphoid, insert 0.68 kb), specific for the centromere of human chromosome 18 (Devilee et al., 1986); (v) LSl21, specific for 21q22.13-21q22.2 labelled with Specirum Orange( (alphoid, insert $2.0 \mathrm{~kb}$ ), specific for the centromere of human chromosome X (Willard et al., 1983). Probes other than LSI13 and LSI21 were labelled by nick translation. The chromosome 18 probe was labelled with FITC-12-dUTP (Boehringer-Mannheim), the chromosome 7 probe was labelled with TRITC-4-dUTP (Amersham, Buckinghamshire, UK), and alliquots of the chromosome 1 and $X$ probes were labelled with FITC-12-dUTP and TRITC4-dUTP. Probes were dissolved in 60\% formamide [FA], $2 \times$ SSC and used at a final concentration of $1 \mathrm{ng} / \mu \mathrm{l}$ in hybridization solution $(60 \% \mathrm{FA}, 2 \times \mathrm{SSC}, 10 \%$ dextran sulfate, $\mathrm{RRNA}$, SSDNA).

\section{FISH protocol}

Two rounds of FISH were performed on each oocyte, as described by Martini $\theta t$ al. (1997). The first round used a probe cocktail for chromosomes 1, 13 and 21. After evaluation and scoring, the secorid round was performed using a probe cocktail for chromosomes 7,18 and $X$. Briefly, slides were treated with pepsin $(100 \mu \mathrm{g} / \mathrm{ml})$ for $15 \mathrm{~min}$ at $37^{\circ} \mathrm{C}$ to remove any remnants of cytoplasm and make the nuclei accessible for hybridization to the probes, then they were fixed in paraformaldehyde for $5 \mathrm{~min}$ at $4^{\circ} \mathrm{C}$, rinsed in PBS and then bidistilled water, and dehydrated through an ethanol series. Ten $\mu$ l of hybridization mixture containing the first 3 probes ( 1 -FITC and 1-TRITC, 13-Spectrum Green $B$ ) and 21-Spectrum Orange(B) was adided to the slide and sealed under a coverslip. The nuclear and probe DNA were denatured simultaneously for 3 min at $72^{\circ} \mathrm{C}$, then incubated overnight in a moist chamber at $37^{\circ} \mathrm{C}$. After hybridization, the slides were washed, dehydrated and mounted in Vectashield anti-fade (Vector Laboratories, Burlingame, CA, USA) containing $0.01 \mu \mathrm{g} / \mathrm{ml}$ 4,6-diamidino-2-phenylindole (DAPI) to counterstain the DNA. After analysis and recording of results from the first FISH round, and on the same day, DAPI was removed with two washes, the slides were dehydrated, and the probes for the second round were applied (X-FITC and X-TRITC, 18-FITC and 7-TRITC). A coverslip was sealed on the slide, and denaturation and hybridization were performed as for the first round, except that hybridization proceeded for onlly $2 \mathrm{~h}$ at $37^{\circ} \mathrm{C}$. The slides were washed, counterstained with DAPI and re-analysed.

The specificity of each probe was tested concurrently on interphase nuclei obtained from ethanol-fixed, single-cell suspensions of human leucocytes. Hybridization efficiencies were optimised using the above conditions and there was limited non-specific binding of probes. 


\section{Evaluation and scoring of slides}

Slides were examined using a DMRBE fluorescence microscope (Leica. Germany) equipped with a triple band pass filter block containing filters for FITC, TRITC and DAPI. The stringent scoring criteria used have been described by Martini et al. (1997). Paired signals reflect the unique nature of oocyte chromosomes at metaphase $\|$, highly contracted, with sister chromatids widely separated and loosely adjoined in the centromere (Dyban et al., 1996). The position of sister chromatids was scored as dyads or pre-division.

Images were recorded using a CCD camera, green, red and blue filters, and the Image Pro System (Metasystem, Sandhausen, Germany). Sharpness was enhanced in Photoshop 3.0 (Adobe Systems Inc., San Jose, CA, USA) at 120 pixels per inch (see Figure1).

\section{Results}

A total of 111 oocytes were processed. After the first FISH round, 63 oocytes could be visualised using DAPI, giving a spreading efficiency of $57 \%$. Of these 63 oocytes, 57 were analysed in both FISH rounds, yielding an overall FISH efficiency of $91 \%$.

Oocytes were categorised into 3 groups based on the number of DNA fragments and the number and arrangement of hybridization signals. Group I consisted of $4800 \mathrm{cytes}(76.2 \%)$ which had one DNA complement and a haploid ( $\mathrm{n}=23,36.5 \%$ of total, $47.9 \%$ of Group 1$)$, aneuploid $(n=21,33.3 \%$ of total, $43.8 \%$ of Group $)$ ) or polyploid $(n=4,6.3 \%$ of total, $8.3 \%$ of Group I) chromosomal constitution. The occurrence of hyperhaploidy and hypohaploidy is shown in Table 1.

Table 1.Single chromatid hyperhaploidy and hypohaploidy rates.

\begin{tabular}{cccc}
\hline Chromosome & $\begin{array}{c}\text { Hyperhaploidy } \\
>2\end{array}$ & $\begin{array}{c}\text { Hypohaploidy } \\
<2\end{array}$ & Total chomals \\
\hline 1 & 10 & - & 52 \\
7 & 17 & 1 & 58 \\
13 & 2 & 12 & 32 \\
18 & 15 & 5 & 52 \\
21 & 3 & 16 & 29 \\
$x$ & 6 & 8 & 40 \\
\hline
\end{tabular}

Group II consisted of 9 oocyles (14.3\%) which exhibited two DNA complements: (i) a haploid chromosome constitution in both DNA complements with only one chromatid signal in each complement $(n=3)$; a haploid chromosome constitution in both complements with dyads and single chromatids $(n=1)$; one haploid complement and one aneuploid complement $(n=3)$ and aneuploidy in both DNA complements $(n=2)$. Group III consisted of 6 oocytes $(9.5 \%)$, which were either unanalysable $(n=3)$ or yielded incomplete FISH results due to failure of one of the two hybridization rounds $(n=3)$.

The results for haploid and aneuploid oocytes from Group / were further analysed to determine whether there was any correlation between aneuploidy and precocious division (predivision) of chromosomal bivalents (Angell et al., 1994). The findings are presented in Table 2. Haploid oocytes displayed mostly dyads using centromeric probes for chromosomes $1, X, 7$ and $18(82.6-91.3 \%$ dyads) as well as using LSI probes for chromosomes 13 and 21 (73.9-78.3\% dyads). Aneuploid oocytes, however, showed an increased rate of pre-division of chromatids for all the chromosomes studied, especially chromosome 21 $(65.8 \%)$. 
Thable 2. Incidence of dyads and premivision of chromatids in haploid and aneuploid oucytes.

\begin{tabular}{ccccc}
\hline & Haploid Oocyes $(n \approx 23)$ & \multicolumn{2}{c}{ Aneuploid Oocytes $(n=21)$} \\
Chromosome & Dyads $(\%)$ & Predivision $(\%)$ & Dyads $(\%)$ & Predivision $(\%)$ \\
1 & 91.3 & 8.7 & 60.3 & 39.7 \\
7 & 82.6 & 17.4 & 51.7 & 48.3 \\
13 & 73.9 & 26.1 & 50.0 & 50.0 \\
18 & 87.0 & 13.0 & 54.7 & 48.3 \\
21 & 78.3 & 21.7 & 34.2 & 65.8 \\
$x$ & 91.3 & 8.7 & 73.3 & 26.7 \\
\hline
\end{tabular}

\section{Discussion}

It is known that oocyte meiosis is sensitive to endogenous and exogenous factors, which could lead to chromosomally abnormal oocytes and hence to abnormal zygotes. However, the signs of chromosomal imbalance in oocytes may be less obvious than in spermatozoa, in which abnormal morphology and reduced sperm number or motility are readily apparent. Hence, reliable techniques are needed to study aneuploidy and other chromosomal anomalies in otherwise morphologically normal human oocytes. We recently reported a method which utilised a modified spreading technique and two rounds of multiprobe FISH (Martini et al., 1997). One of the aims of the present study was to improve the reliability of that method. This was achieved by removing the $\mathrm{PB}$ prior to spreading each oocyte, thereby reducing problems caused by an inability to differentiate between $\mathrm{PB}$ and oocyte DNA. This improved the overall accuracy of the FISH analyses. However, the spreading efficiency, i.e. the presence of DNA from the oacyte on the slide, was lower (57\% versus $85 \%$ ) than in our previous study (Martini et al., 1997). This may have been caused by the pronase treatment which may have reduced the adhesiveness of oocytes, and/or the storage and shipping conditions which may have caused the loss of some oocyte spreads.

\section{Incidence of aneuploidy in human oocytes}

We found a high rate of aneuploidy ( $48 \%$ of oocytes in Group I). This has also beien reported in other studies on human oocytes, but there is still debate as to whether these high estimates are accurate (Plachot, 1997). This high frequency of aneuploidy could be explained in several ways. Firstly, these oocytes failed to fertilise but some of them, especially the ICSI oocytes, would have contained sperm (Flaherty et al, 1995). This might have lead to an incorrect conclusion of hyperhaploidy in a haploid oocyte due to extra signals from the sperm DNA, as already discussed in Martiniet al., (1997). However, it is more likely that this would elevate the polyploidy rate more than the hyperhaploidy or hypolzaploidy rate. Secondly, the 20-24 h period between insemination and fixation, and/ or the pronase treatment, might have adversely affected the meiotic spindle in some of these oocytes leading to de novo aberrations during in vitro culture.

However, it may also reflect the true incidence of aneuploidy in these oocytes which came from a heterogeneous population of follicles and may be physiologically compromised in some way because they failed to fertilise. Dyban et al. (1996) recorded aneuploidy rates as high as $37 \%$ for chromosomes $\mathrm{X}$ and 18 after FISH analysis, which is in agreement with earlier karyotyping reports on metaphase II human oocyles. The results of the present study revealed an overall aneuploidy rate of $44 \%$, but there were different frequencies and patterns for each of the chromosomes studied, which is not surprising given that meiotic NDJ is non-random and exhibits chromosome-specific patterns (Plachot, 1997). In our 

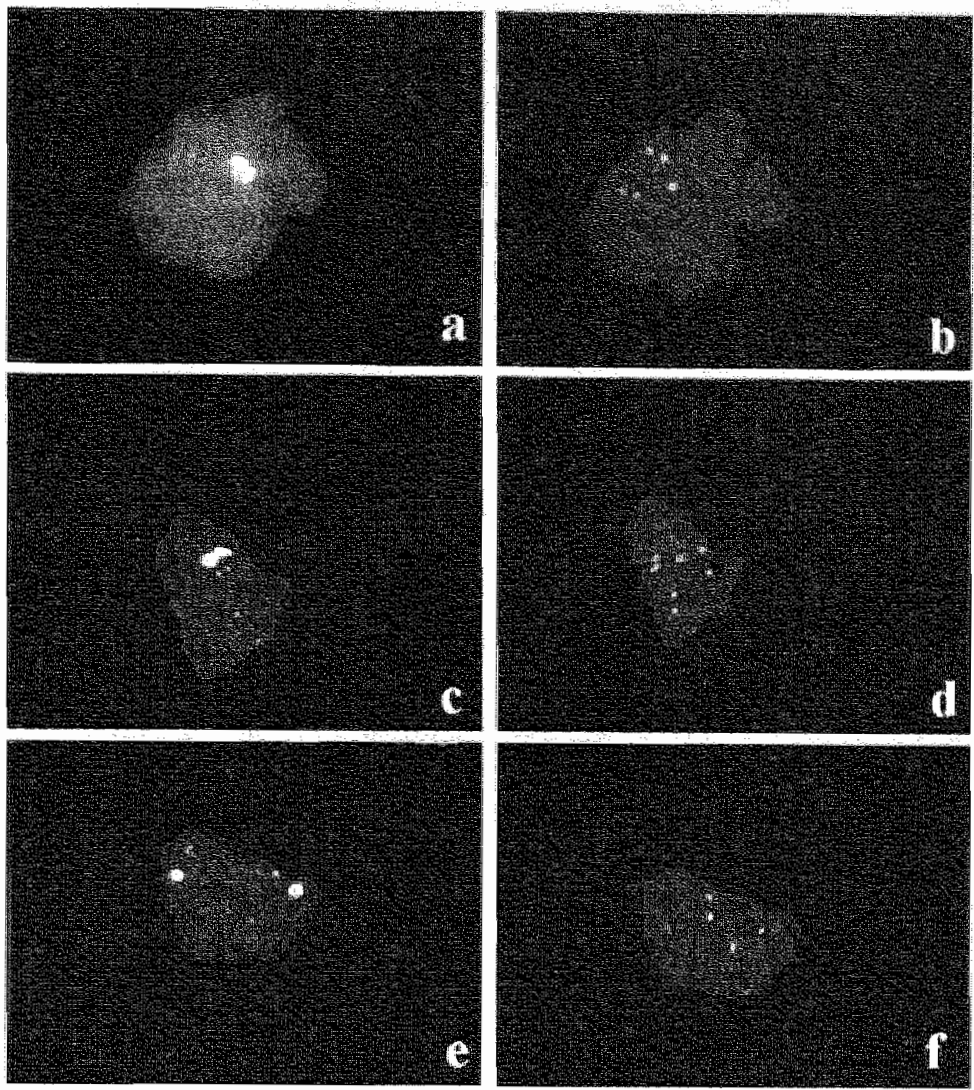

Figure 1. FISH results on human oocytes. Images from the first and second FiSH rounds are shown in $\mathbf{a}, \mathbf{c}$, and $\mathbf{b}, \mathbf{d}$, f respectively. In the first round, the signals are chr. 1 (yellow), chr. 13 (green) and chrr 21 (red). In the second rownd, the signals are chr. $X$ (yellow), chr. 18 (green), chr. 7 (red). DNA is stained bilue. (a-b) Haploid, paired signals in round 1 and hypohaploidy for chr. 18 in round 2. (cd) Haploid, paired signals in round 1 and hyperhaploidy for chr. 7 and pre-division ol chromatids in round 2. (e-f) Haploid oocyle showing pre-division of chromalids for all six chromosomes and hyperhaploidy for chr. 13 in round 1 . For collour illusitration see page 119.

study, there was an excess of hyperhaploidy for chromosomes 1,7 and 18, an excess of hypohaploidy for chromosomes 13 and 21 , and an equal distribution of hyper-and hypohaploidy for chromosome X. Karyotyping studies on oocytes typically report a higher incidence of hypohaploidy than hyperhaploidy and this is often attributed to artificial loss of chromosomes. Therefore the incidence of aneuploidy is often calculated by doubling the hyperhaploidy rate, resulting in so called "conservative estimates" of aneuploidy. This was not the case in our study because hypo-and hyperhaploidy were represented equally overall.

\section{Pre-division of chromatids in oacyles}

Angell et al. (1995) karyotyped human oocytes and reported that hyperhaploidy was not due to extra whole chromosomes (bivalents) but rather to an extra single chromatid or two single chromatids. This suggests that precocious division (pre-division) of chromosomal bivalents during the first melotic division is the most likely mechanism for trisomy forma- 
tion, rather than NDJ of whole bivalents as previously thought. Paired signals corresponding to paired chromatids (dyads) have been reported in FISH studies on human oocytes (Benkhalifa el al., 1996; Dyban et al., 1996; Wall et al., 1996), however the detection sensitivity in those studies was low because only single-probe FISH was applied to a small number of oocytes. We reported in our previous study (Martini et al., 1997) that the centromeres of chromatids where sometimes far apart from each other and not paired, but we did not relate this to the chromosomal constitution of the oocyte. In the present study, we found an association between aneuploidy and the position of the chromatids. Haploid oocytes generally showed dyads (frequency $74-91 \%$ ), with the lowest percentages being associated with the acrocentric chromosomes (chr. 13, 21) and the use of locus specific probes which do not bind to the centromeric region. Aneuploid oocytes displayed a higher frequency of pre-division for all six chromosomes, especially the acrocentric chromosomes (chr. 13,21). These results support the hypothesis that trisomy formation in humans occurs as a result of a premature division of bivalents at meiosis ! (Angell ot al., 1993; Angell 1997). Since chiasma frequency declines with increasing maternal age, the reduction in chiasma frequency may be accompanied by the production of univalents, probably at the origin of NDJ (Angell, 1995). Alterations in cell cycle progression might in furn be the principal cause for maternal age-related predisposition to NDJ (Eichenlaub-Ritter and Boll, 1989). Moreover, Angell (1997) studied oocytes which had been in culture for $\sim 70$ hours prior to fixation. This period is longer than the total culture time the oocytes used in our study were exposed to. Munné et al., (1995) and Dailey et al., (1996) also suggested that some type of abnormalities found by Angell (1991) and Angell et al.. (1994) might be artifacts of in vitro culture and specifically related to time in culture. Unfortunalely, the patient group in the present study was too small to search for correlations between aneuploidy, pre-division of bivalents and maternal age. This warrants further investigation.

In conclusion, the problem of differentiating PB DNA and metaphase II DNA was overcome by removing the zona pellucida and $\mathrm{PB}$ with pronase before spreading oocytes, and two rounds of FISH and six different chromosome probes gave a good insight into the chromosomal constitution of these oocytes and yielded more data than standard multiprobe FISH approaches using 3 probes. Furthermore, we found an association between pre-division of the chromatids and aneuploidy, supporting the hypothesis of Angell (1997) (Angell, 1997). This method is reliable and enables collection of data on multiple chromosomes in large numbers of oocytes.

\section{Acknowledgments}

We would like to thank the patients, laboratory staff, clinical staft and nursing staff of the Reproductive Medicine Units at The Queen Elizabeth Hospital and Waketield Cinic for assisting with this study and Dr. Ton Hopman for technical support. This study was supported by the Dutch "Praeventiefonds" (28- 2582), and by two grants to E. Martini, a joint grant from the Netherlands Organisation for Scientitic Research and Australian Research Council (NNWOARC) and an EC grant (ERB4001GT955293). 


\section{References}

Angell $R$, (1991) Predivision in human oocytes at meiosis 1: a mechanism tor trisony lomation in man. Hum Genet, 86, 383-387.

Angell $\mathrm{A},(1994 \mathrm{a})$ Aneuploidy in older women - Subtitle: Higher rates of aneuploidy in oocytes front older women. Hum Reprod, $9,1199-1201$.

Angell $\mathrm{F}$. (1994b) Possible pitfalls in preimplantation diagnosis of chromosomal disorders based on potar body analysis. Hum Reprod, $9,181-182$.

Angell $R$, (1995) Meiosis I in human oocytes. Oytogenet Cell Genet, 69, 266-272.

Angell $R,(1997)$ First-meiotic-division nondisjunction in human oocytes. Am J Hum Genet, 61,23-32

Angell $\mathrm{R}_{v}$ Xian $\mathrm{J}$, Keith $\mathrm{J},(1993)$ Chromosome anomalies in human oocytes in relation to age. Hum Reprod, 8.1047-1054.

Benkhalifa D, Geneix $A$, Janny $L$, Boucher $D$, Malet $P$. (1990) Chromosone aberrations in human oocytes. Fitth international Congress on Early Fetal Diagnosis.

Benkhalifa $M$. Menezo $Y$. Janny $L$. Pouly J, Qumsiyeh M, (1996) Cytogenetics of uncleaved oocytes and arrested zygotes in IVF programs. J Assis Reprod Genet, 13, 140-148.

Cooke H. Hindley J. (1979) Cloning of the human satellite III DNA: Different components are on different chromosomes. Nucl Acid Res, 6, 3177-3179.

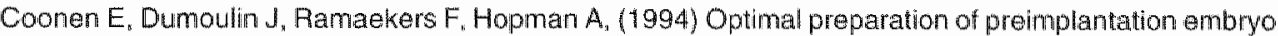
interphase nuclei for analysis by fluorescence in situ hybridization. Hum Reprod, 3, 533-537.

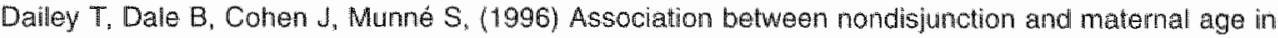
meiosis-ll human oocytes. Am J Hum Genet, 59, 176-184.

Devilee P, Cremer T, Slagboom P. Bakker E, Scholl H, Hager $H_{4}$ Stevenson A. Pearson P. (1986) Two subsets of human alphoid repetitive DNA show distinct preferential localizat on in the pericentromeric regions of chromosomes 13,18 and 21. Cytogenet Cefl Genet, 41, 193-202.

Dyban A, Freidine $M$, Severova $E$, Cleslak J, Ivakhnenko $V$, Verlinsky $Y$, (1996) Detection of aneuploidy in human oocytes and corresponding tirst polar bodies by fluorescent in situ hybridization. J Assis Reprod Genet, 13, 73-78.

Eichenlaubm Ritter $U$, Boll $I,(1989)$ Nocodazole sensitivity, agerrelated aneuploidy and alterations in the cell cycle of maturing mouse oocytes. Cytogenet Cell Genet, 52, 170-176.

Flaherty S, Payne D, Swann N, Matthews C, (1995) Assessment of fertilization failure and abnormal fertilization after intracytoplasmic sperm injection (ICSI). Reprod Fertil Dev, 7, 197-210.

Liebaers I, Bondwelle M, Van Assche E, Devroey P, Van Steinteghem A, (1995) Sex chromosome abnormalities after intracytoplasmic sperm injection. Lancet, 346, 1095.

Martini E, Flaherty S, Swann N, Payne D, Matthews C, (1997) Analysis of unfertilized oocytes subjected to intracytoplasmic sperm injection using two rounds of fluoerescence in-situ hybridization and probes to five chromosomes. Hum Reprod, 12, 2011-2018.

Munné S, Dailley T, Sultan $K_{0}$ Grito J, Cohen J, (1995) The use of first polar bodies for preimplantation diagnosis of aneuploidy. Mol Hum Reprod in Hum Reprod, 10, 1014-1020.

Payne D. Flaherty $S$, Jeffrey $R$, Warnes $G$. Matthews C. (1994) Succesful trealment of severe male factor infertility in 100 consecutive cycles using intracytoplasmic sperm injection (ICSU). Hum Reprod, 9. $2051-2057$.

Payne D, Matthews C. (1995) Intracyloplasmic sperm injection - Clinical results from the reproductive medicine unit, Adelaide. Reprod Fertil Dev, 7, 219-227.

Payne D. McLaughlin K, Depypere $H$, Kirby $C$. Warnes $G$, Mathews $C$. (1991) Experience with zona drilling and zona cutting to improve fertilization rates of thuman oocytes in vitro. Hum Reprod, 6, 423. 431.

Pellestor F, (1991a) Differential distribution of aneuploidy in human gametes according to their sex. Hum Reprod, 6, 1252-1258.

Pellestor F, (1991b) Frequency and distribution of aneuploidy in human female gametes. Hum Genet, 86, $283-288$.

Plachot M, (1997) The human cocyte. Genetic aspects. Ann Genet $40,115-120$.

Plachot $M$, Veiga $A$, Montagut J, deGrouchy J Calderon $G$, Lepretre $S$, Junca A, Santalo J, Carles E, Mandelbaum J, Barri P. Degoy J, Cohen J, Egozcue J, Sabatier J, Salat-Baroux J, (1988) Are clinicial and biological IVF parameters correlated with chromosomal disorders in early life; a multicentric study. Hum Reprod, $3,627-635$.

Quinn P. Kerin J. Warnes G, (1985) Improved pregnancy rate in human in vitro fertilization with the use of a medium based on the composition of thuman tubal fildi. Fertil Steril, 44, 493-498.

Tarkowski $A_{\text {: }}$ (1966) An air-drying method tor chromosome preparation from mouse eggs. Cytogenetics, 5. $394-400$.

Wall M, Marks K, Smith T. Gearon C. Muggleton-Harris A, (1996) Cytogenetic and fluorescent in-situ hybridization chromosomal studies on in-vitro fertilized and intracytoplasmic sperm injected "failed- 
fertilized" humbur oopyles. Hum Reprod, 11, 2230-2238.

Way $\mathrm{d}$, England $\mathrm{S}$, Wildard $\mathrm{H}$, (1987) Genomic organization of alpha satelite DNA on human chromosome 7, evidence for wo distinct alphoid domains on a single chromosome. Mol Cell Biof, 7,349 .

Wiflard $\mathrm{H}$, Smith $K$, Sutherland $J,(1983)$ Isolation and characterisation of a major tandern repeai family from the human X chromosone Nucl Acid Res, 19, 3237-3241. 


\section{Chapter 8}

General Discussion 


\section{Introduction}

Increases in the success and efficiency of VF and ICSI have been paralleled by questions about the chromosomal content of the manipulated gametes. During ICSI, motile spermatozoa showing nomal morphology are selected for injection into the oocyte. An important presumption is that the selected sperm cells are expected to have a nomal chromosomal constitution. It is however known that men involved in ICSI programs have an increased risk of carrying a chromosome abnormality compared with fertile men (Mau et al, 1997; Stuppia et al, 1998; Van der Ven ef al., 1998 ). There is also a risk that the eventual progeny might have infertitity problems. The absence of natural selection of sperm prior to injection may increase the risk of injecting an abnormal spermatozoon. Furthermore, the injection procedure itself might induce aneuploidy by disturbing the meiotic spindle of the oocyte (Plachot 1995; Plachat 1997).

The in situ hybridization (1SH) procedure has in recent years been applied with varying success for the detection of chromosomal aberrations in gametes and embryos.

As outlined in the introduction to this thesis, the specific aims of this study were:

* To improve the efficiency, sensitivity and reproducibility of ISH on human gametes.

* To assess whether or not ISH is a valid alternative to karyotyping for estimating the incidence of aneuploidy in human gametes.

* To analyze the incidence of aneuploidy un apparently normal spermatozoa and unfertilized oocytes.

* To estimate the risk of transmitting chromosomal aberrations using gametes from men with karyotypic abnormalities.

The outcome of these studies will be discussed in a broader perspective using these questions as guide lines.

\section{Efficiency, sensitivity and reproducibility of ISH on human gametes}

In situ hybridization is a technique used to detect numerical and structural chromosomal aberrations in metaphase and interphase cells (Hopman et al, 1988). Many different centres have used ISH to study aneuploidy in human spermatozoa, however, large discrepancies can be noticed in the published results (see Downie et al., 1997 and Guttenbach et al., 1997 a for reviews). These discrepancies are due to the different protocols used for the ISH procedure and the methods used for sample preparation. Also, scoring criteria and interpretation of the results influences the outcome of such studies. As outlined in foregoing chapters of this thesis, partial decondensation of the sperm head prior to ISH is a crucial step for an efficient in situ hybridization. Overdecondensation can cause loss of morphology of the sperm cells and splitting of ISH signals, while underdecondensation reduces the hybridization efficiency (Martini et al., 1995). Wyrobek et al., (1993) showed that in human spermatozoa, fluorescent signals from repetitive probes for chromosomes $Y$ and 8 can split into several signals if the sperm head DNA is overdecondensed. Martin and Spriggs (1995b) and Martin et al., (1995a) who reiterated the importance of optimized sperm pretreatment procedures and strict scoring criteria, validated this. A standard decondensation and hybridization procedure, as well as a correct identification of spermatozoa is therefore essential. In chapter 2 of this thesis it is shown that an exposure of sperm cells for 5 minutes at room temperature to DTT and TRIS (pH 9.5) induces sufficient decondensation of the DNA in the majority of sperm heads to guarantee optimall ISH results (Martini et al. 1995). After counterstaining with Diff-Quik, one can distinguish spermatozoa with aberrant tails (two tails, coiled taill) or deformed heads (two heads, microcephalic, macrocephalic) (Martiniet al, , 1995). Brighttield microscopy enables better dis- 
thinction of morphologically abnomal spermatozoa than fluorescence microsicopy, especially when analyzing sperm in neat semen (without further preparation by swim-up or Percoll gradient) because of the presence of somatic cells and immature gem cells (1GC). This in urn can influence the aneuploidy rate since somatic cels or 1 GC might erroneously be classified as aneuploid sperm cells. Moreover, the method we pioneered has the advantage to produce permanent preparations, since the precipitation products and the counterstaining will not fade, as fluorescent preparations do. However, this technique also has some shortcomings. The ISH signals sometimes overlap, do not localize properly and therefore affect aneuploidy estimates. The basic technical factors that may influence the result include the method of nuclear decondensation, the number of spermatozoa scored. the use of internal controls, scoring criteria, the specificity of the probes and the possible influence of DNA polymorphisms. The latter problem is more likely to be encountered when centromeric probes with a large insert size are used, and can be overcome by using locus specific probes with a smaller insen size. However, in this case, a more sensitive amplification detection system is needed and the combined use of fluorescent malecules (FISH) can help to overcome this limitation (Martini et al. 1998a)

Fewer studies have addressed the chromosomal content of human oocytes, which is largely due to the limited amount of material available for research. Most investigation have used methanol and acetic acid (3:1) for fixation or a modification of Tarkowski (1966), and then performed karyotyping or ISH analysis (see Plachot 1997 for review). The cell spreading technique using $\mathrm{HCl}$ and Tween developed by Coonen ef al., (1994b) which is less aggressive than procedures based on methanol and acetic acid has considerably advanced this aerea of research. The application of chromosome-specific probes can help to analyse the chromosomal content of unfertilized oocytes and provides more precise identification of chromosomal abnormalities than karyotyping (in oocytes), however, FISH analysis is limited to only a small number of chromosomes. This can partly be overcome by simultaneous detection of multiple chromosomes (Dauwerse et al., 1992; Smith et al., 1998) or by multiple hybridizations, each to a different set of chromosomes (Martini et al., 1998b; Martini et al., 1997). For instance, we have analysed 9 chromosomes in the same oocytes using 3 hybridization rounds. The drawbacks are that the quality of the DNA decreases with each hybridization step and metaphase II chromosomes tend to be lost during the repeated washing and detection steps. Some of the limitations of our approach also need to be discussed. First, spreading inefficiencies remain and oocytes are sometimes lost due to mechanical or external factors during spreading. For instance, this might occur by dissolution of the oolemma in the pipette or loss of the oocyte during transfer from culture medium to the slide. Second, the metaphase II DNA of the oocyte is sometimes very difficult to detect, during spreading as well as during ISH analysis. Third, any ISH procedure engenders a certain risk of damaging the DNA, especially during denaturation steps, and this is even more pronounced when studying single cells.

Perhaps a combination of both techniques, FISH on karyotyped gametes, will in future help to obtain the most reliable and accurate results. It is unrealistic to assume that ISH procedures will ever provide error-free estimations of aneuploidy in gametes. However, it is much quicker and easier to perform than karyotyping, and it enables rapid and reliable accumulation of information with respect to the chromosome constitution of large numbers of humangametes.

\section{ISH as a valid alternative to karyotyping for estimating the incidence of aneuploidy in human gametes}

In recent year's, molecular cytogenetic techniques such as 1 SH have been at the forefront 
of research into the genetics of glametes. Human gametes were originally studied using more traditional cytogenetic techniques (Angell 1997; Guttenbach et al., 1997a; Pellestor 1991.; Plachot 1995 for reviews) and sperm karyotyping using the hamster oocyte technique is still considered by many to be the "gold standard" against which new methods such as ISH must be evaluated (Robbinset al., 1995). The direct visualization of human sperm chromosomes in the ooplasm of zona-free hamster oocytes was introduced by Yanagimachi et al., (1976), and many studies have since been conducted (see Downie et al, 1997 for review). One of the major drawbacks of this technique is the high incidence of loss of chromosomes during fixation (Jacobs 1992; Martin ef al., 1993). This problem led to a conservative estimation of aneuploidy based on doubling the disomy rate, yie/ding total aneuploidy frequencies of 0.9 to $4.0 \%$ (Kamiguchi and Mikamo 1986; Benet et al., 1992; Estop et al., 1991; Guttenbach et al., 1997a; Downie et al., 1997). This method provides valuable data because the entire chromosome complement of each spermatozoon can be analysed, and numerical as well as structural abnormalities can be studied. However, it is labour intensive and time consuming, and the results are potentially biased in that only those spermatozoa which can fertilize zona-free hamster oocytes are karyotyped. This may eliminate sperm cells with chromosomal abnormalities or morphological disadvantages that preclude them from fusing with oocytes. Nevertheless, this method provides useful data to compare with ISH results (Martin et al., 1993; Spriggs et al., 1996; Van Hummelen et al., 1996). It is difficult to reconcile the results obtained by karyotyping and ISH analysis. ISH results show higher aneuploidy rates than determined by chromasomal analysis, which may be due to scoring biases resulting from non-specific hybridization, diploid sperm cells or diploid somatic cells (Martin et al., 1993; Martini et al., 1995 and Downie et al., 1997 for review), the tendency of some chromosomes to undergo nondisjunction, especially chromosomes $21, X$ and $Y$, and the effect of alpha satellite DNA polymorphisms on detection of chromosomes using centromeric probes (Egozcue ef al., 1997 for review). Moreover, studies have shown considerable intra- and inter-individual variability in the frequency of aneuploidies (Downie et al., 1997).

Many authors have published results of cytogenetic analysis of oocytes that failed to fertilize after IVF (Plachot 1995; Plachot 1997 for reviews). To date, karyotypic data on 3000 oocytes indicate that the overall aneuploidy rates varies from 8.1 to $54.2 \%$, with an average of 26.5\% (Plachot 1995; Plachot 1997). Aneuplaid metaphase II plates can be attributed to loss of chromosomes during fixation (especially in the case of hypohaphoidy), but also to non-disjunction, anaphase lag, anomalies in the structure or distribution of microtubulles, and alterations in the cyloskeleton. The two main difficulties encountered while studying chromosomes in human oocytes are first, the scarcity of material, and second, the unusual and condensed nature of the chromatids on the metaphase II spindle (Pellestor $1991 \mathrm{~b}$ ). The condition of the chromatids hampers reliable analysis by karyotyping and necessitated the introduction of a modified protocol based on Tarkowski (1966) to effectively spread the chromosomes (Munné et al, 1995c; Pellestor 1991a). However, this method has several drawbacks, such as loss of cells and loss of morphology, which reduces its overall efficiency and reliability.

Another major drawback of karyotyping is that the arrangement and morphology of the chromosomes is critical for obtaining an analysis, but many oocytes do not meet these criteria and therefore cannot be analyzed. Some studies report exclusion of almost $50 \%$ of the oocytes for this reason (Angell 1997; Pellestor 1991a). In contrast, the protocol used in our ISH studies on unfertilized human oocytes yielded spreading efficiencies of 57 to $85 \%$ and ISH efficiencies of 91 to $97 \%$. Moreover, we were able to simultaneously investigate up to six different chromosomes in each oocyte (Martini et al., 1998b; Martini et al., 
1997). All in all it can be concluded that the ISH procedure is a valid altemative to karyotyping for the detection of chromosomal abnormalities in human gametes.

\section{Incidence of aneuploidy in apparently normal spermatozoa and unfertilized oocytes}

Aneuploidy rates for specific chromosomes in spermatozoa vary greatly between published studies. For example, the lowest reported disomy rate for chromosome 1 was $0.02 \%$ (Van Hummelen et al., 1996), while the highest was 0.96\% (Pang et al, 1994). Similarly, disomy rates for chromosomes $X$ and $Y$ vary widely $(0.02$ to $0.7 \%$ and 0 to $0.6 \%$, respectively) (see Guttenbach et al., 1997a for review). It is extremely unlikely that these differences arise solely as a result of inter-individual variations in the disomy rate. It is more likely that, as with the hamster technique for karyotyping sperm, different approaches in the experimental design are responsible for this wide variation (see Guttenbach el al., 1997 a and Downie et al., 1997 for reviews).

Similarly, estimates of aneuploidy rates in human oocytes should be viewed with caution. Women undergoing IVF are not representative for the total population. The hormonal status leading to superovulation is very different from natural cycles and it is plausible that variations in the hormonal regimen may account for some of the reported differences in ploidy levels of oocytes. Whether or not superovulation induces an increase in the aneuploidy rate has not been determined yet (Gras et al. 1992; Plachot 1997). It is important to remember that most studies have used sub-optimal material in that the oocytes used were generally those which failed to fertilize in vitro. Multiple factors associated with this failure are usually not taken into account and the oocytes may therefore not be representative of the entire cohort of oocytes. Procedural differences between studies and the choice of which oocytes are studied may influence such comparisons as well. Furthermore, there are marked differences between studies in the age of oocytes at the time of analysis. For example, Angell (Angell et al., 1993; Angell et al., 1994a and Angell 1994c; 1997) analyzed oocytes at 70 hours after collection, while Munné et al... (1995c) fixed oocytes within 6 hours of retrieval. The oocytes analyzed in our studies were in culture for approximately 18-20 hours. The influence of oocyte age and other factors on the aneuploidy rate estimates warrants further investigation.

In the past years, only a few studies have been published in which ISH was used to analyse unfertilized human oocytes (Benkhalifa ef al., 1996; Dyban et al., 1996; Wall et al. . 1996). Dailey et al., (1996) reported $20 \%$ of oocytes to be aneuploid, despite the fact that they examined only four chromosomes, namely $13,18,21$ and $X$. Since these chromosomes are responsible for approximately one fifth of all trisomies in spontaneous abortions, an implausibly high proportion of oocyles should have been aneuploid to account for the observed distribution of trisomies. A similar problem occurs in ISH studies on cleavage stage human embryos produced in vitro, in which unexpectedly high proportions of aneuploidy were scored (Munné et al., 1995b). Our ISH studies on unfertilized oocytes (Chapter 6 and 7) also suggested a high aneuploidy rate. The fact that we found a higher percentage of aneuploid cells in ISH (38.4 to $44 \%$ ) as compared to karyotype studies (25 to $30 \%$ ) (Benkhalifa ef al., 1990; Pellestor 1991b; Plachot 1995; Plachot ef al., 1988), might be due to the small number of oocytes analyzed, however, it may more accurately reflect the true situation, since the oocytes were obtained from subfertile women who underwent fertility treatment. It should also be kept in mind that oocyte meiosis is very sensitive to endogeneous and exogeneous factors, which could lead to chromosomal abnormalities in oocytes (Plachot 1997). 
The risk of transmitting chromosomal aberrations using gametes from men with karyotypic abnormalities

Useful information can be gleaned from studying the chromosomal constitution of spermatozoa in cases of known chromosomal abnormalities (e.g. $X X Y, X Y Y$, translocations), unexplained infertility or a history of recurrent abortions (Bernardiniet al., 1997; Martini et al., 1996; Martini et al., 1998a).

In the study described in chapter 2, we used ISH to examine sperm from three men with 47, XYYY and 47, XXY numerical chromosomal abnormalities (Martiniet al., 1996). The results revealed that a $46, X Y$ germ cell line with a proliferative advantage over $47, X Y Y$ and $47, X X Y$ cells must be present in these patients, which was recently confirmed by others (Mercier et al., 1996; Blanco et al., 1997; Chevret et al., 1997; Guttenbach et al., 1997b; Mercier and Bresson 1997).

However, the important point to bear in mind is that these patients have an increased risk of spermatozoa carrying sex chromosomal abnormalities ( $15 \%$ in $X Y Y, 3 \%$ in XXY). Recently studies were published where the same findings are supported.

Meiotic segregation, recombination and aneuploidy have been assessed for spermatozoa from translocation carriers in recent studies by sperm chromosome complements (Colls ot al., 1998; Estop et al., 1997) or by ISH (Guttenbach et al., 1997a; Van Hummelen et al., 1997). Chapter 4 presents the results of a study on sperm from a translocation carrier in which a combination of three probes, with different insert sizes (centromeric, cosmid and YAC) was used to evaluate the potential risk to offspring (Martini et al., 1998a). Although this approach furnished results about the sperm cells and provided useful information, it has some deficiencies which are discussed extensively in chapter 4. In particular, the correct choice of DNA probes appeared to be essential and co-hybridization of the probes requires adaptation of the hybridization mixture.

\section{Conclusions}

Unquestionably, gamete genetics still has many challenging areas waiting to be explored. With the continuous evolution of medically assisted reproduction such as $\mid \mathrm{CSI}$, the study of human gametes will become of greater importance in the clinical management of these patients. Knowing the chromasomal constitution of gametes can assist the geneticist to provide better counselling and risk estimations, and help patients to choose appropriate forms of treatment.

\section{References}

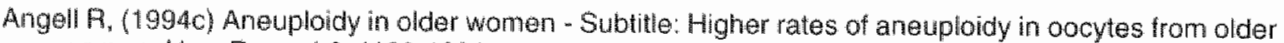
wonen. Hum Reprod. 9: 1199-1201.

Angell A, (1997) Firstmeiotic-division nondisjunction in human oocytes. Am J Hum Genet61:23-32.

Angell $\mathcal{F}_{i}$ Xlan J, Keith J, (1993) Chromosome anomalies in human oocytes in relation to age. Hum Reprod, 8: $1047-1054$.

Angell R, Xian J, Keith J, Ledger W, Baird D, (1994a) First meiotic division abnormalities in human oocytes: mechanism of trisomy formation. Cytogenet Cell Genet, 65: 194-202.

Benet $J_{1}$ Genesca A Navarro $\downarrow$, Egozcue J, Templado $C$, (1992) Cytogenetic sludies in motile sperm from normal men. Hum Genet, 89: 176-180.

Benkhalita D, Geneix A, janny L, Boucher D, Malet P, Chromosome aberrations in human oocytes Fifth International Congress on Eary Fetal Diagnosis, Prague, 1990.

Benkhalifa M, Menezo Y. Janny L. Pouly d, Qumsiyeh M, (1996) Cytogenetics of uncleaved oocytes and arrested zygotes in IVF programs. I Assis Reprod Genet, 13: 140-148.

Bernardini L, Martini E, Geraedts J, Hopman A, Lanteri S, Conte N, Capitanio G, (1997) Comparison of 
gonosomal aneuploidy in spermatozoa of normal fertile men and those with severe male factor de. tected by in-situ hybridization. Molec Hum Feprod, 3: 431-438.

Blanco J, Rubio C, Simon C. Egozcue J, Vidal F. (1997) Increased incidence of disomic sperm nuclei in a $47, X Y Y$ male assessed by fluorescent in situ hybridization (FISH). Hum Gener, $99: 413 * 416$.

Chevret E, Rousseaux S, Monteil M, Usson $Y$, Cozzi J Pelletier $R_{n}$ Sele $B_{i}(1997)$ Meiotic behaviout of sex chromasomes irvestigated by three colour FISH on 35142 spem nuclei from two $47, X Y Y^{\prime}$ males. Hum Genet, 99: 407-412.

Colls P. Martinez-Pasarell O. Perez M, Egozcue J, Templado C. (1998) Sperm chromosome analysis in the father of a child with a de-nove reciprocal tranlocation $1(11 ; 15)(q 12 ; q 22)$ by G-banding and fluorescence in-situ hybridization. Hum Feprod, 13: 60-64.

Coonen E, Dumoulin J, Ramaekers F, Hopman A, (1994) Optimal preparation of premplantation embryo interphase muclei for analysis by flucrescence in situ hybridization. Hum Reprod, 3: 533-537.

Cremer T, Lichter P, Borden J, Ward D, Manuelidis L. (1988) Detection of chramosome aberrations in metaphase and interphase tumor cells by in situ hybridization using chromosome-specific library probes. Hum Genet, 80: 235-246.

Dailey $T$, dale $B$, Cohen $J_{\text {, Munné }} S$, (1996) Association between nondisjunction and maternal age in meiosis Il human oocytes. Am J Hum Geneq 59.

Dawwerse J, Wiegant J, Raap A, Breuning M. Van Ommen G, (1992) Multiple colors by fluorescence in situ hybridization using ratio-labelled DNA probes create a molecular karyotype. Hum Mol Genel, 1: 593 598.

Downie S, Flaherty S, Matthews $C_{1}$ (1997) Review: Detection of chromosomes and estimation of aneuploidy in human sperm using fluorescence in-situ lyybridization. Mol Hum Reprod, 3: 585-598.

Dyban $A_{\text {" }}$ Freidine M, Severova E., Cieslak J, lvakhnenko V, Verlinsky $Y$, (1996) Detection of aneuploidy in? human oocytes and corresponding first polar bodies by fuorescent in situ hybridization. I Assis Reprod Genet, 13: 73-78.

Egozcue $J_{\text {. Blanco }}$, Vidal $\mathbb{F}_{\|}(1997)$ Chromosome studies in human sperm using fluorescence in-situ hyoridization (FISH). Hum Reprod Update, 3: 441-452.

Estop A, Cieply K. Aston C. (1997) The meiotic segregation patten of a reciprocal transiocation $t(10 ; 12)(q 26.1 ; p 13.3)$ by fluorescence in situ hybridization sperm analysis. Eur J Hum Genet, $5: 78$ 82.

Estop A, Cieply K. Van Kirk V, Munne' S, Garver K, (1991) Cytogenetic studies in human sperm. Hum Genet, 87: 447-451.

Gras L, McBain $\downarrow$, Trounson A, Kola !, (1992) The incidence of chromosomal aneuploidy in stimulated and unstimulated (natural) uninseminated human oocytes. Hum Reprod, 7: 1396-1401.

Guttenbach $M_{2}$ Engel W, Schmid $M_{0}(1997$ a) Analysis of structural and numerical chromosome abnomalities in sperm of normal men and carriers of constitutional chromosome aberrations. A review. Hum Genet, 100: 1-21.

Guttenbach M, Michelmann H, Hinney B. Engel W, Schmid M, (1997b) Segregation of sex chromosomes into sperm nuclei in a man with 47, XXY Klinefelter's karyotype: a FISH analysis. Hum Genet, 99: 474477.

Hopman A, Ramaekers F, Raap A, Beck J Devilee P, van der Ploeg لl, Vooijs G, (1988) In situ hybridization as a tool to study numerical chromosome aborrations in solid bladder tumors. Histochemistry: 89 : 307.3116

Jacobs $P,(199.2)$ The chromosome complement of human gameles Oxford Rev Feprod Biol, $14: 47-72$.

Kamiguchi $Y$, Mikamo K, (1986) An improved, efficient method for analysing human sperm chromosomes using zona-free hamster ova. Am J Hum Genet, 38: 724-740.

Lowe X, OHogan S, Moore II D. Bishop W, Wyrobek A, (1996) Aneuploid epididymal sperm detected in chromosomally normal and Robertsonian translocation-bearing mice using a new three-chromosome FISH method. Chromosoma, 105: 204-210.

Martin $R_{1}$ Ko $E_{n}$ Chan $K_{*}$ (1993) Detection of aneuploidy in humen interphase spermatozoa by fluorescence in situ hybridization (FISH), Oytogenet Cell Gonet, 64: 23-26.

Martin R. Spriggs E. (1995b) Sperm chromosome complements in a man theterozygous for a reciprocal translocation $46, X Y, t(9 ; 13)(q 21.1 ; 921.2)$ and a review of the literature. Clin Genet, $47: 42-46$.

Martin R. Spriggs E, KoE, Rademaker A, (1995a) The relationship between paternal age, sex ratios, and aneuploidy frequencies in human sperm, as assessed by multicolor FISH. Am J Hum Gener, 57 .

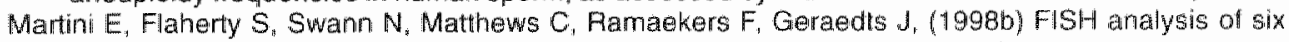
chromosomes in unfertilised human oocytes after polar body removal. subritted.

Martini E, Flaherty S, Swann N, Payne D, Matthews C. (1997) Analysis of unfertilized oocytes subjected to intracyloplasmic sperm injection using two rounds of fluoerescence in-situ hybridization and probes to five chromosomes. Hum Reprod, 12: 2011-2018.

Martini E, Geraedts J, Liebaers I, Land I. Capitanio G, Ramaekers F, Hopmam A, (1996) Constitution of semen samples from XYY and XXY males as analyzed by in-situ hybridization. Hum Feprod, 11: 1638 . 1643:

Martini E, Speel E, Geraedts J, Ramaekers F. Hopman A, (1995) Application of different in-situ hybridiza- 
tion detection methods for human sperm analysis. Hum Reprod, 10: 855-861.

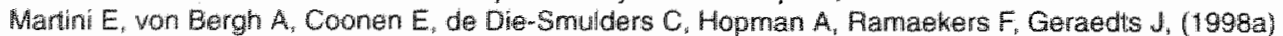
Detection of structural abnomalities in spematozoa of a translocation carrier $t(3 ; 1)(q 27.3 ; 024.3)$ by triple FISH. Hum Genet, 102: 157-165.

Mau U, Backert I, Kaiser P, Kiesel L, (1997) Chromosomal findings in 150 couples referred for genetic counselling pror to intracytoplasmic sperm injection. Hum Reprod, 12:930-937.

McDonough P. (1995) Fiuorescence in situ hybridization aficionados and rater variation, Editorial comment. Ferti Steril, 64:219-220.

Mercier S, Bresson J (1997) Analysis of chromosomal equipment in spermatozoa of a $46, X Y / 47, X Y /+8$ male by means of multicolor fluorescent in situ hybridization: confirmation of a mosaicism and evaluation of risk for offspring. Hum Genet, $99: 42-46$.

Mercier $S$, Morel F, Roux $C$. Clavequin M. Bresson J, (1996) Analysis of the sex chromosomal equipment in spermatozoa of a 47, XYY male using two-colour FISH. Mol Hum Reprod, 2: 485-488.

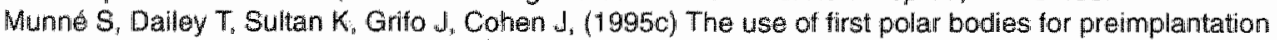
diagnosis of aneuploidy. Mol Hum Reprod in Hum Reprod, 10: 1014-1020.

Munné S, Sultan K, Weler H-U, Grifo $\Downarrow$, Cohen J, Rosenwaks Z, (1995b) Assessment of numeric abnomalities of $X, Y, 18$, and 16 chromosomes in preimplantation human embryos before transfer. Am J Obstet Gynecol, 172: $1191-1199$.

Pang M, Zackowski d, Ryu B, Moon S, Acosta A, Kearns W, (1994) Aneuploidy detection for chromosomes $1, X$ and $Y$ by fluorescence in situ hybridization in human sperm from oligoasthenoteratozoospermic patients. Ans J Hum Genet, 55: A113.

Pellestor $F_{1}$ (1991a) Frequency and distribution of aneuploidy in human female gametes. Hum Genet, 86 : $283-288$.

Pellestor $F_{1}(1991 b)$ Differential distribution of aneuploidy in human gametes according to their sex. Hum Feprod, 6: 1252-1258.

Plachot M, (1995) Oocyte, genetic aspects. In: Yovich JGGaJl (ed) Gametes: The oocyte: Cambridge reviews in Human Reproduction. Cambridge University Press "Cambridge, pp 95-107.

Plachol M, (1997) The human oocyte. Genetic aspects. Ann Gened, 40: 11:-120.

Plachot Ml, Veiga A, Montagut J, deGrouchy J, Calderon $G$, Lepretre $S$, Junca $A_{4}$ Santalo J, Carles E, Mandelbaum J, Barri P, Degoy J, Cohen J. Egozcue J, Sabatier ل ل, Salat-Baroux ل, (1988) Are clinicall and biological IVF parameters correlated with chromosomal disorders in early life: a multicentric study. Hum Reprod, 3: 627-635.

Robbins W. Baulch J, Moore DI, Weier H, Blakey D, Wyrobek A, (1995) Three-probe fluorescence in situ hybridization to assess chromosome $X, Y$ and $B$ aneuploidy in sperm of 14 men from two healthy groups: evidence for a paternal age effect on sperm aneuploidy. Reprod Fertil Dev $7: 799-809$.

Selig $\mathrm{S}_{1}$ Okumura K, Ward D, Cedar $\mathrm{H}_{0}$ (1992) Dellineation of DNA replication time zones by fluorescence in situ hybridization. EMBO $4,11: 1217-1225$.

Smith $S$, Toledo A, Massey $J_{1}, K o r t H_{*}(1998)$ Simultaneous detection of chromosomes $X, Y, 13,18$ and 21 by fluorescence in situ hybridization in blastomeres obtained from preiplantation 11

Spriggs E, Rademaker A, Martin $\mathrm{R}_{n}$ (1996) Aneuploidy in human sperm: the use of multicolor FISH to test various theories of nondisjunction. Am J Hum Genet, 58: 356-362.

Stuppia L. Gatta V. Calabrese $G$, Guanciali Franchi P. Morizio E, Bombieri G, Mingarelli $P$, Sforza $V$. Frajese Gi, Tenaglia R, Palka G, (1998) A quarter of men with idiopathic oligo-azoospermia display chromosomal abnormalities and microdeletions of different types in interval 6 of Yq11. Hum Genet. 102: $566 \cdot 570$

Tarkowski A. (1966) An air-drying method for chromosome preparation from mouse eggs. Cytogenetics, 5 : $394-400$

Van der Ven K., Peschka $B$, Montag M, Lange $\mathrm{R}$, Schwanitz $G$, Van der Ven H, (1998) Increased frequency of congenital chromosomal aberrations in female partners of couples undergoing intracyloplasmic sperm injection. Hum Reprod, 13: 48-54.

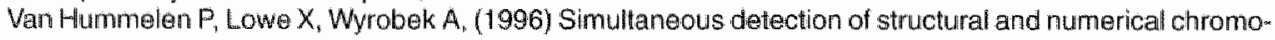
some abnomalities in sperm of healthy men by multicolor fluorescence in situ hybridization. Hum Genet, $98: 608-615$.

Van Hummelen P. Manchester D. Lowe X. Wyrobek A, (1997) Meiotic segregation, recombination, and gamete aneuploidy assessed in a $1(1 ; 10)(p 22.1 ; 922.3)$ reciprocal translocation carrier by three- and four-probe multicolor FISH in sperm. Am J Hum Genet, 6: 651-659.

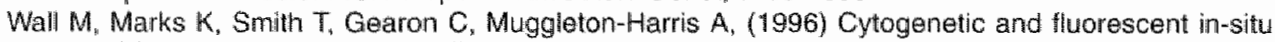
hybridization chromosomal studies on in-vitro fertilized and intracyloplasmic sperm injected "failedfertilized" human oocytes. Hum Reprod, 11:2230-2238.

Wyrobek $A_{4}$ Robbins $W$, Tang $C_{4}$ (1993) Hierarchical organization of human sperm chromatin is a critical factor in the detection of chromosomal aneuploidies in fluorescence in situ hybridization. Am $4 \mathrm{Hum}$ Genet, 53 (Suppl): 130 .

Yanagimachi $F_{\text {, Vanagimachi } H}$, Rogers $B .(1976)$ The use of zona free animal ova as a test for the assessment of the fertilizing capacity of human spermatoza. Biol Reprod, 15: 471-476. 


\section{Summary}

\section{Aim of the study:}

The study of the chromosomal content of single gametes can provide valuable diagnostic information and contribute to basic knowledge in the field of reproductive biology. Patients carrying chromosomal defects or requiring medically assisted reproduction (MAR) techniques may benefit from gamete analysis.

Numerical and structural chromosomal aberrations are correlated with embryonic and fetal wastage, perinatal and infant mortality, mental retardation and congenital anomalies. Some studies suggest that approximately half of all human conceptuses bear chromosomal abnormalities. Analysis of gametes provides information on the origin and frequency of these chromosomal aberrations.

\section{Methodology:}

For this purpose a new protocol was developed to screen a relatively large number of gametes avoiding labour intensive and time-consuming pre-treatment steps. The nonradioactive in situ hybridization ( $\mathrm{SH}$ ) technique allows the detection of chromosomal abnormalities in human interphase nuclei, and can thus be used for detection of numerical and structural chromosomal abnormalities in sperm cells and oocytes.

The combination of ISH, brightfield microscopy and Diff-Quik staining enables visualisation of single spermcells and makes it possible to discriminate between nullisomic, disomic, diploid and morphologically abnormal spermatozoa, overlapping cells, somatic cells and immature germ cells (Chapter 2).

\section{Spermatozoa:}

In Chapter 3 semen from two $47, X Y Y$ males and one $46, X Y / 47, X X Y$ male with fertility problems were analysed with the brightfield ISH procedure. The ratio of $X$ - to $Y$-bearing spermatozoa did not differ from the expected $1: 1$ ratio, but the sex chromosome aneuploidy rate was much higher than in normal $46, X Y$ males. In both $47, X Y Y$ males, approximately $15 \%$ of the sperm cells were aneuploid, while in the $46, X Y / 47, X X Y$ male, the aneuploidy rate was $3 \%$. The most striking finding was the relatively low percentage of spermatozoa in these patients, with an average of $65 \%$ in the XYY males and $84 \%$ in the XY/XXY male. The other cells were immature germ cells (IGC), including spermatogonia and spermatocytes. However, the finding that the majority of spermatozoa in semen of $47, X Y Y$ and $47, X X Y$ males were not aneuploid strengthens the hypothesis that a $46, X Y$ germ cell line must be present, apparently with a proliferative advantage over the $47, X Y Y$ and $47, X X Y$ cells.

In the study described in Chapter 4, semen samples from 15 infertile males were analysed with sex chromosome probes in order to study whether a correlation exists between infertility and increased aneuploidy levels. Semen from fertile volunteers, unexplained infertility patients and severe male factor patients were analysed, and morphologically normal spermatozoa carrying an abnormal chromosome constitution for the sex chromosomes were detected at frequencies of $0.86 \%, 0.75 \%$ and $1.35 \%$, respectively. The value of aneuploidy in the severe male factor group of patients was significantly higher than in the other two groups.

A fluorescent ISH approach was used to detect structural and numerical chromosomal aberrations in spermatozoa from a reciprocal translocation $\mathrm{t}(3 ; 11)(\mathrm{q} 27.3 ; q 24.3)$ carrier 
(Chapter 5). The presence of chromosomal aberrations in spermatozoa is a direci consequence of the meiotic behaviour of the translocation chromosomes. To analyse the meiotic segregation modes, a tallored FISH approach was developed in order to study both numerical and structural aberrations in spermatozoa. A combination of three different probes, hybridising to the centromeric region of chromosome 11 and to two specific DNA loci (a cosmid probe for chromosome 11q and a YAC probe for chromosome 3q) were used. Spermatozoa from the patient and from a normal donor were analysed and the abnormal chromosome constitutions were established. In the translocation carrier, $44.3 \%$ of the analysable sperm cells carried a normal or balanced karyotype, while the remaining cells were abnormal resulting from adjacent I segregation mode (15.9\%), adjacent II segregation $(6.5 \%), 3: 1$ segregation ( $28.9 \%), 4.0$ segregation $(0.8 \%)$ and aberrant segregation $(3.6 \%)$. In the control sperm cells, $92.0 \%$ exhibited a normal chromosome pattern.

\section{Oocytes:}

Although far from being ideal, unfertilised oocytes from IVF or ICSI cycles are the only source of human oocytes available for research. Overall, $30-50 \%$ of oocytes recovered for IVF fail to fertilise and can therefore be used for chromosome analysis. Various lines of evidence imply that oocyte meiosis is very sensitive to endogenous or exogenous factors and that the incidence of abnormalities is correlated to female age.

In Chapter 6 a method for studying chromosomal anomalies in unfertilised, metaphase II oocytes is presented. This new technical approach allowed us to analyse $85 \%$ of the oocytes, compared to the $30-50 \%$ of analysable cells obtained by karyotyping. Two rounds of fluorescent ISH were performed using directly labelled probes: chromosomes 1, 7, 15 (round 1); chromosomes 1, X, Y (round 2). The chromosome 1 probe was included in both rounds as an internal control for the specificity, sensitivity and efficiency of the fluorescent ISH procedure.

In the initial study it was not possible to differentiate between polar body (PB) DNA and metaphase II DNA. Therefore, in the following study (Chapter 7), we modified the technique by removing the first $\mathrm{PB}$ with pronase so that only the metaphase 11 chromosomes were evaluated by FISH. Six different probes were used: chromosomes 1, 13, 21 (round 1) and chromosomes $X, 7,18$ (round 2). Furthermore, since precocious division (predivision) of univalents at meiosis I is thought to be responsible for trisomy formation, the position of chromatids was investigated and an association was found with the chromosomal status of the cell. A prevalence of dyads was found in haploid oocytes while there was an increased frequency of pre-division of chromatids in the aneuploid oocytes, especially for chromosome 21 .

\section{Conclusions:}

The techniques described in this study were successfully applied to study chromosomal abnormalities, both numerical and structural, in human gametes. ISH analysis of spermatozoa from carriers of translocations, numerical sex-chromosomal abnormalities, or on spermatozoa of patients with unexplained fertility problems is realistic. However, it is unrealistic to think that ISH will ever provide error-free estimations of aneuploidy rates in hu= man spermatozoa and oocytes. Nonetheless, it is much quicker and easier to perform than karyotyping. Therefore it enables the accumulation of information about the chromosomal constitution of large numbers of gametes. 


\section{Samenvatting}

\section{Doel van het onderzoek:}

De bestudering van de chromosomale inhoud van individuele gameten kan waardevolle diagnostische informatie bieden en bijdragen aan de basale kennis op het gebied van de reproductieve biologie. Het onderzoek van de gameten kan van nut zijn voor patiënten die drager zijn van chromosomale afwijkingen of gebruik maken van medisch geassisteerde voortplantingsmethoden.

Numerieke en structurele chromosoomafwijkingen veroorzaken embryonale, foetale en perinatale sterfte en mortaliteit op de kinderleeftijd, mentale retardatie en aangeboren afwijkingen. Door sommige auteurs wordt gesuggereerd dat ongeveer de helft van alle humane zygoten chromosomaal afwijkend is. Het onderzoek van de gameten geeft inzicht in het ontstaan en de frequentie van deze chromosomale afwijkingen.

\section{Methodologie:}

Er werd een nieuw protocol ontwikkeld dat het mogelijk maakt een relatief groot aantal gameten te onderzoeken zonder bewerkelijke en tijdrovende voorbehandeling. Met behulp van de niet-radioactieve in situ hybridizatie (ISH) techniek kunnen chromosoomafwijkingen in humane interfase kernen aangetoond worden. Deze methode kan derhalve ook gebruikt worden voor het onderzoek van numerieke en structurele chromosoomafwijkingen van zaadcellen en eicellen. Door ISH te combineren met de Diff-Quik kleuring kunnen individuele zaadcellen in een doorvallend lichtmicroscoop beoordeeld worden op afwijkingen als nullisomie, disomie, diploidie, morfologische afwijkingen, overlap en kunnen zaadcellen onderscheiden worden van somatische cellen en onrijpe geslachtscellen (Hoofdstuk 2).

\section{Spermatozoa:}

In hoofdstuk 3 is de nieuwe methode toegepast bij twee $47, X Y Y$ mannen en een $46, X Y$ / $47, X X Y$ man met vruchtbaarheidsproblemen. De verhouding $X$-: $Y$-dragende zaadcellen week niet af van de verwachte 1:1 verhouding, maar hel percentage numerieke geslachtschromosomale afwijkingen was veel hoger dan bij normale 46,XY mannen. Bij beide $47, X Y Y$ mannen was ongeveer $15 \%$ van de zaadcellen aneuploild, terwijl het aneuploidie percentage bij de $46, X Y / 47, X X Y$ man ongeveer $3 \%$ bedroeg. De meest opvallende bevinding was het relatief lage percentage zaadcellen dat werd waargenemen bij deze patiënten. Dit bedroeg gemiddeld $65 \%$ bij de XYY mannen en $84 \%$ bij de XYY $X X Y$ man. De andere cellen waren voornamelijk onrijpe geslachtcellen, zoals spermatogonia en spermatocyten. De bevinding dat de meerderheid van de zaadcellen in het semen van $47, X Y Y$ en $47, X X Y$ mannen niet aneuploïd was is een sterke aanwijzing voor de hypothese dat er een $46, X Y$ geslachtscellijn aanwezig moet zijn, die waarschijnlijk in proliferatief opzicht in het voordeel is ten opzichte van de geslachtschromosomaal afwijkende cellen. Het onderzoek dat beschreven wordt in Hoofdstuk 4, heeft betrekking op de analyse van zaadmonsters van 15 onvruchtbare mannen. Dit werd gedaan om na te gaan of er een verband bestaat tussen onvruchtbaarheid en toename van aneuploidie. Semen van vruchtbare vijwilligers werd vergeleken met dat van patiënten met onverklaarde infertiliteit en patiënten met een ernstige infertiliteit op basis van een mannelijke factor. Bij deze drie groepen werden in morfologisch normale zaadcellen percentages afwijkingen van de geslachtschromosomen gevonden van resp. $0,86 \%, 0,75 \%$ en $1,35 \%$. Het aneuploidie percentage in de laatste groep was significant hoger dan dat van de andere twee groepen. 
Deze bevindingen werden bevestigd door gebruik te maken van probes voor de autosomen 1 en 17.

Fluorescente in situ hybridizatie (FISH) werd toegepast om structurele en numerieke chromosomale afwijkingen te onderzoeken in zaadcellen van een drager van een reciproke translocatie $t(3 ; 11)(\mathrm{q} 27.3 ; \mathrm{q} 24.3)$ (Hoofdstuk 5). De aanwezigheid van chromosomale afwijkingen in de zaadcellen van een dergelijke translocatiedrager is een direct gevolg van het gedrag van de translocatiechromosomen in de meiose. De verdeling van de bij de translacatie betrokken chromosomen over de meiotische dochtercellen werd onderzocht met behulp van een speciaal ontwikkelde FISH methode waarmee zowel numerieke als structurele afwijkingen van de zaadcellen konden worden aangetoond. Er werd gebruik gemakt van een combinatie van drie verschillende probes, die hybridiseerden met respectievelijk het centromeer gebied van chromosoom 11 en twee specifieke DNA. loci (een cosmide probe op chromosoom 11q en een YAC probe op chromosoom 3q). De zaadcellen van de translocatiedrager werden vergeleken met die van een normale donor en de afwijkende chromosomale constituties werden vastgesteld. Bij de translocatiedrager had $44,3 \%$ van de analyseerbare zaadcellen een normaal of gebalanceerd karyotype, terwijl de overige cellen afwijkend waren tengevolge van adjacent I segregatie (15,9\%), adjacent II segregatie $(6,5 \%), 3: 1$ segregatie $(28,9 \%), 4: 0$ segregatie $(0,8 \%)$ en andere afwijkende segregaties $(3,6 \%)$. In het controle monster liet $92,0 \%$ een normaal segregatiepatroon zien.

\section{Oöcyten:}

Ofschoon ze zeker geen ideaal anderzoeksobject vormen, zijn na IVF en ICSI onbevrucht gebleven oöcyten het enige beschikbare materiaal voor onderzoek van de vrouwelijke humane gameet. In het algemeen kan gesteld worden dat $30-50 \%$ van de oöcyten onbevrucht blijft en derhalve beschikbaar is voor chromosomaall onderzoek. Er zijn allerlei aanwijzingen dat de meiose bij de vrouw erg gevoelig is voor endogene en exogene factoren en dat de incidentie van chromosoomafwijkingen gecorreleerd is met de leeftijd van de vrouw.

In hoofdstuk 6 is een methode beschreven voor de chromosomale bestudering van onbevrucht gebleven, metafase II oöcyten. Deze nieuwe benadering maakte het mogelijk $85 \%$ van de eicellen te analyseren. Na klassieke karyotypering kan een resultaat verkregen worden bij 30 tot $50 \%$ van de cellen. Hiertoe werd FISH met direct gemerkte probes toegepast in twee opeenvolgende ronden: chromosoom 1,7 en 15 probes in ronde 1 en chromosoom 1, $X$ en $Y$ probes in ronde 2 . De chromosoom 1 probe werd in beide ronden toeglepast om een interne controle te hebben voor de specificiteit, sensitiviteit en efficiëntie van de FISH procedure.

In het eerste onderzoek was het niet mogelijk het DNA van het poollichaampje te onderscheiden van dat van de metafase II. Daarom werd de methode in het vervolgonderzoek aangepast door eerst het poollichaampje te verwijderen met pronase zodat slechts de metafase II chromosomen overbleven voor FISH onderzoek (hoofdstuk 7). Zes verschillende probes werden gebruikt: chromosoom 1,13 en 21 probes in ronde 1 en chromosoom $X, 7$ en 18 probes in ronde 2 . Bovendien werd de positie van de chromatiden onderzocht, aangezien vroegtijdige deling (pre-divisie) van univalenten tijdens meiose I verantwoordelijk wordt gehouden voor trisomie vorming. Er werd een verband gevonden met de chromosomale status van de cell. Bij haploide oöcyten overheerste de aanwezigheid van normale univalenten terwijl er sprake was van een verhoogde frequentie van pre-divisie van de chromatiden bij de aneuploide oöcyten en speciaal bij aneuploidie voor chromosoom 21. 


\section{Conclusies:}

De methoden die beschreven zijn in dit proefschrift zijn met succes toegepast bij de bestudering van numerieke en structurele chromosoomafwijkingen van menselijke geslachtscellen. ISH analyse van zaadcellen van translocatiedragers, patienten met geslachtschromosomale afwijkingen of patienten met onverklaarde infertiliteit is haalbaar: Het is echter niet realistisch te veronderstellen dat het ooit mogelijk zal zijn met behulp van ISH tot foutloze bepalingen van het percentage aneuploidie van humane spermatozoa en oöcyten te komen. Daar staat tegenover dat ISH veel sneller en gemakkelijker uitgevoerd kan worden dan karyotypering. Daardoor is het mogelijk informatie te verzamelen over de chromosomale inhoud van grote aantallen gameten. 


\section{Curriculum Vitae}

Elena Martini was born on the 29ir of February, 1968 in Livorno, Italy. She graduated in 1987 at the Deutsche Schule Genua and in the same year started her Biology study at the University of Genoa, where she obtained her Masters degree in 1993. In September 1993 she came to the Stichting Klinische Genetica in Maastricht financed by a Commett Grant from the EC. This initial stage of 6 months developed into a Ph.D. project, to be performed at the University of Limburg, Department of Molecular Cell Biology \& Genetics (Prof. Dr. FCS Ramaekers and Prof. Dr. JPM Geraedts, under supervision of Dr. AHN Hopman) in collaboration with the Department of Obstetrics \& Gynaecology, University of Genoa, Italy (Prof. Dr. GL Capitanio). In 1996 she obtained a 2-years Training and Mobility Research Fellowship from the EC and continued her project as researcher at the University of Maastricht. In September 1996 she visited on basis of a joint grant from the Netherlands Organisation for Scientific Research and Australian Research Council (NWO-ARC), The Queen Elizabeth Hospital in Adelaide, Australia (Prof. Dr. CD Matthews and Dr. SP Flaherty) where she stayed 3 months and performed part of the work published in this thesis.

She is married to Maurice Jansen and they have a one-year old son, Martino. 


\section{Publications}

E Coonen, EMartini, JCM Dumoulin, CEM de Die-Smulders, JPM Geraedts, AHM Hopman, JHL. Evers (1998); Preimplantation genetic diagnosis of a reciprocal translocation (1 3,11$)(q 27.3 ; q 24.3)$ in siblings (submitted)

EMartini, SP Flaherty, NJ Swann, CD Matthews, FCS Ramaekers and JPM Geraedts (1998); FISH analysis of six chromosomes in unfertilized oocytes after polar body removal (submitted).

EMartini, ARM von Bergh, E Coonen, CEM de Die-Smulders, AHN Hopman, FCS Ramaekers and JPM Geraedts (1998); Detection of structural abnormalities in spermatozoa of a translocation carrier $t(3: 11)(927.3 ; q 24.3)$ by triple FiSH. Hum Genet. 102:157-165.

E Martini, SP Flaherty, NJ Swann, D Payne and CD Matthews, (1997); Analysis of unfertilized oocytes subjected to intracytoplasmic sperm injection using two rounds of fluorescence insitu hybridization and probes to five chromosomes, Hum Reprod, 12: 2011-2018.

Bernardini, EMartini, JPM Geraedts, AHIN Hopman, S Lanteri, N Conte and GL Capitanio. (1997); Comparisom of gonosomal aneuploidy in human sperm of fertille men and severe male factor patients detected by in situ hybridization, Molec Hum Reprod, 3: 431-438.

EMartini, JPM Geraedts, I Liebaers, JA Land, GL Capitanio, FCS Ramaekers and AHN Hopman, (1996); Constitution of semen samples from XYY and XXY males as analyzed by in situ hybridization, Hum Reprod, 11: 1638-1643.

E Martini, JPMVI Geraedits, I Liebaers, GL Capitanio, FCS Ramaekers and AHN Hopman, (1995); Combined detection of cytogenetic and morphological abnormalities in spermatozoa using in situ hybridization and an improved cell staining method, In: International Proceedings Division, Monduzzi Editore, $733-736$.

EMartini, EJM Speel, JPM Geraedts, FCS Ramaekers and AHN Hopman, (1995); Application of different in situ hybridization detection methods for human sperm analysis, Hum Reprod, $10: 855-861$. 


\section{Abstracts}

EMarini, SP Flaherty, NJ Swann, CD Matthews and JPM Geraedts (1998); FISH analysis of six chromosomes in untentilized oocytes after polar body removal. Hum Reprod, abstract book: P.208: 233

E Coonen; JCM Dumoulin, EMartini, CEM de Die-Smulders, JPM Geraedts, AHN Hopman, JHL Evers (1998); Preimplantation genetic diagnosis of a reciprocal translocation using repetilive, unique and region-specific DNA probes. Hum Reprod, abstract book; P-205; 232.

EMartin, SP Flaherty, NJ Swann, D Payne and CD Mathews, (1997); Analysis of aneuploidy in unfertilized ICSI oocytes with wo rounds of triple FISH, Hum Reprod, abstract book: 12; $P$. $168,199$.

E Martini. Letter to the Editor, (1996); Staining of undecondensed sperm nucleii, Hum Reprod, 11: 2808.

EMartini, JPM Geraedts, I Liebaers, JA Land, GL Capitanio, FCS Ramaekers and AHN Hopman, (1996); Constitution of semen samples from $X Y Y$ and $X X Y$ males as analyzed by in situ hybridization, Cytometry, Abstracts, International Society for Analytical Cytology, AC44, 107.

EMartini. (1995); Novel methods for the simultaneous study of morphology and chromosome content in human spermatozoa. Syllabus ESHRE Campus Course: Chromosomal analysis of gametes, zygotes and pre-embryos, 14/15 December 1995, Maastricht, The Netherlands.

E Martini, AHN Hopman, E Van Assche, I Liebaers, GL Capitanio, and JPM Geraedts (1995); The application of a novel detection method for genetic and morphological abnomalities in human spermatozoa. Hum Reprod 10 S2: 132.

EMartini, EJM Speel, AHN Hopman, and JPM Geraedts, (1995); Detection of cytogenetic abnormalities in spermatozoa of a 47 ,XYY male with a novel method, J. Assisted Reprod and Genet, 275; OC2.

EMantin. EJM Speel, E Coonen, FCS Ramaekers, JPM Geraedts and AHN Hopman, (1994); New rmethodologies for ISH on chromosomal DNA in human spermatozoa. Hum Reprod 9 S4: 30.

E Coonen, EMartini, CEM de Die Smulders, FCS Ramaekers, JPM Geraedts and AHN Hopman. (1994); FISH using region-specific DNA probes for pre-implantation diagnosis. Hum Reprod 9 S4: 32 

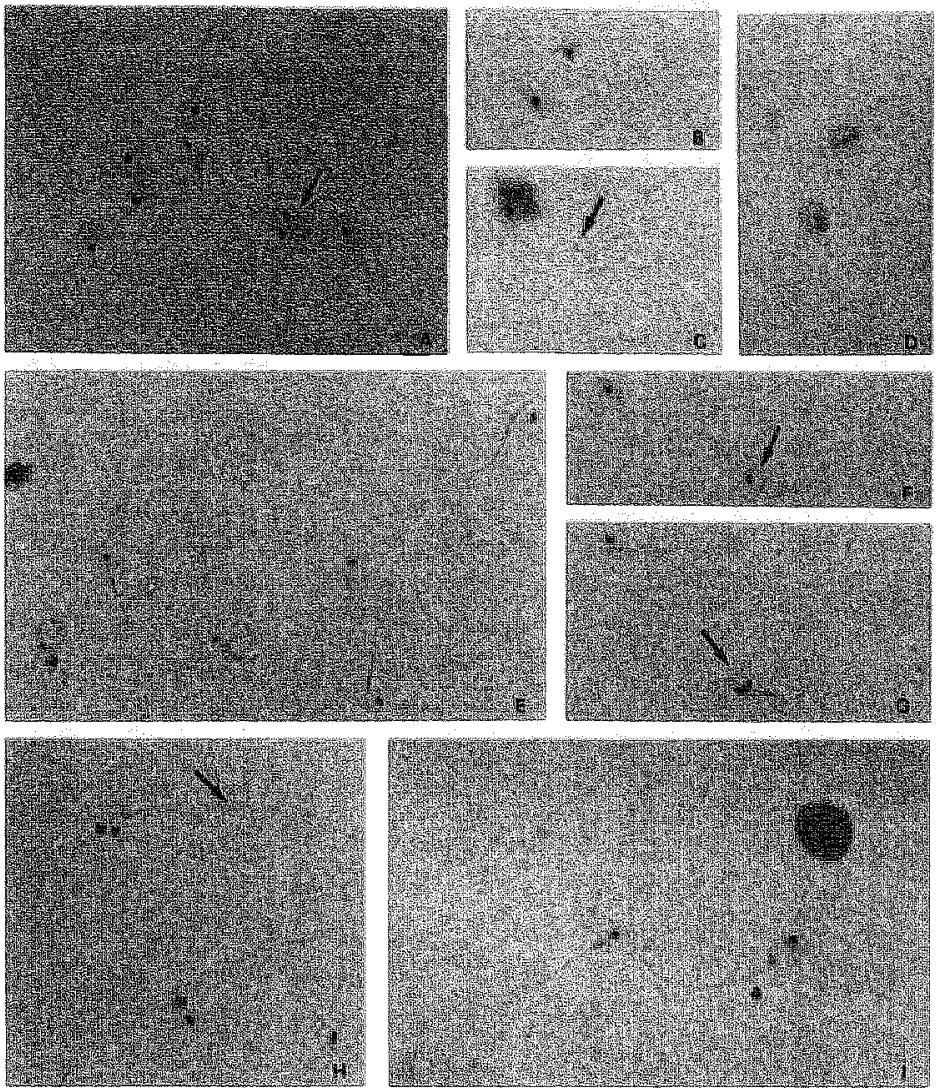

Chapter 2, page 30 - Figure 1. (magnification for Figures $a_{4}, b_{1} d, e_{1} f_{1}, h_{n}$ : $1000 X_{*}$; Figure.c: $2000 X$ ) (a.) Single-target ISH with a biotinylated probe for chromasome 1, detected with the DAB reaction. The arrow indicates a spermatozaa with 2 ISH signals for chromosome 1. (b.) Double-target ISH with al biotinylated probe for chromosome $X$ and a FITC-labelled probe for chromosome $Y$. Detected with the Fast-Fed and the TMB reactions, respectively. (c-d.) Triple-target ISH with a biotinylated probe for chiomosome 1 , a digoxigenin-labelled probe for chromosome 7 and a FITC-labelled probe for chromosome 17. Detected with $D A B$. Fast-Red and TMB, respectively. In Figure 1c the arrow indicates the lail. (a-d) Counterstaining with haematoxylin. (e-g.) Singte-target ISH with a 1-bio probe, detected with DAB. The arrow in (f.) indicates a. spermatozoa with 2 ISH signals for chromosome 1. The arrow in (gi.) indicates a morphologically abnormall sperm cell, with two heads, two signals, two midpieces, but one tail. (h.) Single-target ISH with 1 -bio probe, delected with TMB. The arrow indicates a morphologically abnormal sperm cell with one head but with two ISH signals and two tails. (i.) Somatic cell and double-target ISH with a X-bio probe and FITC-labelled probe for chromosome $Y$, detected with $D A B$ and TMB, respectively. (e-i) Counterstaining with Diff-Quik. 

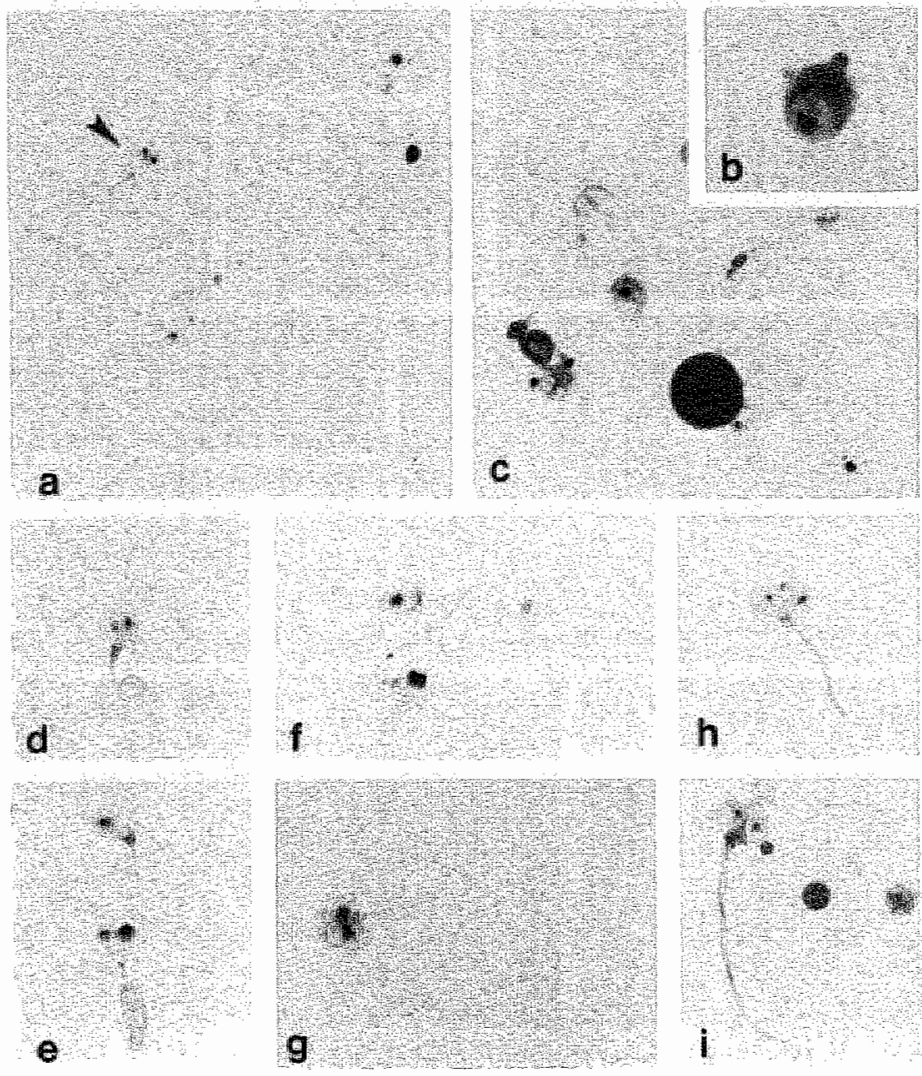

Chapter 3, page 41-Figure 1. Diff-Quik and Haematoxylin stained semen preparation to which double-targell ISH was applied with an X-probe (brown) and a $Y$-probe (green). (a) Control sample showing an XX-bearing spermato$z$ zoon. $(b, c)$ Immature germ cells from an $X Y Y$ male (b) and an $X X Y$ male (c) showing a $X Y Y$ - and $X Y$-constitution respectively. Morphologically normall spermatozoa from an $X X Y$ male $(d, e)$ and an $X Y Y$ male $(f, g)$ showing a normal sex-chromosome constitution and $Y Y$ constitution respectively. ( $h$, 1) Morphologically abnomal spermatozoa from the XXY patient. (Magnification $\times 1000)$. 

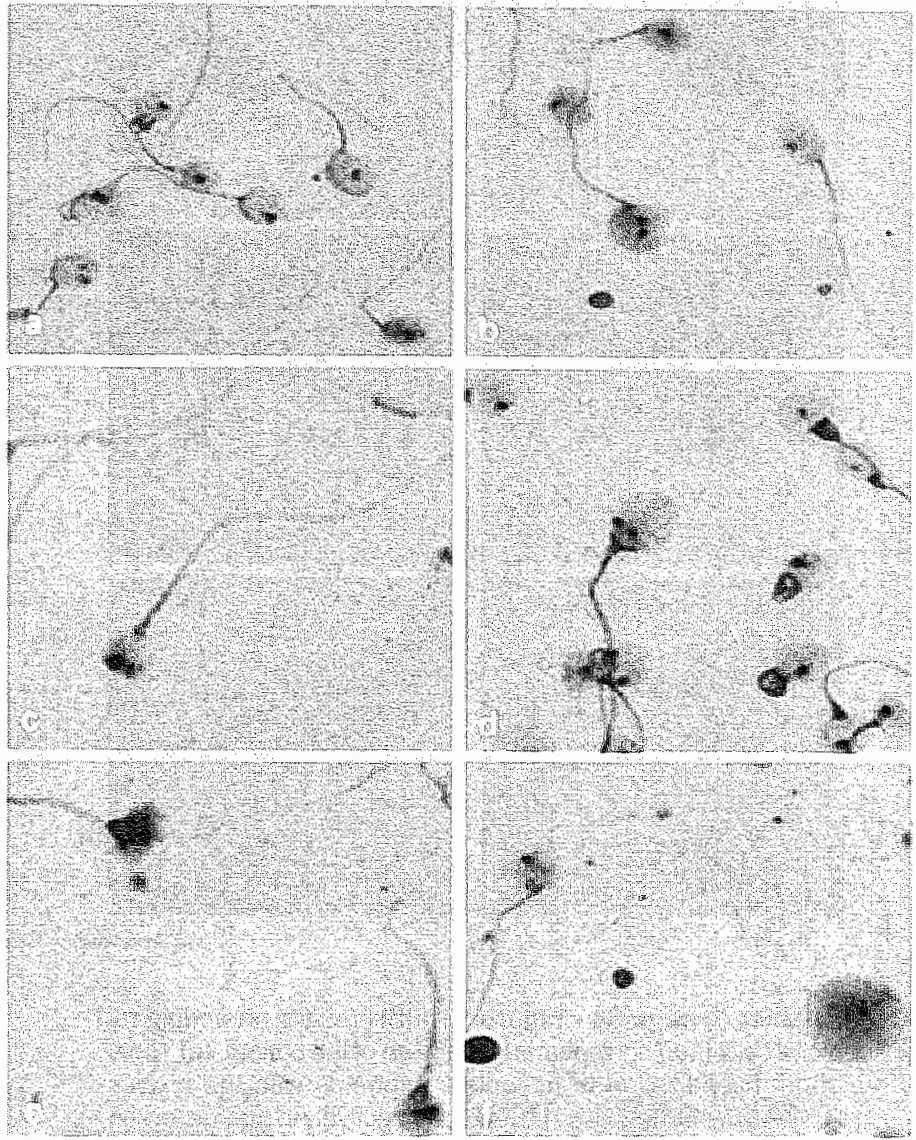

Chapter 4 , page 50 - Figure 1. Double target hybridization of semen samples with biotinylated $X$ probe (brown) and fluorescent isothiocyanate (FITC)-labelled $Y$ probe (green). (a-d) Monphologically normal spermatozoa. (a) Control sample showing either $X$ or $Y$ signal; (b) spermatozoa showing an $X Y$ sex chromosome constitution; (c) Sperm cell with an $X X$ sex chromosome constitution: (d) Sperm cell with an YY sex chromosome constitution. (e) Morphologically abnormal sperm cells, top left with two heads and two chromosome X-signals; bottom right spermatozzon with two tails and an XY chromosome constitution.(f) Immature germ cell with hybridization signal for chromosomes $X$ and $Y$. 

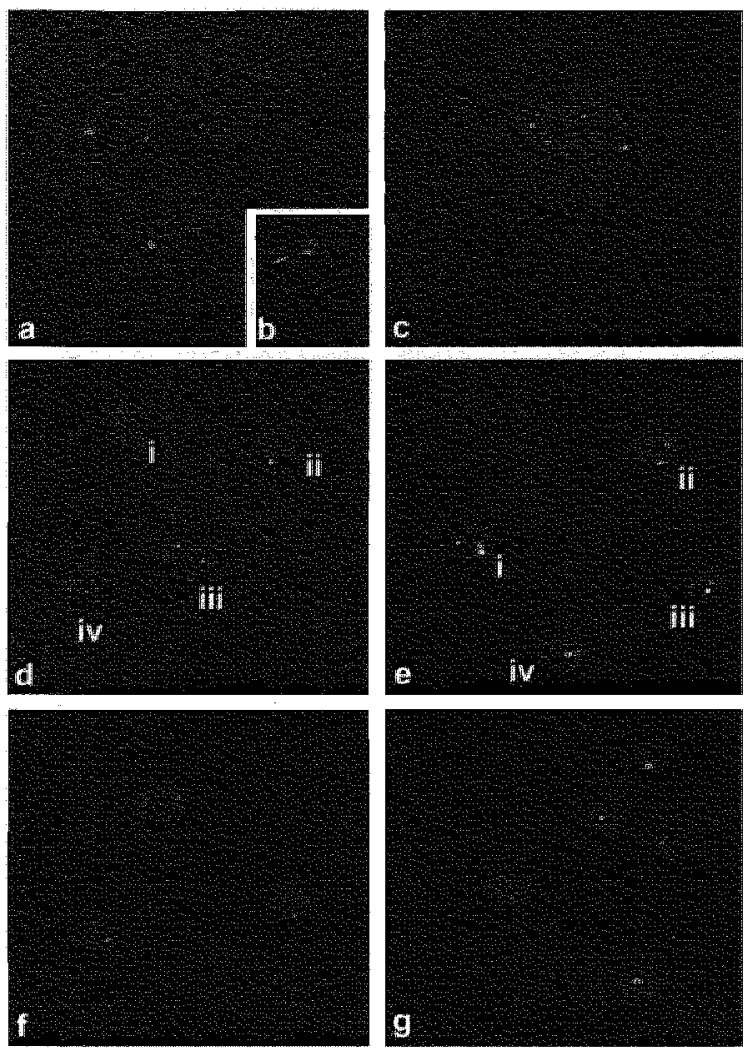

Chapter 5, page 64 - Figure 1. FISH results on peripheral blood cells (a-c) and spermatozoa (d-g) of the patient. (a) Triple target hybridization to metaphase spreads with the probes CEP11, TYAC 162 and D 1 $15-477$, respectively in orange, green and red. (b) Particular of the chromosomes involved in the translocation and the probes applied. (c) Lymphocyte, hybridized with triple FISH, showing the difference in signal size for the centromere and the locus specific probe used. (d) Spermatozoa of the patient hybridized with triple FISH (for explanation see ligure 3). (i) Adjacent II segregation mode, signals for CEP11 and TYAC162; (ii) 3:1 segregation mode, signals for CEP11 and D11S-477; (iii) Alternate segregation, nomal or balanced sperm with signals for CEP11, TYAC 162, D11S-477; (iv) Aberrant segregation mode, two signals for CEP11. (e) Spermatozoa of the patient hybridized with triple FISH (for explanation see figure 3). (i) Adjacent I segregation, signals for CEP11 and twice for TYAC 162; (ii) and (iii) Altemate segregation mode, normal or balanced spermatozoa; (iv) 3:1 segregation mode, signals for CEP11, TYAC 162 and twice for D115-477. (f): double FISH with chromosomal probes for chromosomes 13 (green) and 21 (red). All spermatozoa show a normal , haploid, chromosomal constitution. (g): double FISH with the sex-chromosomal probes. In green the $X$-probe, in red the $Y$-probe. At the bottom, right comer, a sperm cell carrying an $X Y$ constitution is visible. 
the 3
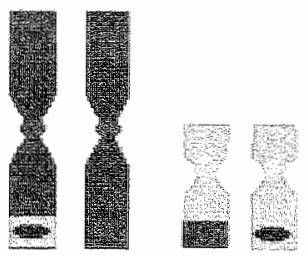

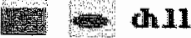

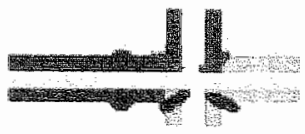

\section{Quaturitustort}

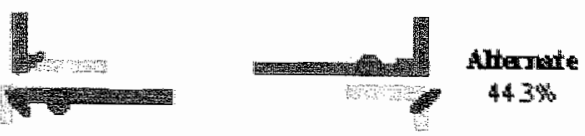

\section{Adjurent I}

$159 \%$
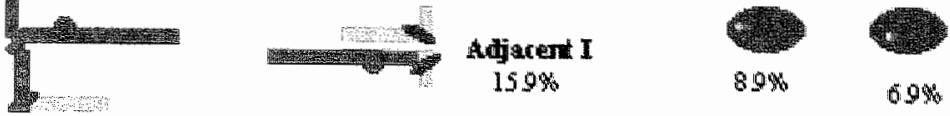

898

690
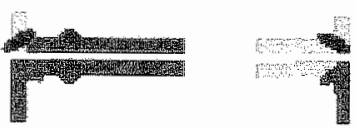

\section{Adjacent II \\ $60 \%$}
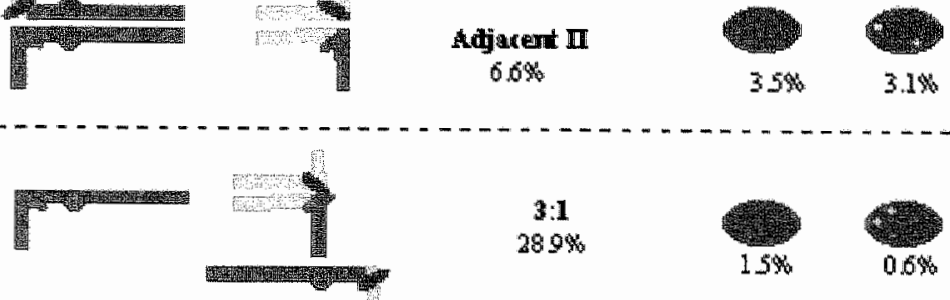

\section{3:1}

$289 \%$

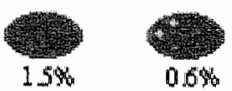

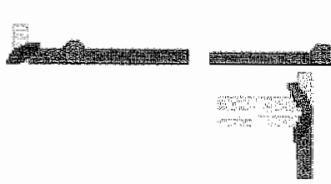
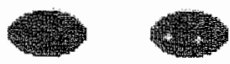

$08 \%$

$0.7 \%$
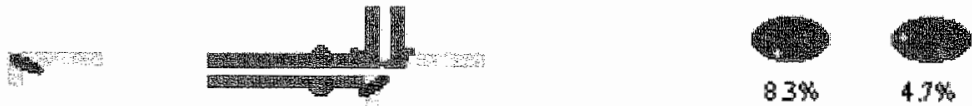

綗
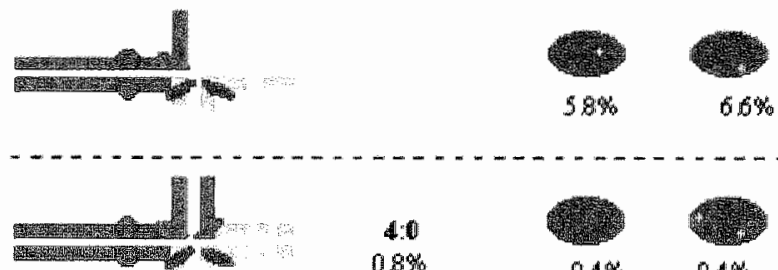

\section{0 \\ $08 \%$}
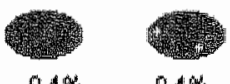

\section{Aberrant \\ $35 \%$}

Chapter 5, page 67 - Figure 3. Schematical explanation of the chromosomes involved in the translocation $t(3 ; 1)$ (q27.3,q24.3) and the probes used. The quadrivalent and the various segregational modes are shown. The corresponding resulting gametes are illustrated. For simplitication the CEP11 signal, which is detected in red, is here illustrated in yellow. CEP $11=$ Yellow, TYAC $162=$ Green, and D11S-477 $=$ Ped. 

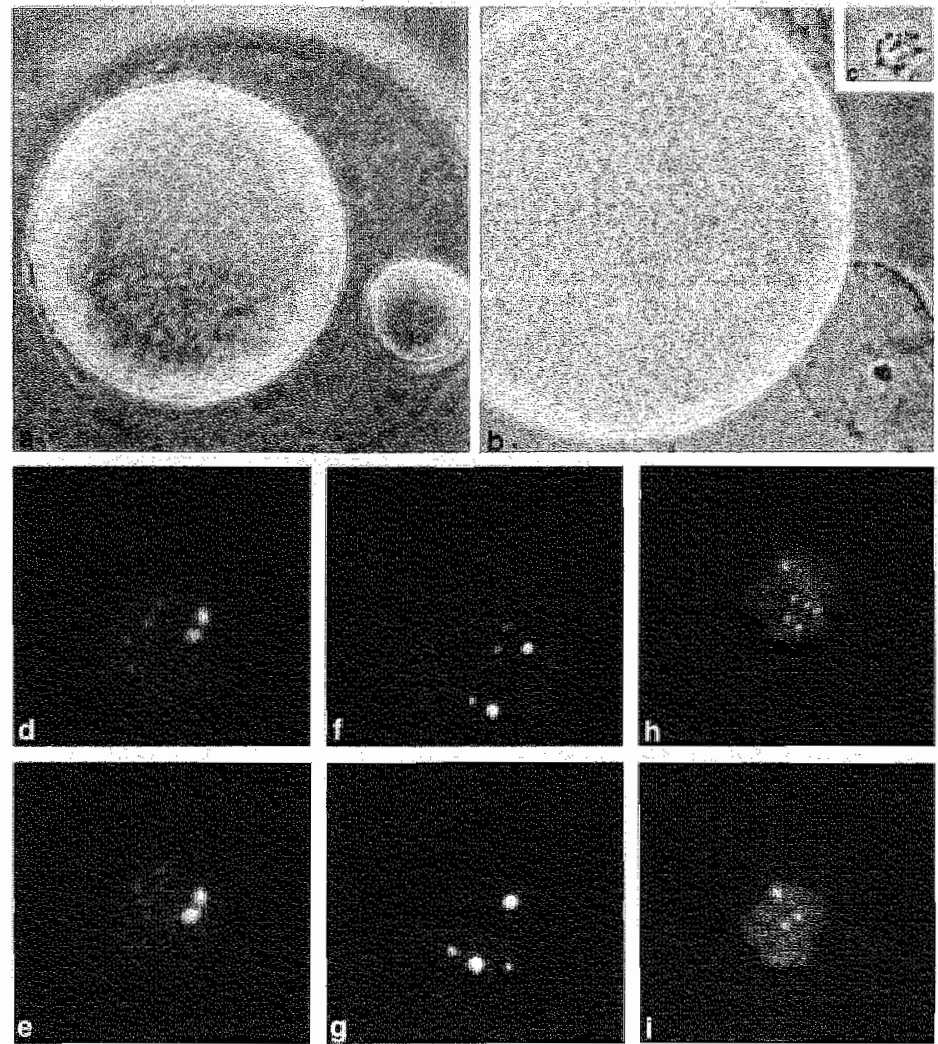

Chapter 6, page 80 - Figure 2. Spreading of the oocyte (a-c): (a) Oocyte with first polar body (PB) and no pronuclei. At the beginning of spreading, the oolemma is still present. (b) Lysis of the PB, the DNA is visible. (c) Isollated metaphase DNA. FISH results (d-i): Directly labelled probes for chromosome 1 (yellow), 7 (green), 15 (red) in the first FISH round $(d, f, h)$ and chromosome $f$ (yeilow) and $X$ (green) in the second FISH round $(e, g, i)$, thybridized to DNA (blue) of unfertilized ICSI oocytes. First and second FISH rounds respectively on the same DNA. (d,e): In (d) signals for the chromatids are close to each other, representing dyads. In (e), the X-chromosome is clearly distinguishable from the remnants of the first hybridization. The signals for chromosome 1 are at the same location as in the first round. First and second FISH rounds respectively on the same DNA (f,g): Example of pre-division of the dyads. The chromatids are clearly separated fromeach other in (f) and are almost at opposite poles. In ( $\mathbf{g}$ ) the X-chromatids are at the same pole. First and second FISH rounds respeclively on the same DNA (h,i): Example of aneuploidy for all the chromosomes analyzed. In (h) three chromatids of chromosome 1 are visible, three for chiromosme 7 and four for chromosome 15 . In (i), three chromatids for chromosome 1 are ewident and four copies of chromasome $X$. 

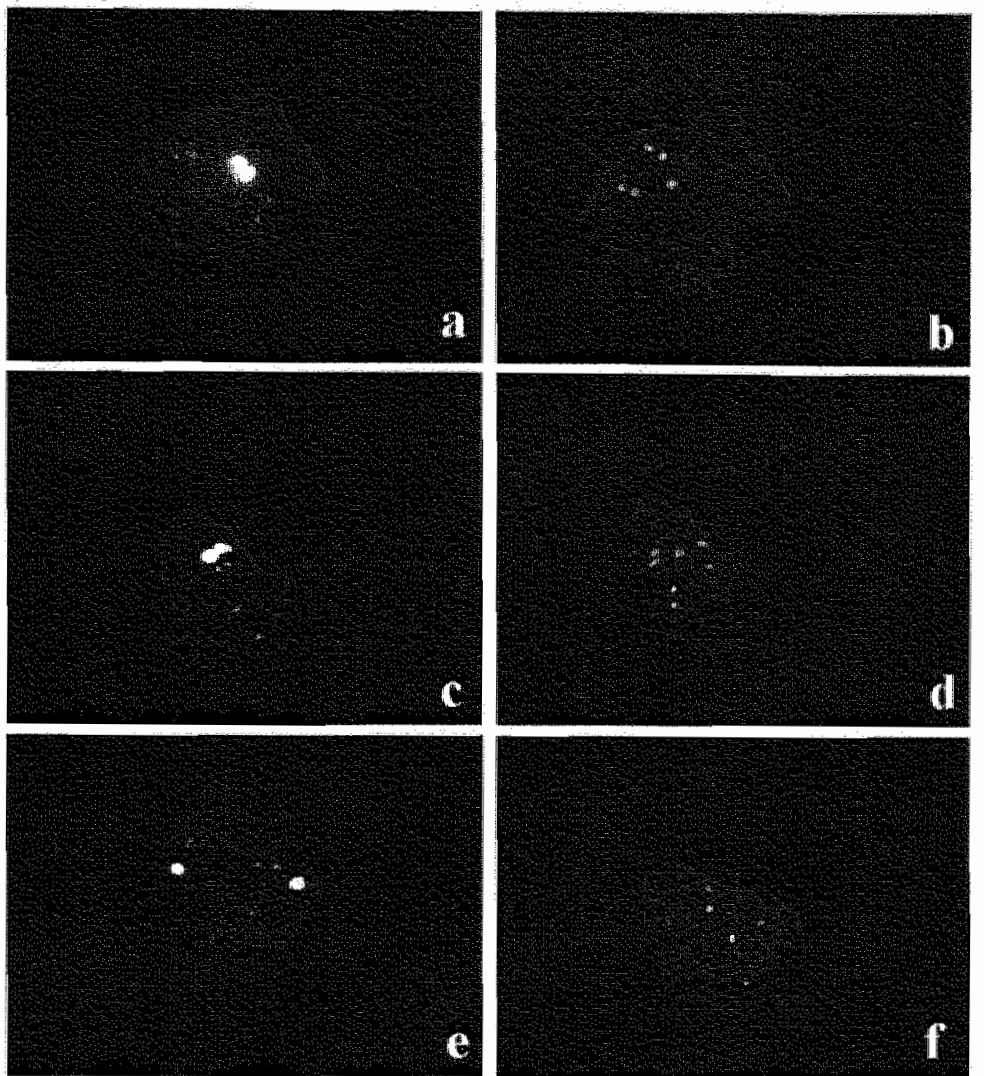

Chapter 7, page 93 - Figure 1. FISH results on human oocytes. Images from the first and second FISH rounds are shown in $a, c, e$ and $b, d$, frespecively. In the first round, the signals are chr. 1 (yellow), chr. 13 (green) and chr. 21 (red). In the second round, the signals are chr. X (yellow), chr. 18 (green), chr. 7 (red). DNA is stained blue. (a-b) Haploid, paired signals in round 1 and hypohaploidy for chr. 18 in round 2. (c-d) Haploid, paired signals in round 11 and hyperhaploidy for chr. 7 and preadivision of chromatids in round 2. (e-1) Haploid oocyte showing pre-division of chromatids for all six chromosomes and hyperhaploidy for chr. 13 in round 1. 